Florida International University FIU Digital Commons

$7-7-2000$

\title{
Elementary music and classroom teachers' time- use: a comparison by grade level, time of day, and day of the week
}

Marilyn Jane Anderson

Florida International University

DOI: $10.25148 /$ etd.FI14032315

Follow this and additional works at: https://digitalcommons.fiu.edu/etd

Part of the Education Commons

\section{Recommended Citation}

Anderson, Marilyn Jane, "Elementary music and classroom teachers' time-use: a comparison by grade level, time of day, and day of the week" (2000). FIU Electronic Theses and Dissertations. 1286.

https://digitalcommons.fiu.edu/etd/1286 
FLORIDA INTERNATIONAL UNIVERSITY

Miami, Florida

ELEMENTARY MUSIC AND CLASSROOM TEACHERS' TIME-USE:

A COMPARISON BY

GRADE LEVEL, TIME OF DAY, AND DAY OF THE WEEK

A dissertation submitted in partial fulfillment of the

requirements for the degree of

DOCTOR OF EDUCATION

in

CURRICULUM AND INSTRUCTION

by

Marilyn Jane Anderson

2000 
To: Dean Linda P. Blanton

College of Education

This dissertation, written by Marilyn Jane Anderson, and entitled, Elementary Music and Classroom Teachers' Time-Use: A Comparison by Grade Level, Time of Day, and Day of the Week, having been approved in respect to style and intellectual content, is referred to you for judgment.

We have read this dissertation and recommend that it be approved.

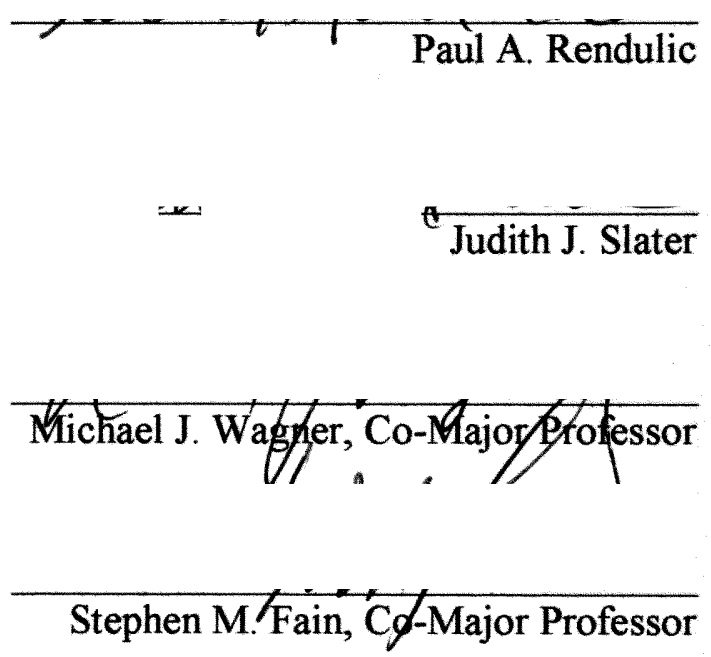

Date of Defense: July 7, 2000

The dissertation of Marilyn Jane Anderson is approved.

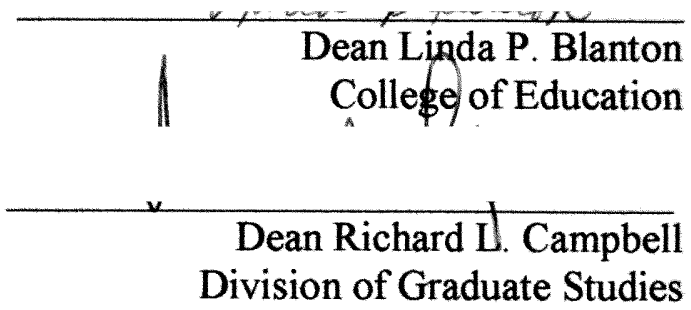

Florida International University, 2000 
(C) Copyright 2000 by Marilyn Jane Anderson

All rights reserved. 


\section{DEDICATION}

This dissertation is dedicated to my father's memory and to my mother who instilled in me a love of knowledge and taught me the art of perseverance. 


\section{ACKNOWLEDGMENTS}

First, and foremost, I am eternally grateful to God who gave me strength, guidance, and endurance throughout the dissertation process. The completion of this research would not have been achieved without the expertise and support of several individuals. I am particularly indebted to the members of my dissertation committee whose encouragement, constructive criticism, and guidance made this study a reality. I would like to acknowledge their contributions individually. Dr. Stephen Fain, co-major gave valuable advice and help concerning this research and provided me with vision in curriculum scholarship that has impacted my own pursuits. Dr. Michael Wagner, comajor inspired conversations where many of my ideas regarding this research emerged and were challenged, gave generously of his time, provided unconditional support, and nurtured me during the entire doctoral program. Dr. Judith Slater provided encouragement, devoted time to the careful reading and editing of this manuscript, and gave help when I needed it. Dr. Paul Rendulic gave guidance and was willing to assist me on many occasions with the methodology and analysis of this research. Special thanks to all of you.

A special acknowledgment to Dr. Herbert Thompson, President of Northern Caribbean University and the University Board of Directors for their support and the opportunity that was granted me to pursue doctoral studies at Florida International University. Thanks to Dr. Silburn Reid who first encouraged me to continue my education at this level. 
My appreciation is extended to the preservice elementary music students who served as trained observers and collected data for this study. I am especially indebted to my immediate family for their incredible understanding, assistance and support: my mother, Hilma, who gave constant encouragement and endured years without me being around; my sister, Manda Lee and her husband, Antonio; my brothers Carlton, Woolton, and Neville, and my sisters-in law Doreen, Pamela, and Joan; and my aunt, Elsa.

To my colleagues Lillia, Sharon, Lillian, Guichen, and Nalini: Thanks for their kind words, assistance, and support. Additional thanks to Dr. Toni Bilbao, Monica Rosales, Mary Wagner, Faye Reid, and Beulah Peterson who assisted in their own way. Finally, thanks to Patrick Blake who in addition to encouraging me, has become a treasured colleague and friend. 


\title{
ABSTRACT OF THE DISSERTATION
}

\author{
ELEMENTARY MUSIC AND CLASSROOM TEACHERS' TIME-USE: \\ A COMPARISON BY GRADE LEVEL, TIME OF DAY, AND DAY OF THE WEEK \\ by \\ Marilyn Jane Anderson
}

Florida International University, 2000

Miami, Florida

Professor Stephen M. Fain, Co-Major Professor

Professor Michael J. Wagner, Co-Major Professor

This study investigated time-use of elementary music teachers and elementary classroom teachers to determine: (1) whether there was a relationship between grade level, time of day, and day of the week and teachers' time-use in teaching, monitoring, and non-curricular, and (2) whether ethnicity, training, and years of experience affect teacher time-use. Sixty-nine music teachers and 55 classroom teachers participated.

A MANOVA was used to examine the hypothesized relationship. ANOVA results were significant for time spent teaching, monitoring, and non-curricular. An independent $t$ test revealed a significance difference $(\mathrm{t}(302)=5.20, \mathrm{p}<.001)$ between the two groups of teachers. A significant difference was found for teaching, $\underline{t}(302)=5.20, \underline{p}$ $<.001$ : music teachers spent more time actively teaching than did classroom teachers. There was a significant difference for monitoring $(\underline{t}(302)=13.62, p<.001)$ : classroom 
teachers allocated more time to monitoring than did music teachers. A significant difference was also found for non-curricular $(\mathrm{t}(302)=7.03, \mathrm{p}<.001)$ : music teachers spent more time in this category of activities than did classroom teachers.

Analyses of the activities subsumed under the major categories indicated significant differences between elementary music teachers and elementary classroom teachers, overall, in subject matter $(\mathrm{p}<.001)$, discussion $(\mathrm{p}<.05)$, school-wide activities $(\mathrm{p}<.001)$, seatwork $(\mathrm{p}<.001)$, giving directions $(\mathrm{p}<.001)$, changing activities $(\mathrm{p}<.001)$, lunch $(\mathrm{p}<.05)$, planning $(\mathrm{p}<.001)$ and interruption $(\mathrm{p}<.001)$. Analyses of the relationship and ethnicity, training, degree, experience indicated significant difference for main effect, ethnicity $(\underline{F}(2,116)=4.22, \underline{p}<.017)$. Time-use for black non-Hispanic teachers was higher than time-use for those who were Hispanic and white non-Hispanic. Analyses of time-use by grade showed no increase for either group as grade level increased. A statistically significant Wilks Lambda $(\underline{\mathrm{F}}(1,294)=.917 \mathrm{p}<.013)$ was found for the independent variable day of the week. ANOVA indicated that elementary classroom teachers monitored more on Thursdays and Fridays: music teachers allocated more time to non-curricular activities on Fridays. 


\section{TABLE OF CONTENTS}

CHAPTER

PAGE

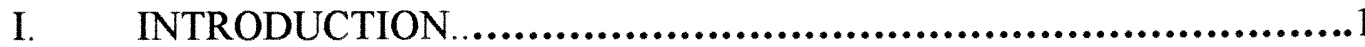

Statement of the Problem.....................................................5

Statement of the Purpose....................................................8

Significance of the Study.....................................................9

Research Questions.........................................................19

Subsidiary Questions......................................................19

Assumptions............................................................19

Limitations............................................................20

Delimitations..............................................................20

Definition of Terms......................................................20

Organization of the Study.............................................23

II. REVIEW OF THE LITERATURE....................................24

Defining Time and Time-Use............................................24

Conceptualizing Time-Use in Education...................................25

Schools' Time-Use..........................................................28

The Elementary Classroom Environment..................................36

School Factors Influencing Teachers' Time-Use...................42

Students' Time-Use.......................................................46

Teachers' Time-Use........................................................552

Classroom Activities Influencing Teachers' Time-Use.............54

Subject Area and Teachers' Time-Use..............................59

Teacher Factors Influencing Teachers' Time-Use..................61

A Historical Overview of Observation Instruments..........................64

General Education................................................64

Music Education................................................66

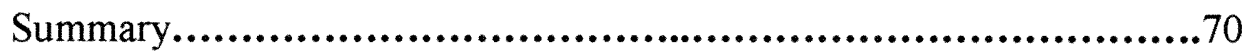

III. METHODOLOGY...................................................72

Participants and Setting...................................................73

Research Design.......................................................75

Instrument..............................................................78

Procedures..................................................................80

Training Observers and Reliability..............................82

Data Analysis...........................................................85 


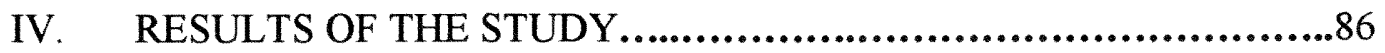

Data Analysis for Participants..............................................86

Data Analysis of the Research Questions...................................92

Summary.................................................................. 109

V. SUMMARY, DISCUSSION, AND CONCLUSIONS.....................111

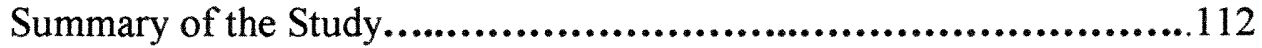

Major Findings................................................................. 114

Discussion related to Research Questions..................................117

Conclusions and Implications for Curriculum and Instruction.............127

Recommendations for Future Research...................................128

LIST OF REFERENCES.................................................130

APPENDICES.............................................................141

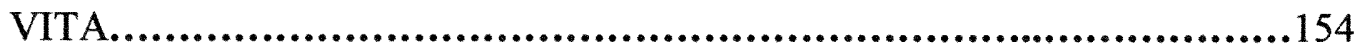




\section{LIST OF TABLES}

TABLE

PAGE

$1 \quad$ Frequencies and Percentages of Observations for Music Teachers and Classroom Teachers in the Sample per Region.....................................88

2 Frequencies and Percentages by Number of Observations Performed per Day of the Week.

3 Frequencies and Percentages by Number of Observations Performed per Morning and Afternoon.............................................................90

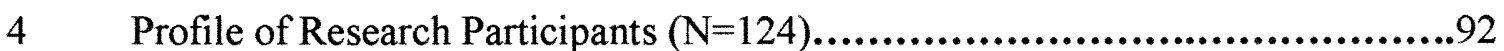

5 Time-use by Group (Elementary Music and Classroom Teachers) Compared by Major Category of Activity......................................................94

6 Comparison of Elementary Music and Classroom Teachers by Detailed Activity Classifications...........................................................95

7 Frequencies of Participants by Ethnicity, Level of Training, and Years of Experience...........................................................................98

8 Analysis of Variance of Ethnicity (White Non-Hispanic, Black Non-Hispanic and Hispanic)

9 Distribution of Mean Minutes for Elementary Teachers' Time-Use in the Major Categories of Activities by Grade Level....................................101

10 Analysis of Time-Use Per Elementary Music Teachers and Elementary Classroom Teachers in Major Categories by Time of day... 
CHAPTER I

INTRODUCTION

Tempus Fugit (Time flies)

"While the amount of time imposes limits on what can be accomplished, the key issue is how time is used".

What We Know About Managing Time by Everston \& Harris

"Tempus fugit" (time flies), a popular Latin verity still used in exasperation in today's complex, modern, post industrial societies, effectively describes the degree to which we perceive time. The frequent use of this expression suggests that societies have become more aware of and concerned about the control that time places on the lives of their citizens who are somewhat convinced that time prevents them from moving forward (Connelly \& Clandinin, 1993; Slattery, 1995). In fact, society has also devised other notions about time as evidenced by the following familiar phrases: "marking time," "no time," "every minute counts," "killing time," "time is short," "I don't have time," "time on my hands," "passing the time," "from time in memorial," and "give me some time." These expressions suggest that contemporary societies have come to realize that their ability to cope with, and modify, time remains a constant challenge.

Popular perception seems to ascribe the achievement of the historically unprecedented high standard of living attained by the citizens of the American modern federal system to activities of the industrialists (Berliner \& Biddle, 1995; Callahan,1962; Smith, 1992). For example, Callahan (1962) states that at the end of the $19^{\text {th }}$ century, the position of visibility, affluence, and prestige as demonstrated by business and industry in America proved to have had tremendous influence on the schools and society at the onset 
of the $20^{\text {th }}$ century. According to Gelberg (1997), America had progressed steadily from an agrarian society to an industrial one by the mid-nineteenth century. From that time until the beginning of the $20^{\text {th }}$ century, the nation was considered a business-oriented democracy, and the influence of the business organization was evident in many facets of society. By 1910, a new system of management known as the Taylor System of Scientific Management had already revolutionized industry in all the major industrial countries throughout the world. Taylor's ideas brought about intense awareness regarding efficiency and much discussion concerning conservation and the elimination of waste. Based on this view, industrialists' efficiency in the production and delivery of goods and services necessary to meet both civilian needs and those of the armed forces was achieved primarily by the continual drive for optimal time use in industry.

Educators were influenced by these scientific management principles, and the introduction of these ideas into the classroom took place during the first 30 years of the 20th century. The premise "what was good for business was good for American schools,"(Gelberg, 1997) influenced the educational system, which imported this philosophy from industry. Although not embraced universally by all educators then, nonpragmatists such as Franklin Bobbitt, W.W. Charters, and E. L. Thorndike aligned themselves with those who employed the scientific management principles. Various instructional methods, accountability, and the concept of time management were new ideas intended to help educators improve the quality of education (Bennett de Marrais \& Le Compte, 1995; Callahan, 1962). Gradually, some educators have come to regard time as an analytical tool, essential for assessing the quantity and quality of schooling in various models of student learning such as those represented by Carroll $(1963,1985)$, 
Bloom (1968) and Harnischfeger and Wiley (1985). These models, recognized as influential models for research pursuits in time-use and the understanding of time-use, have mainly tried to assess the quality of time needed by the student to achieve learning rather than the amount of time utilized by teachers to accommodate learning.

After World War II, there were persistent calls for increase in the number of days in the school year, hours in the school day, and the per hour quantum of instructional time. This reaction by policymakers was influenced by their knowledge of alleged superior educational delivery of school systems already established in Europe and other industrialized countries. Gelberg (1997) notes that since the launching of Sputnik, educators and policymakers have believed that the model of education followed by American schools since the turn of the $20^{\text {th }}$ Century had not been subjected to rigorous reform to bring about the change needed in the educational system. According to Mark (1986), Vice Admiral Hyman G. Rickover, a leading educator, was among those who advocated change in the way American students were prepared academically. Rickover proceeded to compare American and European education, and found that American education was lacking in strong math and science programs. His approach to improving the curriculum was to recommend that certain activities (e.g., assemblies, extra-curricular activities) and subjects (e.g., art, music) be eliminated from the curriculum.

In the late fifties and early sixties the federal government addressed more national recognition advocating educational reform. Organizations such as "Americans to the Commission on National Goals," and "The Woods Hole Conference" focused on change in the curriculum with more emphasis on the basic subjects. The world economic condition, a decrease in student enrollment, a decrease in classroom teachers and low 
student achievement on SAT examinations, all contributed to the decline in education in the seventies. The poor academic performance exhibited by many schools throughout America created much consternation among educators, policymakers and school administrators (Mark, 1986).

Another call for educational reform to improve the state of the American Public School system was reflected in an important document, A Nation at Risk, mandated by the National Commission on Excellence in Education (NCEE) in 1983. According to Karweit (1988), "interest in time as an educational variable reached its peak as the centerpiece of the education reform agenda in A Nation at Risk" (p. 31). Further, this interest in time by American educators and policymakers was influenced by an investigation about time-use in schools located in other industrial countries e.g., Japan and Germany. Findings revealed that students in these countries received more time in instruction as evidenced by longer school days and an extended school year. Funkhouser, Humphrey, Panton, and Rosenthal (1995) claimed that some educators and policymakers attributed the success of students in these industrial countries to the increase in time on academic instruction.

Apart from A Nation at Risk, two other reform documents, America 2000 and Goals 2000 were introduced in 1989 and 1994, respectively. How time is used in the school was identified to be foremost in achieving the success of the nation's school reform. In response to Goals 2000, the National Education Commission on Time and Learning was formed to investigate time in the nation's schools and schools abroad. The Commission reported that schools in the United States of America were lacking in their knowledge of how to use class time. The Commission recommended that new and better 
ways be found to use time more efficiently. Even before Goals 2000, research literature has reflected intent on the impact of time-use on student achievement. The literature also revealed that student achievement is often related to time allotted for teaching and learning in American Schools (Walberg, 1991).

\section{Statement of the Problem}

Before decisions effecting time-use reform in the schools are made, research on the use of class time seems necessary and could prove helpful in school improvement efforts. Karweit (1988) points out that literature of techniques on time-use along with research on each aspect of time-use, has contributed some of the knowledge needed for schools to improve. A considerable number of investigations have been devoted primarily to the pursuit of students' time-use and the influence of time-use on learning. For example, Walberg and Frederick (1991) produced a meta analysis of over 100 studies investigating the effects of time on students' learning. These studies represent studies pursued only during the 1980's.

While there has been focus on how students' spend their time, a thorough search of the literature reveals only a few studies on how teachers spend their time within the school day. In fact, Funkhouser et al. (1995) after reviewing the literature, state that "data concerning teachers' use of time is strikingly absent" (p. 4). A teacher time-use survey conducted by the U. S. Department of Education, National Center for Education Statistics, (USDE/NCES) (1994) found that the teacher's workload during the school's work week amounted to over 40 hours. A strong recommendation resulting from this investigation was that "there is a real need for more research on teachers' use of time" (USDE/ NCES, 1994, p. 2). 
The difference between teachers' time-use and students' time-use is conveyed by the believe that teachers dispense information while the students' responsibility is to receive information in the hope that they will achieve learning in the time allotted (Olson, 1990). The assumption is that the time-use patterns of teachers and students are not similar; the teacher constructs the teaching activities within the confines of the teaching day. According to Olson (1990), "the teacher is the one who authenticates what is transacted and guarantees it" (p. 233).

The need for teachers and school administrators to be informed regarding time allocation in the classroom cannot be overestimated. For example, Jackson (1968), in a study of elementary classrooms, reported that within the classroom environment as many as 1000 interpersonal transactions occur daily. Jackson asserted that, "by focusing on the teacher's behavior in managing classroom activities and interpersonal transactions further insight could be gained regarding the management of classroom events during the class time" (p. 12). One consideration is that the teacher is the official timekeeper who is responsible for determining when all activities or events begin and end. Connelly and Clandinin (1993) clearly state that "Schools are ruled by the clock on a daily basis" (p. 39). The clock and other inventions such as bells and buzzers have been used in aiding the teacher to adhere to a time schedule and to keep track of time within the school day.

The few empirical studies regarding teacher time-use in the classroom represent observed, objective data collected by trained observers, as well as self-reported data collected by teachers. In general, researchers in the category of trained observers (Allard, 1992; Amen, 1982; Goolsby 1996, 1999; Horn and Chalkind 1989; Montgomery 1985; Price and Hardin 1988; Romberg and Pitman 1990; Wagner and Strul 1979; and Zabel, 
Peterson, and Smith, 1988) found specific teacher time-use patterns in a variety of settings in music education as well as in general education. For instance, they found that experienced elementary music teachers were more efficient than neophyte elementary music teachers in their use of time in giving directions (Wagner \& Strul, 1979). Middle and high school experienced instrumental music teachers were more efficient in utilizing rehearsal performance time than were inexperienced elementary instrumental music teachers (Goolsby, 1996,1999). Some studies found no difference found in the allocation of class time when teachers were (1) elementary or secondary teachers in private or public schools (Horn \& Chalkind, 1989); (2) elementary music string specialist or nonstring specialist (Allard, 1992); (3) teaching math to first graders (Romberg \& Pitman, 1990); (4) elementary and secondary teachers of behaviorally maladjusted students (Zabel, et al. 1988); and (5) certified or non-certified elementary music teachers (Price \& Hardin, 1967). It was also found that elementary classroom teachers as well as elementary music teachers' time-use pattern was influenced by the grade level they taught (Amen, 1982; Montgomery, 1985; Wagner et al. 1985).

Conversely, researchers whose work was based on self report include Bromme and Homberg (1990); Wagner, Allen and Shoemaker (1985); Borg, (1980); and Wang and Sogin (1997). Sanford and Evertson (1983) and Wang and Sogin (1997) used both observer ratings and teacher time-use logs to collect data. In general, these studies reported that some elementary music teachers tend to overestimate their class time (Wang \& Sogin, 1997), while some elementary classroom teachers devoted more time to academic instruction (Wagner et al. 1985), and seatwork (Borg, 1980). Two studies 
(Bromme \& Homberg, 1990; Sanford \& Evertson, 1983) reported that there were no differences in time-use patterns.

Teachers' time-use also has implications for students' learning in the classroom and student achievement. For instance, two major school reform reports- $\underline{A}$ Nation at Risk (National Commission on Excellence in Education, 1983) and Goals 2000 (U. S. Department of Education, 1996) identified time as one of the most important factors in attaining school reform. Abeles, Hoffer, and Klotman (1994) noted that because the National Commission on Excellence in Education (NCEE, 1983) report entitled A Nation at Risk was concerned with "the substandard time allocation attributed to the education of students...they recommended that...there be fewer intrusions in class time, and that the school day be lengthened" (Abeles et al. 1994, p. 25). Reform advocates believed that an increase in time would increase learning. Robert Rossi, reporting in an Issue Brief for the U. S. Department of Education, National Center for Education Statistics (NCES, 1994), suggested that teacher time-use research is necessary-especially, before school administrators make their final decisions regarding alternative time-use strategies, and before they implement professional standards and engage in educational reform activities. Essentially, managing teacher's time in school by the teacher is the issue in focus. Empirically-based information that could contribute to important teacher decisions regarding time-use and students learning would prove useful in organizing the instructional day.

The Purpose of the Study

Researchers in the field of general education (Brophy \& Good, 1986; Funkhouser et al. 1995; Rosenshine, 1980; Walberg, 1988) and in the field of music education 
(Allard, 1992; Moore, 1981; Price \& Hardin, 1988; Wagner \& Strul, 1979; Watkins, 1993) have identified and quantified differences in time-use within certain areas of specialization. To date, only one comparison between elementary music teachers and generalists has been done (Wagner \& Anderson, 1999). Therefore, the purpose of the current study is to examine even more closely the time-use allocation patterns of elementary music teachers and elementary classroom teachers. In the present study the elementary music teacher is defined as a state certified specialist in music education who may have a strong minor or a second major in music, is trained to teach general music in the elementary school, and holds at least a Bachelor's degree in that field (National Commission on Instruction, NCI, 1972). While the elementary classroom teacher is identified as a teacher who is state certified in elementary education, trained to teach in elementary school, and holds at least a Bachelor's degree in that field. The present study is designed to: (1) determine and refine how elementary music teachers and elementary classroom teachers use their time as influenced by grade level, time of day, and day of the week, and (2) determine whether differences in teacher time-use patterns are influenced by the teachers' demographic characteristics such as ethnicity, years of services, and highest level of training.

\section{The Significance of the Study}

The management of time in all facets of human activity presents greater challenges to society in the $21^{\text {st }}$ century. Educators in particular have realized that the lack of time in American schools has strong implications for academic instruction and student learning (Frederick \& Walberg, 1980; Walberg 1984, 1988; Walberg \& Frederick, 1991). For example, Slattery (1995) indicates that in recent times "educators 
are overwhelmed and frustrated as they try to implement ambitious goals, complete expanded curriculum requirements and accomplish more complex objectives with less and less time" (p. 614). The reference to "less and less time" seems to imply that the sixhour school day and the 180-day school year can no longer be considered the adequate time frame in which teachers can accomplish all school and learning activities.

The need for ambitious goals, the expansion of the curriculum, and more complex objectives seemed to have resulted from certain reform documents such as $\underline{\mathrm{A}}$ Nation at Risk (National Commission on Excellence in Education, 1983) and Goals 2000 (U. S. Department of Education, 1994). These reform documents have encouraged action by educators and policymakers toward extending the school day and the school year to provide American students with more allocated time for learning (Abeles, et. al. 1994; Funkhouser, et al. 1995). However, before such decisions can be made, educators should be interested in knowing about the various activities currently related to time-use within the school day in order to determine whether it is prudent to increase or decrease instructional time. In essence, is time used wisely within the classroom, and, if it is, how would increasing time add to student success? If it is not used wisely, how can time allotments be restructured to be more effective? Furthermore, Everston and Harris (1992, p. 75) observe that a "close look at how classroom activities revolve reveals the need for a classroom management system that is visible, established, monitored, modified, refined and re-established."

Before the last decade of the $20^{\text {th }}$ century, numerous time-related studies were conducted. These studies dealt with various aspects of time-use and learning in different settings and under different conditions. The pursuit of the present study has been in part 
a response to one of the recommendations of the study of Funkhouser and colleagues that called for more teacher time-use investigations (Funkhouser et al.1995). Surprisingly, further scrutiny of the literature revealed that music education has kept abreast of the general field of education regarding teacher time-use research. In other specialized fields such as art and physical education, there was no evidence of teacher time-use studies in the literature.

Research in music education regarding teacher time-use began around the midnineteen seventies. Some examples of music education studies that have addressed timeuse and teacher activities are presented in subsequent paragraphs.

When teachers were asked to engage in self-reporting their time-use, they tended to overestimate their own time-use as compared to their actual time-use reported by observers (Wang \& Sogin, 1997). Other factors such as teachers' region of residence (Montgomery, 1985; Moore, 1981) and teachers' type of certification (Price \& Hardin, 1988) had little influence on how teachers used their time. However, in the Wagner and Strul (1979) study, a relationship was found between teachers' level of experience and time-use in giving directions. Type of class taught by the teacher did not appear to exert any influence on teacher's time-use pattern (Witt, 1986). The time-use pattern of string specialist teachers and string non-specialist teachers revealed that the teachers represented in each study were similar in their time-use patterns except for a few marginal differences (Allard, 1992). Grade level was found to be an influential factor on teachers' time-use in both the Amen (1982) and Montgomery (1985) studies.

A few investigations concerning teacher time-use conducted in specific settings were found in the general education literature. For instance, in both elementary and high 
school, Horn and Chalkind (1989) investigated public and private school teachers' timeuse, while Wagner et al. (1985) were interested in exploring classroom teachers' timeuse, their feedback and student's attentiveness in the elementary classroom setting. Specifically, Zabel et al. (1988) pursued the time-use of elementary and secondary classroom teachers who were involved in teaching behaviorally disordered students. In contrast, other researchers (Bromme \& Homberg, 1990; Romberg \& Pitman, 1990) were concerned with how mathematics teachers spent their time in teaching mathematics both in elementary and secondary classroom settings.

The studies of Zabel et al. (1988) and Horn and Chalkind (1989) indicate that teachers represented in each of these comparative studies showed similar time-use patterns. Wagner et al. (1985) found that elementary classroom teachers tend to devote more time to academic instruction as grade level increased. Romberg and Homberg (1990) reported that mathematics teachers were better at estimating chunks of time (the time duration of a lesson) more than time allocations to individual students. Romberg and Pitman (1990) found that first grade elementary classroom teachers varied considerably in their time-use allocation when teaching mathematics. Sanford and Evertson (1983) looked at teacher time-use in mathematics and English classes at the junior high school level and discovered that the teachers showed variation in the use of their classroom time.

It is worth noting that even after a thorough search of the literature, there was no evidence, until recently, of teacher time-use studies that compare both elementary music teachers and elementary classroom teachers. Knowledge regarding the paucity of this type of investigation influenced the pursuance of a recent study (Wagner \& Anderson, 
1999). The time-use pattern of both elementary music teachers and elementary classroom teachers was investigated, and the findings indicate that music teachers and elementary classroom teachers differ in their use of time. Elementary music teachers spend more time than elementary classroom teachers teaching (44.6\%) and engaged in non-curricular activities (38.2\%). Besides, elementary classroom teachers spend considerably more time in class monitoring activities (44.2\%) than elementary music teachers. The findings of the study offer insight into the differences in time-use patterns of both elementary music teachers and elementary classroom teachers.

Further clarity regarding the interpretation of the foregoing results is possible if it is considered in the context of the nature of the content areas, environment, schedules, and teacher differences. The differences that exist between the classroom environments of elementary classroom teachers and music teachers generate reason for closer scrutiny by researchers. For instance, the self-contained elementary classroom is a place where thirty or more students of a specific grade level spend approximately six hours each school day with the same classroom teacher over the duration of the school year. According to Jackson (1968), physical objects (e.g., chalkboards, desks, textbooks, teachers), social relations (e.g., fellow classmates and teachers), and major activities (teaching, monitoring, and non-curricular) are regular features of the elementary classroom. There are daily and weekly schedules that account for the presentation of specific subjects, the sequence of activities and their designated times. It is not uncommon that the weekly time schedule is placed at a vantage spot where it can be seen by both teacher and students so that they can keep tract of activities. 
In the context of the elementary classroom, the classroom teacher is the sole person designated to teach diverse subject matter content (e.g., math, science, language arts). In addition to the content, there are identifiable classroom activities (e.g., seatwork, teacher's demonstration, question-and-answer session, testing period) that facilitate learning the subject matter and also require the teacher's skillful time management ability to provide a balance in time allocated for those teacher-led academic activities and monitoring activities.

In the elementary classroom ample consideration is required regarding the sequencing of classroom activities and the allocation of time to the various subjects within the curriculum. Evertson et al. (2000) claim that "such considerations lead many elementary teachers to plan reading and at least some language arts activities (or a combined literacy block) for the first two hours or so of the morning" (p. 86). Generally, the monitoring activity that is linked to these subject matter content activities - reading and language arts-is seatwork. Cunningham (1991) agrees that "most of the seatwork is done during the reading and language arts time and often occupies two-thirds of the allocated time" (p. 286). Further, in comparing elementary classroom teachers and music teachers, Wagner and Anderson (1999) found that elementary classroom teachers allocated the greatest proportion of time (19.1\%) to "seatwork".

In the elementary classroom it is expected that time be allotted to the teaching of other subjects such as math, science, social studies as well as to special subjects such as music, art and physical education. Designated times and special scheduling are often established for the special subjects that are assigned to specialist teachers. Garretson (1976) mentioned that music teachers are sometimes required to teach in a single school 
or may be asked to function as a traveling teacher, visiting a number of schools on a rotational basis. Each music teacher participant represented in Wagner and Anderson's (1999) study and in the present study, either made periodic visits to each elementary classroom (Kindergarten through Grade 5) within the assigned school, or had her or his self-contained music classroom, where students from each grade level went to the teacher instead. Regardless of the arrangement, duration of instructional period for each grade level varies from twenty to thirty minutes (Garretson, 1976). The primary grades usually receive music instruction twice per week, while the intermediate grades might have as many as three music periods per week. In some instances, the music teacher sees as many as four different grade levels within the school day. This scheduling seems to influence how music teachers manage time during each class period.

Hendel (1995) observes that music teachers seem to possess the ability to pace and distribute their instructional time efficiently. For example, the author (1995) reports that elementary music teachers in her study:

averaged about $44 \%$ of their class time presenting and reinforcing academic content that varied student-centered music-making activities at a rapid pace. This efficient pattern confirmed previous research that recognized fast paced instruction on the elementary level as a quality frequently attributed to exemplary and/or experienced music educators (p. 195).

Wagner and Anderson (1999) found that music teachers allocated 16.1\% more time to teaching than did classroom teachers. Planning period for the music teacher can range from 45 minutes to 60 minutes (Music Educators National Conference (MENC), 1986, p. 26). Wagner and Anderson (1999) reported that allocated time for 
planning, a non-curricular activity, was twice as much for the music teachers as compared to classroom teachers (i. e., $23.1 \%$ vs $13.1 \%$ ).

The present study was another approach to probing teacher time-use for elementary music teachers and elementary classroom teachers. By using three independent variables: grade level, time of day (morning or afternoon), and day of the week, this study provides valuable data for decisions related to time-use and instruction. Further study and analysis of specific demographic characteristics of the teachers in this study provides information that can be used to compare the relative influence of each characteristic to the prediction of teachers' time-use allocation patterns. Consequently, a knowledge base regarding time allocation patterns of teachers is available for educators. Ultimately, such knowledge will enable educators to identify classroom activity factors that may affect student learning.

The selection of elementary music teachers over other specialist teachers for this comparative study is of personal interest to the researcher, who is a music educator. One of the reasons for this choice relates to the nature and content of music education. The consensus of most music educators, many supporters of arts education, school administrators, and some policy-makers, is that music is a means for developing students' potential, giving opportunity for the success for underachieving students, and providing a better understanding of human relationships globally (Lehman, 1987). Lehman (1987) clearly states that "the curriculum should not consist solely of activities so similar to one another in their intellectual demands that those individuals whose abilities lie elsewhere are destined to fail in everything they do" (p.10). Therefore, music teachers are 
perceived to have a central role in bringing a balanced perspective to the school curriculum (Lehman, 1987).

Another reason for targeting music teachers as participants for this study is that as specialist teachers, they are responsible for approximately nine percent of instructional time in elementary school. Although the minimum time allocation for general music as recommended by the Music Educators National Conference (MENC) varies from 100150 minutes per child per week, the general practice in elementary schools within MiamiDade County Public School System is 150 minutes per child every two-week period. The music teacher is expected to be an efficient and effective manager of the music activities and procedures that occur during the 24 contact hours per week that are designated for music (MENC, 1986; Nye \& Nye, 1977). Also within a school day, the elementary music teacher will teach several grade levels of approximately eight classes per day, 30 to 35 minutes each (MENC, 1986, p. 26). The nature of the subject matter and the time constraints that have been imposed on the music teacher through scheduling are among the valid reasons to pursue music teachers' time-use patterns. Some studies on music teachers' ability to manage class time in a precise manner have offered further insight into teacher time-use in giving fewer directions (Moore, 1976; Wagner \& Strul, 1979), managing content (Moore, 1981), managing activities that create off-task behavior (Forysthe, 1977), and managing instructional time (Allard, 1992; Forysthe, 1977; Moore, 1976, 1981; Wagner \& Strul, 1979).

The results of Wagner \& Anderson's (1999) study seem to substantiate certain assumptions of some music and general educators regarding teacher time-use patterns (Hendel, 1995; Prater, 1992; Rosenshine, 1980; Rossmiller, 1983; Walberg, 1991). The 
first assumption was that elementary music teachers are more efficient than elementary classroom teachers in pacing their instruction time, and therefore, are able to allocate more time to teaching (Hendel, 1995). Wagner and Anderson's (1999) study confirmed this assumption when findings revealed that elementary music teachers allocated more time to teaching activities (44.1\%) than did elementary classroom teachers. The second assumption stated that elementary classroom teachers tend to allocate more time to "seatwork," a monitoring activity more than do elementary music teachers (Rosenshine, 1980; Walberg, 1991). Findings from Wagner and Anderson's (1999) study support this claim-elementary classroom teachers allocated more time to monitoring activities $(44.1 \%)$ than did elementary music teachers. "Seatwork" of all total monitoring activities had the highest proportion $19.1 \%$ of time allocation. The third assumption was that noncurricular activities attract 40 to 50 percent of the school day (Prater, 1992; Rossmiller, 1988). Wagner and Anderson (1999) reported that elementary music teachers allocated $38.2 \%$ of class time to non-curricular activities than did elementary classroom teachers. As evidenced by the foregoing results, the study could contribute a clearer picture of time-use pattern of these two diverse groups (elementary classroom teachers and music teachers). The assumption is that if these same two groups of teachers were to be compared by investigating their time-use based on other variables-grade level, time of day, and day of the week - additional insight would be gained regarding these variables and their influence on teacher time-use. Such information would enable educators in general, administrators, and policymakers to base decisions on instructional time and learning on solid data. 
The Research Questions

1. What differences exist in elementary music teachers and elementary

classroom teachers' time-use for teaching, monitoring and non-curricular categories across grade levels?

2. What differences exist in elementary music teachers and elementary classroom teachers' time-use for teaching, monitoring, and non-curricular categories by day of the week?

3. What differences exist in elementary music teachers and elementary classroom teachers' time-use for teaching, monitoring, and non-curricular categories by time of day?

\section{Subsidiary Questions}

1. How does time-use for the activities subsumed under the teaching, monitoring and non-curricular categories compare for elementary music teachers and elementary classroom teachers?

2. Does time-use vary with demographic characteristics - ethnicity, level of training, and years of experience- - for elementary music teachers and elementary classroom teachers?

\section{Assumptions}

The basic assumptions guiding this study are as follows:

1. It is assumed that teacher characteristics such as ethnicity, gender, teaching experience, level of training and the teacher time-use behaviors observed in this study are representative of the general population of teachers represented in the study.

2. It is assumed that teaching, monitoring and non-curricular activities and the 
activities subsumed under each category are the only teacher activities that occur during the school day.

\section{Limitations}

The limitations that affect this study are as follows:

1. The sample size is limited to elementary music and classroom teachers who teach kindergarten through grade five in field schools approved by Florida International University (FIU) and who allow FIU pre-service elementary teachers to observe and code their behavior in their classrooms.

2. The data collected on elementary music and classroom teachers are limited to the combination of an original pool of data from a previous study (Wagner \& Anderson, 1999) with additional data collected for this study involving the observation of 34 elementary music teachers.

\section{Delimitations}

The delimitations that affect this study are as follows:

1. Because the sample comes from elementary schools, the results of this study can be generalized only to other teacher populations in elementary schools and also to elementary schools in Miami-Dade County, Florida.

2. The observation of teacher time-use was limited to the quantity and not the quality of time-use.

\section{Definition of Terms}

Activity. A discreet unit of school time that is relatively short in duration. In this study, examples of an activity would be subsumed under the major categories as follows: 
the teaching category (i.e., reading), the monitoring category (i.e., seatwork), the noncurricular category (i.e., lunch) (Doyle, 1986, p. 398).

Category. "A specifically defined division in a system of classification" (Second College Edition: The American Heritage Dictionary, 1976). There are three major divisions of teacher time-use in this study: teaching, monitoring, and non-curricular.

Elementary Classroom Teacher. A teacher who is state certified in elementary education, trained to teach in elementary school, and holds at least a Bachelor's degree in that field.

Elementary Music Teacher. A state certified specialist in music education who may have a strong minor or a second major in music, trained to teach general music in elementary school, and holds at least a Bachelor's degree in that field (NCI, 1972, p. 60).

Episode. an instance of any teacher activity within the school day (Jaques, 1982, p. 33).

Half-day. In this study, the term is applied to a three-hour period either (1) beginning at the ringing of the tardy bell in the morning and extending for three consecutive hours or, (2) beginning exactly three hours before the ringing of the school's dismissal bell (Wagner \& Anderson, 1999).

Monitoring. The time teachers spend with their assigned students, either supervising them at independent or group tasks, or directing them for non-academic purposes. Monitoring encompasses the tacit supervision of students, preparing them to do an activity (e. g., getting ready), moving children from place to place, and teacher talk that is irrelevant to academic or social instruction (Wagner \& Anderson, 1999).

Non-curricular. The time teachers spend during the teaching day away from 
their assigned students. A non-curricular activity might also require that the teacher spend this portion of school time alone or supervise a larger area other than his or her own class. The non-curricular activities are: lunch, assemblies, planning, administratively assigned duties, teacher travel time and consultation (Wagner \& Anderson, 1999). These activities are further explained in Appendix B.

Region. One of the six divisions into which the Miami-Dade County Public Schools (Miami, Florida) is grouped. The school district is divided into six administrative units based on geographic boundaries, each with a region superintendent and an administrative staff. In addition, there are Alternative/Specialized/Education centers that report directly to the central Office (Miami Dade County Public Schools, MDCPS, 1996-97, 1997-98).

Subject Matter. Refers to the subtitle given to include the five activities that are considered content area within the teaching category. Subject matter activities are different for each teacher population. The elementary music teacher's content area consists of five activities: singing, playing instruments, rhythm, movement, and listening. The elementary classroom teacher's content area consists of five activities: reading, language arts, mathematics, social studies, and science (Wagner \& Anderson, 1999). These activities are further explained in Appendix B.

Teaching. The act of delivering information related to the curriculum to the students via frequent and brief presentations arranged in organized lessons (Brophy \& Good ,1986). In this study, teaching refers to teacher-led activities such as academic instruction, social instruction, and teacher-led activities in which students are actively 
engaged - discussion, reinforcement activity, subject matter, and combinations of activities (Wagner \& Anderson, 1999).

Time-use. This term originates with this study and is applied to the time that the teacher utilizes in teaching, monitoring and doing non-curricular activities within the classroom. The term pertains to teaching activities within the time frame that involves a three-hour period either beginning at the ringing of the tardy bell in the morning and extending for three consecutive hours or beginning exactly three hours before the ringing of the school's dismissal bell (Wagner \& Anderson, 1999).

Organization of the Study

The remainder of the study is structured in the following manner: Chapter II covers the review of the literature on time-use in education. It also includes the related literature regarding the research questions. Chapter III describes the methodology including participants and setting, the research design, the research instrument, and procedures. Chapter IV presents the findings and the analyses of the data. Chapter V is devoted to the summary, discussion, and conclusions of the study. Recommendations for further research are also provided in Chapter V. 


\section{CHAPTER II}

\section{REVIEW OF THE LITERATURE}

The purpose of this chapter is to review the literature on the various aspects of time-use in education. These aspects include a definition of time and time-use, and the conceptualizing of time-use in education as it relates to the school, student, and teacher. A brief historical perspective of observation instruments and time-use studies that are related to the research questions that guide this study are also presented in this chapter.

\section{Defining Time and Time-Use}

The construct of time is prominent in studying teacher behavior in the context of the school organization (Ben-Peretz \& Bromme, 1990; Brophy \& Good, 2000; Bruno, 1997; Walberg, 1984). Bruno (1997) advocates the need for clear definitions concerning "time" and "time-use". He believes that "the school organizational search for productivity and legitimacy has led to the precise definition of time and time-use for its classroom teachers" (p. 85).

The present study utilized the concept of time as a yardstick in probing how elementary teachers use their time in schools. However, a more specific term, "time-use" is employed in, and originates with, this investigation. In this context, "time-use" applies to the time that the teacher utilizes in teaching, monitoring, and doing non-curricular activities within the classroom. Everston and Harris (1992) state that "while the amount of time imposes limits on what can be accomplished the key issue is how time is used" (p. 74). Essentially, this statement accurately pinpoints the main focus of this researchhow time is used. 


\section{Conceptualizing Time-Use in Education}

Time became an important factor in the school organization, in part, through the influence of business management practices. Specifically, the business sector utilized time management along with business practices and accountability that were based on scientific methods. The application of these concepts and ideas contributed to the success experienced in the business sector placing business executives as the most capable leaders with power and status in the American society at the beginning of the 20th century. The business industry's success and dominance overshadowed all other institutions including education (Gelberg, 1997). Anxious to improve the principles and practices in the schooling process, educators and policymakers sought to adopt some of these ideas from business. They reasoned that "what was good for business was good for American schools"; therefore, on this premise, the educational system imported from industry many of their concepts, including time management (Bennett de Marrais \& Le Compte, 1995; Berliner \& Biddle, 1995; Gelberg, 1997).

The actual transfer of scientific management ideas to education occurred around 1912, and Franklin Bobbitt, a most influential leader in education, was instrumental in shaping this point of view as presented in his article, "Elimination of Waste in Education" (Bennett de Marrais \& Le Compte, 1995). Bobbitt's approach to scientifically managing the curriculum in school was to eliminate all nonessential knowledge and skills noted to hamper students' success in school or in the work place. First, he recommended that students be measured scientifically then be taught the subject matter that best suited their ability and their predicted future roles in society. Even though Bobbitt's efforts concerning scientific management of the curriculum did not 
stress time-use management, his pioneering attempts as an efficiency advocate laid the ground for the time management aspect of efficiency to become an important component of schooling.

Bruno (1997) asserts that "the time-management movement is, of course, a natural extension of scientific management" (p. 84). The development of the principles of scientific management that were so essential to the success of the business sector at the turn of the century originated with Frederick Taylor. The principles that he thought would simulate high achievement in business areas follows: (1) Time and motion controlled by the stopwatch that fully symbolized "management based on measurement", (2) Standardization was an important factor concerned with the speed of production, (3) Clearly defined tasks to be performed by workers within a given time frame, (4) Functional foremanship involved expert teachers whose responsibility was to instruct workers and to see that the production process was achieved (Callahan, 1962, pp. 28-32).

Taylor's approach was designed to give greater control to managers and planners over workers while increasing productivity through observation, testing and record keeping. Taylor's principles soon permeated all facets of the corporate world, and, therefore, became a major influence in many aspects of American life as well as life in other countries. A leading physician-educator, Joseph Mayer Rice, was influenced by Taylor's ideas. Rice led American educators into action by producing articles, books and reports on economy, efficiency, and standardization in education. Soon the influence of Taylorism was evident from elementary schools through universities. Some significant changes were made in school equipment and design as well as in management, recordkeeping, curricula, and time allocations for instruction (Bennett de Marrais \& Le 
Compte, 1995). Kliebard (1995) asserts that "the use of scientific management techniques ... ultimately provided the language and hence the conceptual apparatus by which a new and powerful approach to curriculum development would be wrought” (p. 83).

From 1912 to 1930 , education reformers attempted to put in action the new scientific management system that was demonstrated in the classroom almost immediately after it was adapted from business. Efforts on the part of school administrators and policymakers were seen in major attempts to develop achievement tests and also rating sheets. For instance, Callahan (1962) reports an early attempt by Theodore Mitchell at the beginning of the $20^{\text {th }}$ century to bring the education system on par with industry concerning the matter of the time management in the classroom. Mitchell claimed that "use should be made of all the available time. No time should be wasted in calling roll, and too often valuable time is lost where groups are sent to the blackboards and the several tasks assigned to each one by one, while all the rest wait their turn. As much as four minutes idle time is spent by some" (Callahan, 1962, p. 102).

This description regarding the state of classroom time management at the turn of the $20^{\text {th }}$ Century was hardly different at the end of the century. This fact is supported by a number of researchers in education (Anderson \& Walberg, 1993; Ben-Pertz \&Bromme, 1990; Bruno, 1997; Prater, 1992; Rossmiller, 1983). Slattery’s (1995) comments regarding the state of time-use in today's classrooms indicate that teachers are still faced with the challenge of managing numerous tasks within the limited time constraints. The constraints placed on managing time within the framework of the school's organization have served to influence the conceptualization and investigation of time-use. However, from the perspective of the present study, the intent of the literature review is to include 
relevant research regarding schools' time, students' time, and teachers' time. Although the study involves a comparison between elementary music teachers' time-use and elementary classroom teachers' time-use, it was necessary to refer to schools' time-use as well as students' time-use, because all three aspects of time-use- teacher, school and student-are inter-related. For example, the school controls the scheduling of time and determines how the school districts' curricular time-lines will be accomplished (Bruno, 1997; Karweit, 1988). The amount of time needed by the student to accomplish a task and also the amount of time the student is attending to a task are aspects of the student's involvement in class time, which, in turn, influence teacher's time-use.

It is significant to note that it is the teacher within the classroom setting who is ultimately responsible for the allocation of time for learning and who determines how much time should be spent on each activity. Conversely, the student's responsibility is to pay strict attention (i.e., remain on task) while being instructed. Further, Rossmiller (1983) notes that " the actual amount of time that students will be on-task will depend upon such things as their interest in the subject, their attention span, their motivation to achieve, the mode of instruction, the behavior of their classmates, the skill of their teacher, and physical conditions within the classroom"(p. 47). Karweit (1988) states that the issue regarding time-use in the school is truly the responsibility of the school, the student, and the teacher (p. 32).

\section{Schools' Time-Use}

The school organization is believed to be the major claimant of the teachers' time and requires a great deal from its teachers. Bruno (1997) suggests that the school's control over the teacher's time is evidenced in the manner teachers adhere to class 
schedules, school calendars, lesson plans, and regular monthly events. Of all the control strategies mentioned, lesson planning has been one method the school organization uses to keep track of teacher's time every minute of the school day.

Bruno (1997) says, schools display their power and ability in exercising control over the:

'where' of student-related time-consuming activity (schedules and calendars), the 'rate' or normal progress and the frequency of activities (number of times an activity is needed and time expectation with regard to curriculum delivery), and the sequencing of activities (how activities are linked in time to each other or grade-to-grade articulation). (p. 82)

Additional curriculum requirements, curriculum related activities and noncurriculum activities usually encroach upon teachers' instructional time. For example, recently school administrators nationwide have encouraged more attention to the administration and supervision of statewide tests in the elementary schools. The involvement of teachers and students in this extensive testing has created the situation where teachers have had to prioritize testing above other classroom activities. Statewide testing usually occurs during the first half of the second term. The amount of time spent on testing and preparing for those standardized tests by teachers and students has resulted in the allocation of less time to academic instruction and other learning activities (Bruno, 1997).

Policymakers and school administrators' unusual emphasis regarding students' academic performance in school dates back to the launching of Sputnik in 1957. It was then that Americans discovered that, compared to the Russians, they were underachievers 
in space technology. This discovery influenced a surge of school reforms and statewide iniatives including the "back-to-basics" movement that started in the late nineteen fifties and continued through the nineteen seventies (Mark, 1986).

Despite the school reforms during those years, the decline of education and poor student performance in the seventies exhibited by many schools throughout the United States of America continued, and this did not lessen the consternation among educators, policymakers, and school administrators. Another call for educational reform to improve the state of the public school system was reflected in 1983 in the important document, $\underline{\mathrm{A}}$ Nation at Risk, published by the National Commission on Excellence in Education (NCEE). T. H. Bell, Secretary of Education, formed this commission to investigate and report on the state of American education. The major finding of the Commission's report indicated that American educational foundations were presently in danger due to the high level of mediocrity that was prevalent and that threatened the bright future of the United States of America (NCEE, 1983).

In addition, the report cited several shortcomings of the educational system, including the use of time in the classroom. The information received via this report created awareness among reformers, policymakers, and educators regarding time-use and its possible implication for students' learning in the schools. This awareness was further heightened by the realization that, when compared with the other industrialized countries, students in the United States of America spent less time in school, used class time inefficiently, and received little help from school administrators and teachers as to how to improve their time-use. Examples of time-use disparity were also cited: 
(1) British students experience an 8-hour school day and 220 days for the school year as compared to American students who have a 6-hour school day and a school year of 180 days.

(2) Academic instruction for American students amounts to 17-22 hours per week.

(3) An investigation of some Californian elementary schools revealed that timeuse for academic instruction in reading comprehension was only one-fifth of the amount that other students received. (NCEE, 1983, pp. 22-23)

Accompanying the A Nation at Risk report was a set of recommendations, including one, which called for "significantly more time to be devoted to learning the new basics-English, mathematics, science, social studies, and computer science. This will require more effective use of the existing school day, a longer school day, or lengthened school year" (NCEE, 1983, p. 29). This statement declared time as a key factor linked to student learning. NCEE (1983) called for "more effective use of the existing school day, a longer school day or the lengthening of the school year"; they also suggested ways to implement this improvement in American Schools. Two of the implementing recommendations stated that: (1) the time available for learning should be expanded through better classroom management and organization of the school day; and (2) administration burdens on the teacher and related intrusions into the school day should be reduced to add time for teaching and learning (NCEE, 1983, pp. 29-30). These recommendations point out that schools need to make effective use of existing time. However, policymakers and administrators did not at first consider how time was used or 
how to make use of existing time in the school before recommending its adjustment (Funkhouser et. al., 1995; Karweit, 1988).

NECTL (1994) mentioned that “Teacher's instructional methods and classroom management techniques determine how productively learning time is used; that is how much teaching and learning actually occurs in the minutes and hours devoted to the process" (The Report of the National Commission on Time and Leaning, NECTL, 1994, p. 25). For example, the classroom teachers in American schools are known to allocate a great deal of class time to seatwork activity especially during the reading/language time (Rosenshine, 1980). Therefore, the amount of time that teachers spend on this activity varies, and, according to Walberg (1991), active engagement in the learning process usually declines with seatwork activity and learning increases with active engagement (NECTL, 1994, p. 25). Ritualistic activities (preparation, transition, calling the roll, distributing paper), extra curricular activities (recess, lunch, assemblies), and unscheduled interruptions are also attributable factors to the erosion of academic learning time in the schools (Evertson \& Harris, 1992; Rich \& McNelis, 1988; Rossmiller, 1983). Following the release of A Nation at Risk (NCEE, 1983), several state proposals advocating lengthening the school day and year were generated. Consequently, policymakers and educators have supported an increase in instructional time for students in the classroom (Funkhouser et al. 1995, p. 4). Yet there have been arguments that oppose the increase of school time (day or year) as having an inconsequential effect on student performance. While some agree that there is a time effect on achievement, the National Education Association (1987) asserts that some would make "more efficient use 
of existing time rather than consider an increase in school time" (Funkhouser et al. 1995, p. 5).

Karweit (1988) mentions that "some schools, for a variety of reasons do not make use of their available time" and should do this before considering lengthening the school day, term, or year (p. 32). Even before Karweit made the foregoing statement, some researchers were already investigating the use of available school time. For example, Cawelti and Adkisson (1985), selected elementary school principals throughout America to report on the length of daily instruction allocated to student instruction. These schools averaged in allocating time for academic instruction five and six and a half hours daily. Approximately three-fourths of the day was devoted to instructional activities. The researchers compared the amount of time school allocated to different subject areas, (i.e., math, science, social studies, reading, health, physical education, music, and art). The total time allocated to all subject areas amounted to four hours and 38 minutes with the greatest amount of time (100 minutes) allotted to reading and the least amount to music (14 minutes) and art (13 minutes).

Karweit (1988) makes the following suggestions if schools want to improve their use of existing time. First, each school should determine how time is used in their organization, then compare the results with other schools. Secondly, administrators should use "time profiles" to collect and assess time-use data. Thirdly, disaggregate active learning time so as to determine time-use patterns by teachers and students. This act of disaggregation of active learning time will enable administrators to determine sources of variance for time-use in the schools (pp. 32-33).

Although support for reform in the educational uses of time seemed reasonable, 
state legislators and supporters have presented some compelling arguments without tangible results. The debate to find ways of improving American education continued well into the 1990's. Proposals such as America 2000 (U. S. Department of Education, 1991) initiated and legislated by President Bush in 1989 and Goals 2000 (U. S.

Department of Education, 1996) by President Clinton in 1994 echoed the sentiments of the first report (A Nation at Risk, National Commission on Excellence in Education, 1983) that American education was on the decline. American students had failed to achieve high standards.

The threat of students of other industrial countries outperforming American students became a serious national concern. Hence, Goals 2000 required each state to implement reform programs that would guarantee that schools meet the achievement of core academic subjects. Science and mathematics were targeted as key subjects in which students in the United States of America would gain highest achievement in order to be first on the international front (Berliner \& Biddle, 1995; USDE, 1994).

In response to Goals 2000 and its agenda, educators and legislators identified time as the most important factor in attaining the nation's school reform (e.g., Florida's response was Blueprint 2000). An independent advisory body, The National Education Commission on Time and Learning (NECTL), was formed in 1991 to investigate relationships between time and learning in American, Japanese, and German schools. As many as 19 elementary and high schools and 150 teachers, administrators, parents, and students were included in this research.

The Report of the National Education Commission on Time and Learning (NECTL, 1994), entitled Prisoners of Time, resulted after a two-year in depth study. The 
study found that schools in the United States allocate less time to academic learning than their foreign counterparts. It was also revealed that the already limited time allocated to learning was in competition with a number of non-academic activities that were forced into the school day. The most disturbing finding was that students in Japan and Germany were allocated more time for learning and teachers and students made better use of time, therefore resulting in higher achievement than students in the United States of America. Further, the report claims that the results of this study were predictable because in all countries, all the activities and events occurring in the school environment are driven by the clock.

Further insights regarding how American schools attended to time-use were revealed. The study found that "Despite the obsession with time, little attention is paid to how it is used" (NECTL, 1994, p. 9). It was also observed that in 42 states approximately $41 \%$ of school time is allocated to core academic subjects. The Commission also called for reform in the way time is used in the schools. The Commission's suggested reform agenda regarding time in American Schools is cited here:

a) The fixed clock and calendar is a fundamental design flaw that must be changed

b) Academic time has been stolen to make room for a host of non-academic activities

c) Today's school schedule must be modified to respond to the great changes that have reshaped American life outside school

d) Educators do not have the time they need to do their job properly

e) Mastering world-class standards will require more time for almost all students. (NECTL, 1994, p. 13)

The last decade has seen much effort by educators and legislators to address the issue of time in the schools. To avoid making speculative assumptions regarding timeuse, relevant research and reports suggest that educators and researchers keep searching 
for answers based on solid evaluative data (Funkhouser et al. 1995; NECTL,1994; US Department of Education, 1994; Walberg \& Frederick, 1991).

Miller (1980) points out that "the very organization of the school places enormous constraints on the uses of time in individual classrooms" (p. 163). The classroom is considered the place where the management of time-use becomes crucial and has the strongest implications for learning. For instance, an elementary school student may be in the classroom approximately seven hours per day, 35 hours a week, 36 weeks per year for 12 years (Thompson, 1984, p.36). This represents a considerable portion of time for any student to spend in a controlled environment. Thompson (1984) cites that "if this time is carefully structured toward an ongoing educational process, society is strengthened and expanded. The one continuous thread in the process is the teacher. The amount of time this person spends with the child will be very influential in the developmental process" (p. 36).

Hence, it is established that the elementary classroom teachers more than the specialist teachers-music, art, and physical education — spend most of their time during the school day in the classroom. Moreover, elementary classroom teachers anticipate the time when the specialist teachers are scheduled to teach so that they can have some time away from the students (Lewin \& Nolan, 2000). Therefore, the classroom teacher may use this designated time as planning or break time. For most elementary students, music time is significant especially if taught by the specialist teacher.

\section{The Elementary Classroom Environment}

The elementary classroom has been viewed by most researchers as a setting conducive to empirical investigations on all aspects of teacher and student behavior 
(Brophy \& Good, 2000; Doyle, 1986; Jackson, 1968). For instance, Tabel (1992) claims

that the systematic observation of life in the classroom has strong implications for curriculum and instruction. He believes that data gathered in the context of the classroom can provide educators and evaluators of teachers a dependable basis for implementing pedagogical improvements. Further, the literature provides some research about the influence of certain elementary classroom variables on teacher and student behavior.

For example, Jackson (1968) explored certain aspects of teacher and student activity within the classroom. Among the findings, the study revealed that the classroom with all its complexity is indeed an active environment where approximately 1000 interactions occur daily. He mentions that by observing the teacher much can be gained regarding the general milieu of the elementary classroom. In addition to the main activity of teaching, the elementary teacher is involved in many time-consuming tasks such as time required for lunch, announcements, preparation, procedural activities, and so on. Almost two decades after Jackson's study, Feiman-Nemser and Floden (1986) observed that the general milieu of the elementary classroom had scarcely changed. They noted: not only do teachers have a variety of things to do, they must often attend to more than one thing at a time. As they help individual students, teachers must monitor the rest of the class. As they conduct lessons, they must anticipate interruptions, distribute opportunities to speak, and keep an eye on the time (p. 516). In the nineteen nineties, the general milieu of the classroom seemed to have intensified. Slattery (1995) declares that numerous tasks and activities impinge on regular class time, producing urgent time constraints within the school day. Teachers unable to cope are overwhelmed and frustrated. In addition, other factors such as changes 
in societal expectations and demands for reform and change can impact teachers' use of time.

The pressures of the classroom environment are real. Doyle (1986) identifies them as:

- Multidimensionality, meaning the large variety of events and tasks that are present in the classroom (e.g., keeping records, meeting schedule).

- Simultaneity, meaning that many things happen at once in the classroom (e.g., teacher teaches, monitors, handles interruptions, renders assistance, and keeps track of time).

- Immediacy, meaning that events in the classroom occur at a rapid pace, for example, Gump's (1967) and Jackson's (1968) studies report over 500 daily student and teacher interactions.

- Unpredictability, meaning that classroom events often take unexpected turns (e.g., distractions, interruptions).

- Publicness, meaning that classrooms are public places where events especially those lead by teachers, are witnessed most often by the students.

- History, meaning that a common set of experiences, routines, and norms are initially established, thereby providing a base for conducting activities (Doyle, 1986, pp. 394-395).

The pressures referred to above are typical of most elementary classroom environments. However, in reference to the elementary music teachers' classroom environment, the pressures sometimes vary. Occasionally, the music teacher is assigned a self-contained music classroom or is required to travel from one classroom to the next 
during the school day. There is greater occurrence of scheduled student entrances and exits in self-contained classrooms than there is in the regular classroom. The music teacher is scheduled to see more than one grade level during the school day as compared to the classroom teacher who is assigned only one specific grade level during the day (MENC, 1986; Nye \& Nye, 1977). In the self-contained music classroom there are fewer quantity of events and tasks (e.g., housekeeping activities, routine activities). However, in the regular classroom, the classroom teacher routinely allows students to listen ritualistically to announcements over the intercom, engages them in reciting the school pledge, reminds them of the classroom rules, collects money if needed and takes the roll. In the music classroom, the pacing of activities tends to occur more rapidly because the music teacher is challenged to fit all learning activities within the specified time allotted to each grade level. (Garretson, 1976; Nye \& Nye, 1977).

The differences in instructional content variety between the elementary music teacher and the elementary classroom teacher also contribute to the way time is used by these two groups of teachers. Nolin (1991) claims that "learning takes place best in an environment conducive to the task and nowhere is a positive atmosphere more important than in the general music class" (p. 36). According to Wang and Sogin (1997), the elementary general music class taught by the elementary music teacher is "probably the best and the only opportunity for most elementary students to receive systematic instruction in music" (p. 444). The content of instruction in the general music class consists of singing appropriate simple unison and two-part harmony songs, playing simple percussion instruments, moving to music, responding to rhythmic activities, listening as a function of all musical involvement, reading music, writing and creating 
music. Harrison (1983) asserts that these "activities are the vehicles through which music is experienced and that the content of the music curriculum of the elementary school is the music" (p. 16).

Nolin (1991) found that there were positive and negative attitudes of elementary students across grade levels towards their elementary school music experiences. Students' positive attitude toward all music experiences tend to decline over grade levels; however, only a modest decline was found toward activities such as singing, playing instruments and movement. Nolin (1991) claimed that "almost any approach to singing produced the most positive attitudes consistently throughout all grades and for both genders" (p. 35). Playing instruments was an activity in which students displayed a high level of on task behavior. Depending on the teacher's approach, movement was the other activity that attracted positive attitudes from students. The teaching of "music lends itself to interest in curricular events by the nature of the variety of activities in which children can be involved" (Harrison, 1983, p. 15). Therefore, musical activities that occur in the general music class tend to stimulate children's interest, involvement in learning, and ontask behavior. For instance, Forsythe (1977) found that the attending behavior of elementary students in the general music class was a function of the type of activities in which students were involved. In addition, Forsythe (1977) indicated that most of the class time was allocated to singing and listening activities, and also to verbal interaction. Moore (1981) found that of all the musical activities, singing received the highest proportion of allocated time both by American and British teachers in elementary general music classes. 
Findings of Baldridge's (1984) study indicate that listening as a function of all musical involvement claims most of the class time in the general music class. Studies report that in the general music classroom, music teachers allocated more time for presenting and reinforcing academic content (Hendel, 1995; Moore, 1981; Price \& Hardin, 1988; Yarbrough, 1988). For example, Hendel (1995) found that class time was proportioned as follows: $67 \%$ for academic related activities and $32 \%$ for directionrelated activities.

In reference to the differences in instructional content for the classroom teacher, it should be noted that the classroom teacher is solely responsible to instruct all students of a specific grade level in all the core subjects—science, math, language arts, and social studies. The classroom teacher has to be skilled in seeing that each subject area receives appropriate amounts of time, even though some subjects (e.g., math, language arts) require more time than others (e.g., social studies, art). According to Doyle (1986), "the nature of the work students do plays a central role in getting lessons accomplished in real time" (p. 416). Usually each subject area requires that the classroom teacher present new information with appropriate instructional activities to help students learn. The traditional approach to presenting content takes the form of involving the whole group and presenting the content information through lecture and demonstration for designated period of time. This is sometimes followed by discussion, questions, recitation, or seatwork.

According to Evertson et al. (2000), sometimes the management of teaching and related activities reflects a different approach in the elementary classroom. The presentation of content might involve a small group, a whole class setting, or an 
individual. Doyle (1986) claims that in a number of elementary classrooms, the presentation of subject matter may be proceduralized. In other words, a set of procedures guides the delivery of the subject matter content. The main focus is to practice and complete assignments after the teacher gives directions concerning the completion of the assignment. In essence, the teacher acts as facilitator and monitors what is considered "seatwork".

Understanding the variations inherent in the two types of classroom environments can provide the context whereby a more meaningful interpretation of the data gathered can be achieved. Apart from the classroom environment, there are specific school factors that have served as determinants of teachers' time-use in different settings. The factors considered in the present study include grade level, time of day, and day of the week.

\section{$\underline{\text { School Factors Influencing Teachers' Time-Use }}$}

The influence of certain school factors such as grade level, time of day, and day of the week on time-use has not been ignored by researchers, but research involving these factors has not been rigorously pursued. Only a few researchers have studied these factors in relation to teacher time-use inquiry.

Tabel (1992) expressed that "studies of teacher and/or student variability across grade level or within grades should be undertaken" (p. 323). During the nineteen eighties, a few researchers, including Amen (1982), Wagner, Allen and Shoemaker (1985) and Montgomery (1985) recognized the need for such inquiry and examined elementary teachers' time-use in both regular classrooms and in music classes for various grade levels. Each of these studies examined teacher time-use by identifying percentages of allocated time to various activities during class time across grade levels. For example, 
Amen (1982) investigated the allocation of time to music instruction by elementary classroom teachers. Twelve factors were selected as predictors. Of the total number of selected factors, grade level, total number of selected music materials available, and teacher's pre-college preparation were the three predictors that had significant influence on increased instructional time. Amen (1982) stated that grade level emerged as the most significant predictor of instructional time. The pattern of teacher time-use allocation showed that in the lower grades (K-3) time allocation for music instruction decreased as grade level increased. Time allocation for music instruction further decreased in the upper grades (4-6).

In another investigation of regular classrooms, Wagner, Allen and Shoemaker (1985) were concerned with elementary classroom teachers time allocation for activities that occurred in the their classrooms. The researchers examined the data by grade level. The findings revealed that as grade level increased, time allocated for academic instruction teaching activities increased while time for seatwork, reinforcement and preparation decreased. The percentage reported for time allocation for teaching activities for K-5 ranged from $21 \%$ to $40 \%$ across the grade levels. They concluded that grade level seems to be a key factor in determining the amount of time spent in academic instruction in each classroom activity.

Montgomery (1985) used 18 independent variables to examine time-use by elementary music teachers for several music classroom activities. She found that of all these independent variables, the county in which teachers' school was located, grade level, years of teaching experience, and workshop participation showed the most significant effects on how teachers allocated their time to music classroom activities. For 
example, the analysis for grade level showed that the teacher spent more time on moving and singing activities in the lower grades (K-3), than in the higher grades (4-6). More time was allocated to playing instruments, listening, and writing activities in the upper grades (4-6) than in the primary grades (K-3). Montgomery (1985) suggested that time allocation across grade level for the various activities seems to indicate that the teacher's perception of the developmental stages, attention span, and greater physical capacity to manage and handle instruments could be attributing factors to the difference in time-use in these activities, across grade levels.

Connelly and Clandinin (1990) claim that "there are certain school cycles such as annual, monthly, weekly, day that are important, and, when scrutinized, give further insight regarding schools and their personnel - teachers, students, and administratorsroutine cyclic patterns and time allocations" (Connelly \& Clandinin, 1990, p. 38). The researchers further explain that, in general, the weekly cycle is perceived as a seven-day cycle that has five days for work and two days of rest. In the school setting, the five days known as the work week have a temporal structure that has significance. For instance, the school district and school administrators require that certain subjects be taught by specialist teachers on certain days (e.g., physical education on Tuesdays and Thursdays and music on Mondays and Wednesdays). Teachers seem to have distinct patterns for structuring and allocating time for academic and non-academic activities during the school week. Having observed some classrooms, Connelly and Clandinin (1990) reported that, generally, teachers plan activities during the school week in the following manner. They introduce new materials and engage in academic instruction from Monday through Wednesday; Thursday and Friday seem to be lighter days in terms of academic 
activity in most school settings. Rossmiller (1983) asserts that students' "on-task behavior is generally lower on Mondays and Fridays and before and after holidays" (p. 48).

For example, Cornbleth and Korth (1980) used day of the week (Monday through Friday) along with two other contextual variables (subject area and activity format) to investigate students' time-use in fourth grade. The researchers found that main effect of day of the week was not significant, but interaction effect of the day of the week and subject area yielded significance. However, day of the week emerged as a predictor of student's time based on the subject area. Time allocation for subjects such as science and social studies showed an increase across days of the week. Conversely, student time allocation for language arts and math showed a decrease especially on Tuesday and Thursday. Results also showed that there was 'down time' on Fridays. In general, these results imply that the study of students' time allocation pattern is certainly one way to gain further insight into how teachers allocate time for a certain subject area and on any given day of the week.

The variable time of day (morning or afternoon) has not produced much research in education. Interestingly, a study by Fitzgerald, Wright, Eason, and Shapson (1978) was found and reported in the present review of the literature. However, time of day was not a variable in the cited investigation. It was only mentioned that the researchers varied the time of their observations (day of the week as well the time of day-mornings and afternoons). 


\section{Students' Time-Use}

Over the last 60 years, the focus of many investigations on time-use in the classroom has been students' time-use rather than teachers' time-use. A major reason for including student's time-use research is that its research stream is the source of relevant terminology and concepts needed to understand the relationship between time-use and students' learning. For example, early studies from the beginning of the $20^{\text {th }}$ century through the 1960s, served to influence later investigations students'on time-on-task (Good \& Beckerman, 1978; Rich \& McNelis; 1988 Rosenshine, 1980), time-use and student achievement, and academic learning time (Denham \& Liberman, 1980; NECTL, 1994; Walberg \& Frederick, 1991). In the same manner, time-use conceptual models (Bloom, 1968; Carroll, 1963; Harnischfeger and Wiley, 1985) dealing specifically with students' time had tremendous influence on numerous studies of students' time-use. These time-use studies and conceptual models will be described in this section.

The literature search uncovered the first empirical investigation involving timeuse by Joseph Mayer Rice in the last decade of the $19^{\text {th }}$ Century. According to Berliner (1990), Rice studied the effects of allocated time in the elementary school by observing time-use of teachers and students engaged in a spelling activity. He was concerned about learning outcomes analogous with instructional time spent on spelling. Findings revealed a curvilinear relationship indicating first, an increase in achievement in spelling when more time was allocated to spelling drills, and then a decrease in achievement in spelling even though a certain amount of time was allocated to spelling drill. Rice's pioneering efforts in time-use research in education sparked the interest of others to 
pursue the time phenomena of duration, time-on-task, attentiveness, allocated time, and engaged time.

Berliner (1990) claims that between 1913 and 1940, educational researchers like E. L. Thorndike emphasized that duration of time was important to the learning process, and William James stressed the importance of time-on-task. The influential Herbartians, a group of American educators, claimed to possess a scientific approach to education. They required teachers to be trained in the management of instructional time as an essential part of teacher preparation (Kliebard, 1995). Judd (1918) was concerned about students' attentiveness as an important aspect of instruction and learning while Morrison (1926) was interested in quality of instruction and in allocated and engaged time. These early research efforts formed the basis for conceptual models, research, and student attentiveness concerns that followed in the1950s through the1970s.

The general discourse concerning student time-use studies pursued in the 70's and 80 's is familiar. For example, Good and Beckerman (1978) time-on-task study of sixth grade students revealed higher on-task behavior when students were high achievers, female, in small or large groups led by the teacher, or when the subject matter was mathematics or English. The classic time-on-task study by Rosenshine (1980) investigated how classroom time was spent by elementary teachers and students. It was reported that time-use in academic subjects (math, reading, social science, and science) for second and fifth grade students claimed 60 percent of class time. Engaged time differed in reading and mathematics. Second graders spent an average of one hour and 30 minutes while fifth graders spent one hour and 55 minutes. Another time-on-task study pursued by Rich and McNehlis (1988) investigated academic time-on-task of 
students in six elementary schools. Results revealed that during the school day, elementary students were on task $32 \%$ of the time. A specific teacher behavior such as eye contact helped students increase on-task behavior. Conversely, it was found that "wait time" negatively affected on-task behavior.

Research on time-use and student achievement intensified during the 1980s and into the early 1990s. Already in the 1970s, this area of interest had become the main focus of the California Commission for Teacher Preparation and Licensing. What started out to be a study to identify teaching competencies with the purpose of helping neophyte teachers became focused on teacher behavior and student achievement. The main focus of this study was Academic Learning Time (ALT) as a measure of learning. Denham and Liberman (1980) define ALT as "the amount of time a student spends engaged in academic tasks of appropriate difficulty" (p. iii). Although this effort was entitled the Beginning Teacher Evaluation Study (BTES), the study was research based, involved experienced elementary classroom teachers, involved students in second and fifth grade mathematics and reading, and consisted of three phases over a period of six years (19721978). Phase I was concerned with the actual planning of the research, Phase II was the initial fieldwork, Phase III was divided into IIIA (additional fieldwork) and IIIB (final field study). Denham and Lieberman (1980) have documented all the developments, research procedures, methodology, findings, and implication commentaries by other educators concerning this study. The main contribution of this study is the concept of ALT and its relationship to student achievement. Findings also indicate that there were great differences in allocated time, engaged time, and success rates. Brophy and Good (1986), commenting on these differences over a school year, note that "second graders 
received an average of 15 minutes of mathematics instruction per day, while others average 50 minutes... Some students were attentive to lessons or engaged in tasks only about $50 \%$ of the time, but others average $90 \% "$ (p. 353).

The 1983 reform document, A Nation at Risk, whose emphasis was time-use effects on student learning and achievement, directly influenced the pursuit of numerous studies. This is evidenced by Walberg and Frederick's (1991) meta analysis of over 100 major time-use studies, which covered research activities through the1980s. These selected studies dealt with how time is used in the schools, how time can be used efficiently, and how increase in instructional time affects achievement. For instance, studies of the effect of time-use on learning and achievement reviewed by Walberg and Frederick (1991) revealed (1) higher achievement scores in mathematics by Asian students than by American students (Stigler \& Stevenson, 1991), (2) a lower correlation between students time-use and achievement in mathematics $(\mathrm{r}=.42)$ and a slightly higher correlation in English (Sanford \& Evertson, 1983), and (3) low achievement of fifth grade students of low socio-economic status in primary-level mathematics as influenced by students time-on-task (Leach \& Tunnecliffe, 1984).

In the 1990 s, increased state requirements and emphasis on the achievement of higher standards as articulated by government administrators and policymakers influenced more research efforts. The National Commission on Time and Learning (NECTL, 1994) was a selected group of researchers designated to pursue research on time-use in schools of United States of America together with schools in other industrial countries (Japan and Germany). Apart from the finding that students of those industrial countries were out performing American students, researchers found that Japanese and 
German students received more than twice as much time in instruction as did American students; besides, Japanese and American students were required to be in school longer during the day as well as during the year. The general response to these findings was that American students would need more time provided for instruction if they were to meet high standards as outlined by the policymakers (NECTL, 1994). The implications of the over-all efforts of this line of research indicate that more time-on-task by students, attentiveness by students, allocated time, better use of teacher's time were identified as influences on student achievement.

It is instructive to mention the time-use conceptual models of Carroll (1963), Bloom $(1968,1974)$ and Harnischfeger and Wiley $(1985)$ that focused specifically on students' time-use and contributed much to the relationship between time-use and instruction and learning. For instance, Carroll (1963), realizing that student time is an essential factor in the learning process, conceptualized the relationship between time and student achievement. He identified two instructional time variables (allocated instructional time and time on-task) as a function of student achievement. He studied: (1) the amount of time available for the student to accomplish a task; and (2) the amount of time needed by the student to do the task. The equation that he used is cited here:

$$
\text { Degree of learning }=\mathrm{f}\left(\frac{\text { Time actually Spent }}{\text { Time needed }}\right): \begin{aligned}
& \text { Learning is the function of time } \\
& \text { needed in relationship to the } \\
& \text { time allowed by the teacher. }
\end{aligned}
$$

The extent to which student ability, aptitude, and quality of instruction impact the time needed predicts the amount of achievement. According to Carroll's equation, time for learning is somewhat dependent on how schools as well as teachers manage their class 
time; and, consequently, makes time available for students' learning. His insights influenced other investigators to seriously pursue the study of time-use in school.

Bloom's (1968) conceptualization was influenced by Carroll's ideas, and, like Carroll, he considered time to be the basic concept in his model for the teaching and learning process. Students' mastery as it relates to additional time and the assistance the student needs is central to Bloom's concept. This mastery conceptual model accommodates human variation in learning and stresses that individual differences in learning are essential factors in time-use and in the schooling process. Bloom argued that "equal amounts of time and help do not have equal results in learning at all stages in the learning process" (p. 685). He believed that if the slower students were allowed more time and were also motivated to use the time and help available, the result would be a higher level of mastery and achievement.

Harnischfeger and Wiley's (1985) model was concerned with quality of instruction and task engagement as related to student's achievement and, like Carroll's model, was considered one of the most useful theoretical formulations. According to Frederick and Walberg (1980), the "Harnischfeger and Wiley (1985) model distinguishes different types of classroom events, and, hence, argues for specificity in measuring time that is instructionally used as opposed to that which fulfills other purposes" ( p. 192).

Berliner (1990) has contributed the concept of instructional time that is linked to an entire family of concepts common to a number of time-use studies. Among the terms that he defines, three (i.e., allocated time, academic learning time and transition time) can be linked to the present study. Berliner (1990) defines allocated time or scheduled time as time that is provided by the state, the school, and the teacher for instruction. Academic learning 
time is defined as time that is allocated for instruction and activities in dealing with a specific subject matter. Transition time is defined as preparation before or after an instructional activity (Berliner, 1990, pp. 4-5). These time metric concepts introduced by Berliner and other educators were used in a number of research efforts in the 1980s.

For example, Rosenshine $(1979,1980)$ considered the foundation studies of time on task, explored time allocation and engaged minutes of second and fifth grade students. This involved time allocation for all academic subjects (e.g., mathematics, reading, language arts) in grades two and five. Rosenshine (1979) was concerned with the relationship between allocated time and engaged minutes and student achievement, and found that they were moderate predicators of student achievement. Rosenshine (1980) revealed that allocated time amounted to approximately 60 percent of the school day. The study also reported that in second grade students spent more time engaged in studying academic subjects than did fifth grade students.

Other studies generated during the 1980s that focused on efficient use of time, its use in the classroom, and its effect on students' achievement were summarized and reviewed by Walberg and Frederick (1991). The 100 studies reviewed by these educators clearly indicate the degree to which time as an analytic tool was used in the schools to analyze student's time-use.

\section{Teachers' Time-Use}

Teachers' allocation of time in Carroll's (1963) equation is perceived as the opportunity that the teacher provides for students to learn. Therefore, the teacher is essentially responsible for, and plays a key role in, creating these opportunities. Bruno (1997) clearly states that the school organization has empowered classroom teachers by 
giving them certain ownership over time in their classrooms. He asserts further that "actual allocation of time in the formal classroom setting, therefore, is still mainly controlled by teachers" (p. 75).

From the beginning of the $20^{\text {th }}$ century, educators saw teachers as the primary agent in the efficient use of time, as they have been empowered by school administrators to be in control of class time. Even though there has been keen interest in time research in the field of education, Funkhouser et al. (1995) state clearly that researchers of time management have used this analytical tool over many decades to assess time use by students only, rather than to assess time-use by teachers. The researchers observed that even in the decade of the 1990's time use research, as it relates to teachers, are few (Funkhouser et al. 1995). The U. S. Department of Education (1994) also realized the paucity of teacher time-use research and recommended that more research be done.

The classic time-use conceptual model (Carroll, 1963) has clearly conceptualized time-use as it relates to the student. However, Wyne and Stuck (1982) suggest that from teachers' perspective, the two factors in the Carroll (1963) model indicate that the teacher's input is important. This is manifested in the teacher's ability to allocate time for student's learning and also to provide quality instruction. Wyne and Stuck (1982) point out that one of the ways classroom teachers can allocate more instruction time is to minimize wasted time in the classroom. There are specific behaviors and activities that erode meaningful instructional time. For example, non-curricular activities such as announcements over the intercom, assemblies, students' tardiness, lengthy breaks between activities, classroom interruptions, and other disruptions affect the availability of instructional time. Rich and McNelis (1988), in an investigation on time-on-task in six 
elementary schools, reported that, on a daily basis, one hour of classroom time was allocated to procedures, transitions, waiting, and interruptions. These researchers found that transition time per classroom "averaged almost 20 minutes per day and ranged from 15 to 40 minutes per classroom" (Rich \& McNelis, 1988, p. 40). They also discovered that unscheduled interruptions averaged about five minutes daily per classroom. The most frequent sources of interruptions from outside the classroom were intercom announcements, other teachers intruding, and unscheduled entrance of students into the classroom.

\section{Classroom Activities Influencing Teachers' Time-Use}

It is a common practice in most schools that the elementary teacher assumes responsibility for all activities that occur within the classroom. In the present study, the term "activity," is defined as, "a discreet unit of specialized school time that is relatively short in duration." Doyle (1986) reports a few studies that identify the rate at which activities occur in the elementary classroom.

The number of activities varied from one study to the other. For example, Ross, as cited by Doyle (1986), uncovered 30 activities occurring daily in the elementary classroom, while Berliner (1983) identified only 11 different types. Stodolsky, Ferguson, and Wimpelberg (1981) reported the occurrence of 17 activities, and Yinger (1977) reported 53 activities occurring in the elementary classroom. Some examples of activities identified in these studies include seatwork, transitions, housekeeping, one-way presentations, two-way presentations, discussion, giving instructions, and assembly, among others. Doyle (1986) reported that some investigations of time-use of classroom activities (Borg, 1980; Rosenhine, 1980; Sanford \& Evertson, 1983) claim that the 
allocation of time-use is approximately $65 \%$ for seatwork, $35 \%$ for whole-class presentation (teaching), and 15\% for transitions, and other housekeeping activities.

For the purpose of the present study 18 activities were identifed as those occurring most frequently in the elementary classroom. These activities were further grouped into three major categories - teaching, monitoring and non-curricular. The definitions for the 18 activities and the three categories are taken from the descriptions in Wagner and Anderson (1999).

Teaching. Teaching refers to the act of delivering information related to the curriculum to the students via frequent and brief presentations arranged in organized lessons (Brophy \& Good , 1986). The activities that are subsumed under this category include academic instruction, social instruction, and teacher-led activities with students actively engaged — discussion, reinforcement activity, subject matter (e.g., classroom teacher's subject matter-reading, language arts, mathematics, social studies, and science; and music teacher's subjects—-singing, playing instrument, rhythm, movement and listening) and combinations of activities.

In general, activities that have been considered teaching activities sometimes vary from one teacher to the other as well as from class to class. For example, Denham and Liberman (1980), reporting the findings of the Beginning Teachers Evaluation Study, claimed that time allocated for academic instruction in the elementary schools was $58 \%$ of the school day. Also, within the school day in another elementary classroom setting, students spend approximately $50 \%$ on academic learning (Rich \& McNelis, 1988). Stigler and Stevenson (1991), who compared the teaching of mathematics to elementary students, grades one through five in Japan, Taiwan, and the United States, found that the 
time spent in academic instruction was 80 percent for Asians and 46 percent for Americans. However, some activities are considered common to all elementary classroom teachers and to all music teachers, as well. For example, the activities that have been selected as teaching activities in the present study and that are assumed common to all elementary classroom teachers include academic instruction, social instruction, discussion, reinforcement activity, and subject matter (reading, language arts, mathematics, social studies and science). The subject matter activities that are different for the music teachers are singing, playing instruments, rhythm, movement, and listening.

Music researchers also found that teaching activities account for the greatest portion of class time in elementary general music classes. Examples of studies in music education reporting variation in time spent for teaching are cited. Moore (1981) reported 33 percent of the total school day was devoted to teaching, while Forysthe (1977), Wagner and Strul (1979), and Moore (1981) reported approximately 40 percent of the classtime for teaching. However, Allard (1992) reported a slightly higher percentage of about 49\%. Only the Wagner and Anderson (1999) study was not consistent with priorstudies, having reported about $15 \%$ for time allocated for teaching activities.

Monitoring. Monitoring refers to the time teachers spend with their assigned students, either supervising them at independent or group tasks, or directing them for non-academic purposes. Monitoring encompasses the tacit supervision of students, preparing them to do an activity (getting ready), moving children from place to place, and teacher talk that is irrelevant to academic or social instruction (Wagner \& Anderson, 1999). The activities subsumed under this category include seatwork, preparation, giving directions, changing activities, and teacher talk. 
The five activities-preparation, giving directions, seatwork, changing activities, and teacher talk-have been identified in the present study as monitoring activities that occur most frequently in the classroom on a daily basis. Traditionally in the elementary classroom, seatwork is the classroom activity that is allocated more time than other monitoring and teaching activities. Doyle (1986) argues that the elementary teacher should not consider seatwork a substitute for active teaching. Instead, this activity should be one that provides the opportunity for a student to gain practice and to engage in the application of instruction received, all under the tutelage of the teacher.

The degree to which seatwork activities occur in the elementary classroom setting is exemplified in a study by Rosenshine (1980) who investigated how elementary students spent their time in reading and mathematics. Rosenshine (1980) reported that students' engagement on task in seatwork activity consumed 66 percent of the class time for reading and 75 percent of the class time for mathematics. In a study on the allocation of the fourth grade mathematics classes, Walberg (1991) reported that time-use allocated for seatwork was 47 percent of the total class time. In a more recent comparison of timeuse, Wagner and Anderson (1999) found that elementary classroom teachers monitored seatwork 27 percent more than did music teachers.

How teachers orchestrate the change of activities can affect time-use in the classroom. Rossmiller (1983), Arlin (1979), and Doyle (1986) seem unified in their belief that the teacher's ability to manage transitions between activities helps minimize loss of time. Research in music education is consistent in reporting the trend among elementary music teachers in handling "getting ready" and "preparation" time. For example, studies such as Moore (1976, 1981), Wagner and Strul (1979), Forysthe (1977), 
Allard (1992), and Wagner and Anderson (1999) reported significant variation in "getting ready" or "preparing" or "transitional" time usage"; that ranged was 8 to $22 \%$ of class time.

Non-curricular. Non-curricular refers to time spent by the teacher during the teaching day away from assigned students. It might also require that this portion of time be spent by the teacher alone or supervising an area larger than her own class. The noncurricular activities, as their category implies, included lunch, assemblies, planning, administratively assigned duties, teacher travel time (i.e., teacher's movement from location to the next within the school), and consultation.

Non-curricular activities usually claim a significant portion of the school day and have an impact on academic learning time. Prater (1992) reports that as much as 50 percent of the teacher's time is allocated to non-curricular activities. It has been previously reported by Rossmiller (1983) that 40 percent of the school day is allocated to non-curricular activities. Findings from another study (Walberg, 1991) reveal that 15 percent of total learning time in the elementary classroom was allocated to non-curricular activities. The skill of the teacher to manage non-curricular activities is important because proper management will increase the time available for academic instruction. Rossmiller (1983) agrees that "administrators can increase the amount of time available for instruction by examining more closely the merit of activities which erode instructional time and which too frequently are taken for granted" (p. 49).

The assumption here is that these categories of activities represent all activities that occur in the elementary and elementary music classrooms. Differences in activities grouped within the major categories—-teaching, monitoring, and non-curricular-have 
been accounted for in the literature and reveal an interesting trend in time allocation in the elementary classroom.

\section{$\underline{\text { Subject Area and Teacher Differences }}$}

Most importantly, elementary music teachers and classroom teachers differ in the subject areas taught. Differences emerge when the nature of the subject area and type of activities are considered. For example, the main activities of the general music class consists of five basic music activities - singing, rhythm, listening, playing instruments, and movement. The core of musical activities used in today's general music class originated with the chief pioneer of music education, Lowell Mason. In the early $19^{\text {th }}$ century, Mason convinced the Boston School Committee to make music an integral part of the public schools curriculum. He advocated that specific time be allocated for vocal instruction.

A century after the introduction of music in the schools, the Music Education National Conference (MENC) adopted resolutions that allowed for five basic music activities — singing, rhythm, playing instruments, listening, and creativity-to be the core for all music instruction in the elementary schools. MENC also mandated that scheduled time for music instruction be instituted in the elementary schools. The minimum daily time allocated for grades K-3 was 20 minutes and 25-30 minutes for grades 4-6 (Leonhard \& House, 1972). The five basic music activities recommended by MENC have remained the core activities for every general music class. Colwell (1992) reports that researchers have investigated these five basic music activities. For example, Forsythe and Kelby (1989) studied singing, Shehan (1987) and Wang (1984) investigated moving and rhythmic activities, Baldridge (1984) listening activities while Wig and 
Boyle (1982) explored playing instruments. It was not until the 1960's--through the influence of the Tanglewood Symposium convened in 1967 to discuss the state of music in America - that more musical activities such as arranging, composing, using notation, and learning about musical styles were added to the basic curriculum.

According to Doyle (1986), the elementary classroom teacher is employed to teach a designated grade level of approximately 20 to 30 students for specific time period on a daily basis. The State Department of Education requires that the classroom teacher be state certified in elementary education, trained to teach in elementary school, and hold at least a Bachelor's degree in elementary education.

It is assumed that classroom teachers are responsible for all the instruction children receive in the core academic subjects_reading, mathematics, language arts, science, and social studies (Petzold, 1978). These teachers teach all the core subjects to students in kindergarten through Grade Six.

According to Brophy and Good (2000), classroom teachers show great disparity in the way they allocate time to specific subjects. For example, the authors cited a study (Berliner, 1979) whose findings revealed that time allocated for second grade math ranged anywhere from 24 to 61 minutes, while time allocation for reading ranged anywhere from 32 to 131 minutes.

Rosenshine (1980), reporting findings of the Beginning Teacher Evaluation Study (BTES) on how time is spent in the elementary classroom, indicated that time allocation varied for different subject areas. This study dealt with the amount of time teachers allowed students to spend on any given activity in specific subjects (math, reading, science, language arts, and social studies). Results showed time allocation for the 
academic activities (math, science, reading, and social studies) was highest—occupying $58 \%$ of the school day.

Colbert (1979), in studying experienced elementary classroom teachers, observed that subject matter does have an influence on teacher and student behavior. Findings revealed that certain teacher behaviors were exhibited more during the teaching of certain subject matter. For example, during the teaching of math, science, and social studies, teachers displayed the behavior of facilitator $75 \%$ of the class time. Such behavior was manifested in instructional directions or praising and reinforcing. During the remaining $35 \%$ of class time, teachers acted as managers by, monitoring seatwork, organizing, distributing learning materials, or giving directions. Of the three subject areas, teacher facilitator behavior was more than four times greater in science.

Demographic factors may also affect time-use patterns. Thus it is important to examine other teacher factors that might influence the elementary music and classroom teachers' allocation of time to the various activities subsumed under the three major categories - teaching, monitoring and non-curricular. Such supplemental examination may unearth further knowledge about teacher time-use; therefore, the additional factors used to define teacher time-use include ethnicity, level of training, and years of experience.

\section{Teacher Factors Influencing Teachers' Time-Use}

Some studies have included demographic characteristics in the analysis of teacher time-use. Studies that have looked at ethnicity (Horn \& Chalkind, 1989), level of training (Horn \& Chalkind, 1989) and years of experience (Goolsby, 1996,1999; Horn \& 
Chalkind, 1989; Moore \& Bonney, 1987; Wagner \& Strul, 1979) have served to reveal further variance in teacher time-use allocation patterns.

Ethnicity. Ethnicity was selected for the Horn \& Chalkind (1989) study as a possible source of influence on teacher time-use. The researchers reported that ethnicity (Hispanic vs non-Hispanic) did not yield any significant similarities or differences. This factor was selected for the present study on the premise that there is a significant representation of individuals-professionals, students, and teachers-from different ethnic backgrounds residing in South Florida. The general population of teachers in this study is representative of this cross section of cultures. Therefore, using ethnicity as a variable to scrutinize teacher time-use in this setting seems wise.

Educational Level. Educational level refers to the highest degree of training a teacher received prior to entering the classroom or during classroom tenure. Horn \& Chalkind (1989) also studied the influence of educational level on teacher's time-use. Findings revealed that elementary teachers with postgraduate degrees contributed more time to the category of extracurricular supervision than did elementary teachers with post graduate degrees.

Years of Teaching Experience. Years of teaching experience as a possible source of variance in teacher time-use has been reported in general education as well as in music education. Horn and Chalkind (1989) discovered that elementary classroom teachers who were more experienced spend more time teaching, more time planning, and evaluating and less time in extra curricular supervision.

Only a few studies in music education have scrutinized the role of years of teaching experience in teacher time-use. For example, Montgomery (1985) examined 
selected factors in relation to the time-use patterns of Canadian elementary music specialists. One of the factors, years of teaching experience, significantly influenced teacher allocation of time to five of the eight classroom activities utilized during music class instruction. The more experienced teachers spent more time on singing and moving activities in the upper grades (4-6) than did the less experienced teachers. Moore and Bonney (1987) compared teacher time-use of 30 student teachers and 30 experienced teachers in elementary music classes. The researchers found that the experienced teachers used time more efficiently than did student teachers. The efficiency in time-use by the more experienced teachers was reflected in less time being allocated to teacher talk and more time allocated to instruction activities.

Wagner and Strul (1979) also found that teachers with different levels of experience (pre-interns, interns, and experienced teachers) each used time differently. Findings revealed that experienced teachers spent significantly less time giving directions than did pre-interns and interns. At the high school level, Goolsby $(1996,1999)$ pursued three casual-comparative studies in teacher time-use of novice and expert teachers in high school band classes. The overall result of all three studies indicates that novice teachers used more time giving verbal instruction while expert teachers spent more time in music performance.

In summary, the literature has established that the teacher factors of ethnicity, level of training, and years of experience have been pursued in previous research and have served as determinants of teacher time-use in different settings. Goolsby (1999) points out that one way to either support or challenge conventional wisdom is to utilize the information derived through systematic inquiry regarding teacher time-use. Thus 
factors discussed in this section of the literature review may generate a useful knowledge base for edifying conventional wisdom.

A Historical Overview of Classroom Observation Instruments

Both in the general field of education and music education, various research methods have been used to investigate life in the elementary classroom. However, observation seems to be the most frequently used method of inquiry for pursuing investigations in many settings. According to Colwell (1992) "observing life in the classroom is vital to successful evaluation if for no other reason than that it provides the teacher and the evaluator the best starting point for instructional improvement" (p. 314 ). Therefore, engaging in this type of research has its value. Certain systematic techniques are generally used to ascertain how instruction time is used in the classroom. The literature shows that the instruments used in observation research have a well-established and documented history. A brief overview on observation instruments is presented in this section. It is noteworthy that the observation instrument used in the present study is linked to a convincing history of scientific observational instrumentation.

\section{General Education}

According to Evertson and Green (1986), the observation approach in the field of educational research has been a widely used approach, and the history regarding its development is well established. The observation approach involves a range of instruments, techniques, and procedures developed by various researchers to observe and record human behavior and physical environments. Stalling and Mohlman (1988) outlined several elements that are common to all observational approaches. These 
common elements include the purpose of the observation, a set of operational definitions, a setting, a unit of time, an observation schedule, a method to record data, and a method to process and analyze data. In addition to the common elements, several observational techniques can be used in any specific setting. The observational techniques include a (1) prepared checklist of expected behaviors, (2) a rating scale to rate the occurrence of specific behavior within a given time, (3) an interactive coding system designed to record all aspects of interaction of the observed within a given time, and (4) a narrative description of all aspects of the observation.

The selection of the observation instrument is usually influenced by the purpose of the observation. The observation instrument is designed to record elements of events or classroom arrangements that are considered educationally significant. According to Colwell (1992), information regarding general education's very first classroom observation instruments has been documented in the works of Medley and Mitzel (1963) and Rosenshine and Frust (1973). Evertson and Green (1986) assert that the development of observation instruments peaked during 1958-1973. Brophy and Good (1986) felt that the motivation behind the measurement of the teacher behavior through systematic observation was a direct result of educators' concerns about the effects of teaching competencies. Post-Sputnik initiatives influenced researchers to explore curricular effects rather than teacher effects on student learning.

A proliferation of observation systems occurred during 1958-1973, for as many as 100 classroom observation systems were in place by 1970 . There were even more types of instruments generated in the 1980s that included checklists, rating scales, scripting, and category systems. A number of these observation instruments developed during this 
time are specific for certain investigations that have been reviewed by Brophy and Good (1986). According to Galton (1988), most of these observation instruments were derived from the Flanders System of Interaction Analysis (FSIA; Flanders, 1970) and was concerned about the level of teacher talk versus student talk in the classroom. Flanders wanted to see more input from the student in teacher-student interactions. The relationship of the teachers' indirect and direct teaching was important to Flanders; therefore, his instrument was designed to analyze only verbal behavior of both teacher and student. This instrument reflected ten categories, each representing a behavioral unit with a specific type of behavior. Four of these categories represent teachers' indirect influence, while three categories represent teacher direct influence. Flander's instrument is an example of a categorical system. The FSIA system followed the coding of observations every three seconds and did not allow for the separate coding for academic interaction versus conduct interactions.

\section{Music Education}

There is clear evidence that music educators have over many years (1960-1999) engaged in classroom observation. In addition, there exists a history of the techniques, forms, and procedures for classroom observations developed by music educators.

Colwell (1992) mentions that Flander's category system was pioneered by some researchers in music education (Snapp, 1967). Approximately, four years after Flanders (1970) introduced his system of coding and collecting data of teacher and student interaction in the classroom, music educators Madsen and Madsen (1983) developed and introduced an instrument designed to collect data of interaction between teacher and student. This instrument, together with its procedures, has lived up to the expectation of 
music researchers as being scientific and reliable tools for data collection. The instrument is designed to collect data by using 15 -second intervals for observation and five-second intervals to record. There are three such segments of observation-each for the duration of one minute. The total length of time for the overall observation is 15 minutes.

Madsen and Madsen (1983) designed two different types of instruments. The first collects data on teacher behavior in terms of teacher reinforcement patterns of approving and disapproving students' appropriate and inappropriate academic and social behavior. There was also a student's observation form designed primarily to collect data on students' on-task or off-task appropriate and inappropriate behavior.

A set of procedures is required for the Madsen and Madsen (1983) observation instrument. First a set of precise category definitions provides the basis for noting and recording the behavior reliably. Secondly, the observer should possess materials such as a pencil, a stop watch, observation form and a clip board. In addition, the observer should have a protocol that guides the observation process. For example, teachers and students who are being observed should be unaware of the presence of the observer in the class. While observing, the observer should not engage in any form of dialogue with the teacher or the students. Teachers are required to be as natural as possible in their class setting. Both teachers' and students' observation instruments are self-contained and provide for a complete analysis that can be later graphed or summarized (Madsen \& Madsen, 1983).

Several studies have employed the Madsen and Madsen's observation instrument published in 1974 (cited in Madsen and Madsen, 1983). During the 1970's, Kuhn (1974), 
Murray (1974), and Forysthe (1977) employed Madsen and Madsen's (1983) form and techniques in their investigation. Kuhn (1974) used this instrument in the investigation of music teachers' rating of approval or disapproval on attentiveness, musical achievement, and attitude of fifth graders. Murray (1974) modified Madsen \& Madsen's observational instrument to study the effect of elementary classroom activities on student attentiveness.

Other music educators influenced by Madsen and Madsen (1983) developed their own observation instruments around musical activities of students, and teachers. For example, Yarbrough (1975) developed her own observation form to investigate the effects of high school choral conductor on student attentiveness. Moore (1976) followed with a new form called Music Teaching Interaction-Activities Form (MTIA). The MTIA was designed to provide a more accurate analysis of teacher classroom behavior. This form was first used in 1976 when Moore investigated time-use for both beginning and experienced elementary music teachers. Later, Wagner and Strul (1979) employed the MTIA form and replicated Moore's (1976) study using the same type of teachersinexperienced and experienced elementary music teachers - but in a different setting.

The eighties produced more studies that employed Madsen and Madsen's observation instrument and procedures. For instance, Madsen and Geringer (1983) used this form to investigate the attending behavior of university students in music classes. Witt (1986) investigated time-use and student attentiveness in secondary instrumental music rehearsals. She modeled her observation procedures after Madsen and Madsen (1983) using the student observation instrument that allowed observers to record the frequency of off-task behavior and type of activity. Each rehearsal was recorded on 120minute cassette tapes and then analyzed. However, Kostka (1984) studied reinforcement 
and time-use in student's attentiveness to piano lessons. She used live, audio, and video assessments to collect data. An observation form developed by Kostka was used to record data.

A number of studies pursued in the nineties utilized the observation approach to inquiry. Music educators have also continued to use Madsen and Madsen's observation instrument and procedures in their research pursuits. Sogin and Vallentine (1992) used the Madsen's observation procedures to explore time-use in applied music classes at the university level. Allard (1992) applied the same observation procedures in his study of string teachers (specialists and non-specialists) in elementary schools. He compared these teachers' effectiveness in teaching beginning string music in terms of teacher timeuse, student attentiveness, and the music performance quality of classes.

Later studies that used Madsen and Madsen's observation instrument and techniques were Watkins (1993, 1996), Brendell (1996) and Wang and Sogin (1997). Watkins used Madsen and Madsen's observational procedures twice in her investigation of the non-performance time-use of high school choral teachers during choral rehearsal. Brendell (1996) was more concerned with teacher time-use, rehearsal activity, and student off-task behavior during the initial minutes of high school choral rehearsal. He employed Madsen and Madsen's observational procedures together with an observation instrument developed by Murray (1974) to analyze audio taped recordings of the first 30 minutes of high school rehearsal. Wang and Sogin (1997) used video taping observation and self-reporting of teacher time-use in elementary general music class. They too, employed observation procedures modeled after Madsen and Madsen (1983). 
Using data gathering techniques from the earlier studies, Wagner and Anderson (1999) developed a contemporary instrument from a synthesis of these earlier time-use categories and forms ( Moore, 1976, 1981; Wagner, et al. 1985; Wagner \& Strul, 1979). This new instrument, the Teacher Time-Use Form, (see Appendix D) could be adapted for use across disciplines at the elementary school level. It was used to record time-use of both elementary music teachers and elementary classroom teachers. Labels for classroom time-use categories were adapted, and the Teacher Time-Use Form was developed to closely follow the activities of elementary music teachers and elementary classroom teachers. After substantial consultation with music teachers, classroom teachers, professors, principals, and teacher education students, the Teacher Time-Use Form (Appendix D) was field-tested. Its companion, Teacher Time-Use Categories (Appendix B), listed and defined categories that occur and re-occur as episodes of time-use. The reliability coefficient of the instrument is .96 (Wagner and Anderson, 1999). This observation instrument was used to collect the additional data for the present study.

\section{Summary}

Although time-use as an analytic tool was first established in industry, it has become an indispensable tool in the analysis and understanding of schooling and learning (Berliner, 1990; Bruno, 1997; Gelberg, 1997). The literature revealed that timeuse of the school, student, and teacher contribute to the effective delivery of the curriculum (Bruno, 1997; Karweit, 1988; NECTL, 1994). Schools in America are perceived as busy places that control the classroom teacher through time and schedules (Brophy \& Good, 2000; Jackson, 1968; Lewin \& Nolan, 2000). In the context of the elementary classroom environment, teachers are isolated, and subjected to various 
pressures, but are empowered by the school organization to be primarily in charge of their students and to be managers of all activities, events, and time (Bruno,1997; Doyle, 1986).

In addition, the literature indicates that school factors such as grade level, time of day, day of the week, and personal characteristics such as ethnicity, years of experience, and level of training do influence teacher time-use (Amen, 1982; Cornbelth \& Korth, 1980; Fitzgerald et al. 1980; Horn \& Chalkind, 1989; Montgomery, 1985; Wagner, et al. 1985; Wagner \& Strul, 1979). The influence of school factors and teacher factors vary from school to school and also from teacher to teacher (Karweit, 1988).

The literature also reveals that the nations' major concerns since Sputnik (1957) has been the delivery of the curriculum in relation to students' achievement. This fact influenced a number of school reforms (e.g., A Nation at Risk and Goals 2000) and initiatives within the past 50 years. Specifically, the report, A Nation at Risk identified time-use as an important link to student learning and achievement. The time issue, specifically teachers' time-use, continues to be a critical problem and requires empirical research whose findings can support and inform consequential policies and decisions. (Mark, 1986; NECTL, 1994). 


\section{CHAPTER III}

\section{METHODOLOGY}

Although the review of the literature indicated that the school personnel consisting of the school administrators, students, and teachers are important in the efficient use of school time, there is need for further research to provide clearer understanding about how teachers spend their time in the classroom. The intent of this study is to focus on elementary teachers-specifically classroom and music teachersand compare their time-use as it relates to three variables, namely, grade level, time of day, and day of the week. A full knowledge of teacher time-use in the elementary classroom as predicted by these variables allows teachers and school administrators to efficiently and effectively modify the school day so that more time can be allocated to areas of the curriculum needing additional time. By examining the influence of grade level, time of day, and day of the week on elementary classroom and music teachers' time-use, the investigation sought to get a clear understanding of both elementary classroom and music teachers time-use patterns. Teachers' personal characteristics such as ethnicity, years of service, and level of training were used to further identify influences on time-use differences.

Specifically, observational data collected from the Miami-Dade Public Schools were combined with a pre-existing data pool from Wagner and Anderson's (1999) study that served as a data set for analysis in this investigation. This chapter provides a description of the participants and setting, research design, instrument, and methods used to collect and analyze the research data. 


\section{Participants and Setting}

Elementary teachers employed in the Miami-Dade County Public School System were the targeted population for this study. This school system is the fourth largest in the United States, with over 350,000 students and 22,000 teachers secondary and elementary teachers. It extends over a wide area and includes schools that are located in urban, suburban, and rural regions of the county. According to the description in the District and Schools Profiles (1997-1998), the "school district is divided into six administrative units based on geographical boundaries with the schools grouped into seven regions" (MDCPS, 1997-1998, p. ii). The existing data pool was gathered from six of the seven regions. The seventh region was not included because it consists of "Alternative" centers rather than elementary or secondary schools. The Miami-Dade area can be described as one with an influx of immigrants from various countries. According to Nazareno and Bousquet (1999), Miami-Dade County has a high rate of limited English speaking immigrants, single parent families, and a number of low-income families. It was observed also that 70 percent of the students who attend school in this county qualify for free or reduced-price lunch.

The elementary teacher population during 1997-1998 consisted of approximately 8,089 classroom teachers and specialist teachers. Approximately 5,904 are classroom teachers of kindergarten through Grade 5, and 303 are music teachers (MDCPS, 19971998, p. 144). Elementary music teachers and elementary classroom teachers from across the Miami-Dade County Public School System served as participants. The elementary classroom teachers and music teachers who were observed were not from different schools. This research used, in part, an existing data pool that was collected 
during 1996 -1997 for the Wagner \& Anderson (1999) investigation and was coupled with additional data that were obtained in $1997-1998$ for the present study. For the original study (Wagner \& Anderson, 1999), data were collected for 22 elementary music teachers and 68 elementary classroom teachers. Because of unequal sample size (22 elementary music teachers versus 68 elementary classroom teachers) represented in the original pool (Wagner \& Anderson, 1999), it was necessary to gather additional data to increase both sample size as well as data for the music teachers. An additional sample of 34 music teachers was selected and observed using research procedures as described in this chapter.

For the previous investigation (Wagner \& Anderson, 1999) as well as for this study, the samples were made up of elementary teachers within the Miami-Dade County Public School System. These field teachers permitted preservice student teachers from Florida International University (FIU), an urban, public university, into their elementary schools and classrooms to obtain their field required experience.

The sampling method used for the previous study and for this study is a convenience sampling. According to Gall, Borg, and Gall (1996), a convenience sample is "a group of cases that are selected simply because they are available and easy to access" (p. 756). This method of sampling was chosen for the following reasons. First, the selection of the teachers for this investigation was carried out on the basis of those who volunteered and allowed FIU pre-service students into their classrooms to obtain field experience. Second, FIU pre-service elementary teachers who take MUE 3210 (Music in the Elementary School) the class for students in the Elementary Education undergraduate program - are required to systematically observe teachers teaching in their 
field schools and to learn from their behaviors. These students were assigned to field teachers in the sample by FIU's Office of Student Placement. Third, the teachers and students of all four sections of the MUE 3210 classes were available to the investigator of the present study. This sample was limited to the elementary grade levels-kindergarten through fifth grade.

For the additional data collected, a total of 34 elementary music teachers were selected on the basis of the following criteria: (a) they currently teaching music from kindergarten through fifth grade; (b) they met the state requirements to teach in both the state of Florida and the Miami-Dade County Public School system; (c) they permitted FIU's pre-service student teachers into their classrooms; and (d) they were willing to participate in this study. Those teachers who met these criteria comprised the sample pool. All 34 elementary music teachers met the criteria as outlined.

For this study, the pool of participants (the present study and Wagner \& Anderson, 1999) consisted of 69 elementary classroom teachers and 55 elementary music teachers, making a total of 124 participants. Using both data pools selected from the target population of elementary teachers $(8,089)$, it was determined that the three independent variables - grade level, day of the week, and time of day - could be isolated and studied.

\section{Research Design}

Colwell (1992) states that observation, as a mode of inquiry and method, is an effective means to observe life in the classroom. The observation method as the mode of inquiry was used in this research because it is an accurate and reliable way to record and report the time-use pattern of elementary classroom and music teachers. Gall et. al., 
(1996) mention that the advantages of observation outweigh the disadvantages in that it is a more superior and accurate approach than self-report in producing more precise data $(\mathrm{p}$. 328 ). However, there are a few disadvantages:

- Observational data sometimes miss subtle dimensions of a research question

- The observer sometimes, unintentionally changes the situation being observed

- The observational method is more time-consuming than other methods of inquiry (Gall et. al., 1996, p. 329).

According to Evertson and Green (1986), observation as inquiry and method has four classification systems that can be used as a framework: (a) category systems-a closed system consisting of preset categories, (b) descriptive systems - an open system that may have preset categories, (c) narrative systems - an open system consisting of no preset categories, and (d) technological records-an open system that has no preset categories. The present investigation used the category system that involved a set of operational definitions used by trained observers to code selected behaviors of teachers--behaviors which occur within a specified length of time, recorded in increments of minutes, hours, and days over a wide cross section of classrooms (Evertson \& Green, 1986, p. 169).

This descriptive study employed non-participation observation where the obsever operates as an outsider. Specifically, naturalistic observation requires the observer to observe the participant's behavior in a natural setting (Gall et. al., 1996; Galton, 1988; Stallings \& Mohlman, 1988). Based on the evidence in the literature (Colwell, 1992; Gall et al. 1999; Galton, 1988; Gay, 1996; Stallings \& Mohlman, 1988), the observation method and its procedures are a reliable mode of inquiry. This method was used to collect data that addressed the following research questions: 
1. What differences exist in elementary music teachers' and elementary classroom teachers' time-use for teaching, monitoring, and non-curricular categories across grade levels?

2. What differences exist in elementary music teachers' and elementary classroom teachers' time-use for teaching, monitoring, and non-curricular categories by day of the week?

3. What differences exist in elementary music teachers' and elementary classroom teachers' time-use for teaching, monitoring, and non-curricular categories by time of day?

The subsequent subsidiary questions were derived from the research questions.

1. How does time-use for the activities subsumed under the teaching, monitoring and non-curricular categories compare for elementary music teachers and elementary classroom teachers?

2. Does time-use vary with demographic characteristics - ethnicity, level of training, and years of experience-for elementary music teachers and elementary classroom teachers?

The study focuses on the management of time-use in the classroom rather than on teachers' teaching strategy. The design attempts to identify differences in each of the three independent variables. The independent variables include: (1) grade level, (2) time of day, and (3) day of the week. The first independent variable, grade level, was investigated by Montgomery (1985), Amen (1982), Wagner, Allen and Shoemaker (1985), Moore and Bonney (1987). The second variable, time of day, was studied by Fitzgerald, et. al., (1978). The third variable, day of the week, was examined by 
Cornbleth and Korth, (1980). These variables are used to analyze a combination of an existing pool of time-use data and additional data that were gathered specifically for this investigation. The design also included data on teachers' demographic characteristicsgender, ethnicity, level of training, and years of experience. These characteristics as predictors of teachers' time-use would give further insight into teacher's time-use and would allow educators and researchers to extrapolate their effects on student learning.

\section{Instrument}

An instrument titled the "Teacher Time-use Log" (Appendix D) that originated with the Wagner and Anderson (1999) study was used to gather data for this study. Even though this instrument has its origin firmly grounded in music education, it was adapted to facilitate and collect data regarding teacher time-use for both elementary music and classroom teachers. This instrument is based on the evolution of an instrument initially developed by a music educator, Randall Moore, in 1976. Forsythe (1977) was among the first group of music education researchers to use an observation form developed by Madsen and Madsen (1983) and to reanalyze data gathered from the Columbus, Georgia Title III Project. This form allowed Forysthe and others to code - minute-by-minute - all activities that occurred in the classroom. Interobserver agreement was .72. Shortly, thereafter, Moore (1976) conceived an innovative, seemingly continuous method of recording music teachers' time termed, the MTIA form (Music Teaching InteractionActivities). MTIA validated a quasi-continuous recording technique using five-second time increments that yielded information concerning the structure of elementary music classroom activities. These classroom activities included singing, listening, playing instruments, rhythms, and movement. 
According to Moore (1976), the MTIA form also allowed observers to record "(1) the number and kind of activities occurring chronologically in the music class, (2) the number of seconds spent in each activity, (3) the frequency of approvals and disapprovals given by the teacher, (4) demographic information on grade level, class size, date, time, teacher and observer names" (p. 64). Moore (1981) used the MTIA form to investigate elementary music teachers' time-use and classroom activities in both the United States of America and Great Britain (1981). The interobserver agreement was a high .93, using the MTIA form. Wagner and Strul (1979) adapted the MTIA for their investigation of the differences between music teacher's time-use from "field experience teaching,"and the Practicum (student teaching). They compared those data to "experienced teachers" use of class time. Again the interobserver agreement reported was high .91. While Moore (1976, 1981), Forysthe (1977), and Wagner and Strul (1979) were interested in observing time-use in the general music classroom involving specific categories of classroom activities, Baldridge (1984) was concerned with time allocation in the general music classroom and with one specific activity-listening.

Montgomery (1985) used a "Time Form" that she constructed for recording elementary music teachers' time; the 11 definitions used for coding were derived from coding definitions used in studies investigated by Baldridge (1984), Wagner and Strul (1979), Forsythe (1977), and Flanders (1970).

For the regular classroom setting, another incarnation and adaptation of Moore's MITA form was used by Wagner, Allen, and Shoemaker (1985) to investigate the timeuse of regular elementary classroom teachers. In this investigation, teachers anecdotally 
recorded their own activities on a classroom "time log". Experimenters then coded and categorized the anecdotal records post hoc. External observer teacher reliability was .89 . In a recent study by Wagner and Anderson (1999), the "Teacher Time-use Log" (Appendix D) was used to gather teacher time-use data on elementary music teachers and classroom teachers. Interobserver reliability using this form was .92 for music teachers' observation data and .96 for the elementary classroom teacher observation; therefore, the form can be used for both elementary classroom teachers and music teachers. This instrument was designed to ascertain a precise record (within one minute) of the number of minutes spent by elementary classroom teachers and elementary music teachers on each of the 18 categories over a three-hour period (i.e., half-day). Those 18 special activities are grouped under three major categories "Teaching", "Monitoring", and "Noncurricular" categories. Each classroom teaching activity is defined in Appendix B, and activities are derived from activities used in previous studies (Moore, 1976; Wagner, Allen, \& Shoemaker, 1985; and Wagner \& Strul, 1979). Teacher demographic information was noted at the top of the observation form; information regarding the specific time, category code, activity and grade level, sub-code and minutes spent in activity (teaching episode) was placed below by the student observers.

\section{Procedures}

For the purposes of this study, the period of time designated for observations was the "half-day". A "half-day" is defined as a three-hour period either beginning at the ringing of the tardy bell in the morning and extending for three consecutive hours, or beginning before the ringing of the school's dismissal bell. Trained_observers recorded changes of teachers' episodes on the "Teacher Time-use Log". They recorded changes in 
activities within the prescribed categories and activities and the exact times (to the minute) as they occurred. Because the present study was concerned specifically with elementary general music classes and general classroom activities, these activities were defined and coded (Appendix B).

Each teacher's use of time during their teaching day was first classified under one of the three broad categories: "Teaching", "Monitoring", or "Non-Curricular " episodes. Then, each episode was further defined with regard to a specific activity within that broad category (Appendix B). This way, all of the episodes were accounted for and recorded. Categories for the present study were derived from two previous studies-Wagner and Strul (1979), and Wagner, Allen, and Shoemaker (1985)--and are similar to those used by Wagner and Anderson (1999). It should be noted that five subject matter activities listed under the "Teaching" category differ for the music teachers who teach singing, playing instruments, rhythm, movement, and listening and the classroom teachers who teach reading, language, mathematics, social studies, and science (see Appendix B). The coding that was developed to help observers distinguish the five subject matter activities taught by each type of teacher was done as indicated below.

The five subject matter activities for the music teacher had these codes: $s i=$ singing, $p i=$ playing instruments, $r=$ rhythm, $m o=$ movement, and $l=$ listening. The five subject matter activities for the classroom teacher had these codes: $R e=$ reading, $l a$ $=$ language arts, $m a=$ mathematics, $s s=$ social science, and $s c=$ science. For the purpose of analysis, the five subject matter activities for each type of teacher (classroom and music) were identified as " $S M=$ subject matter." All other activities subsumed under the major categories of monitoring and non-curricular remain exactly the same (See 
Appendices A \& B). This notation regarding subject matter holds true for the study by Wagner and Anderson (1999).

Reliably trained observers used the definitions and codes (Appendix B) to record teaching activity on the "Teacher Time Use Form" (Appendix A) and to precisely categorize the way elementary music and the classroom teachers' time were spent. Instructions (Protocol) for all observers are included in Appendix C.

\section{Training Observers and Reliability}

Observers in the investigation by Wagner and Anderson (1999) and in the present study were upper division undergraduate and graduate students in the college of education of a large urban university. The undergraduates were enrolled in MUE 3210, "Music in the Elementary School"; graduate students were enrolled in MUE 3340, "Elementary School Teaching Methods". In both of these classes, as part of teaching methods training, Music Education and Elementary Education majors are taught classroom observation techniques for use in their field schools.

The purpose of this training is to prepare them to reliably record elementary school classroom events. It is expected that they will become so familiar with the techniques that they will incorporate proper time use into their own teaching. Because the study of the efficient use of teaching time is traditional content for such courses, this observation training is a part of students' college teaching methodology classes. Hence, there was no resistance to participate in the present research endeavor. However, the instructors of all sections of MUE 3210 "Music in the Elementary School" class and MUE 3340 "Elementary School Teaching Methods" who were trained by the researchers 
of the present study by Wagner and Anderson, 1999 investigation made sure that the accuracy of these observations were upheld.

Additional data were collected in Fall, 1998 for the 34 elementary music teachers, by teacher education preservice students in MUE 3210. These students were trained as observers in a three-tiered training program that occurred during August, 1998 through the end of October, 1998. The first tier of observer training lasted three weeks; the second tier of observer training lasted three weeks. The third tier helped establish interobserver reliability, and the actual collecting of the data took place over seven weeks. The observer training was done prior to making the observations of South Florida elementary music and classroom teachers.

More specifically, during the first tier of observer training, students in methodology classes were furnished data collection forms (Appendix A) and a copy of the time use glossary (Appendix B). Their first assignment was to observe an elementary school teacher twice for one hour each, and, using the form and glossary, code the observed teacher's use of time. Completion criterion of the first tier of training was that they simply complete and return two one-hour teacher observations (either music or classroom). Care was taken to explain what the observations were about and how to complete the data collection forms. When the two forms were completed and returned, all questions regarding the recording of data were discussed and answered in class. Students then became eligible for tier-two training.

During tier-two training, each observer was paired with another "reliability" observer and two independent one-hour observations were completed and returned. The assignment for this training level required that: (1) two one-hour observations be 
completed by each member of the pair, (2) the observations be done independently by each observer and completed during the same time interval, and (3) results were checked for reliability set at better than .80 for both observations. The observer pair continued making one-hour observations until .80 reliability (agreement on time and category) or greater was achieved. The researcher monitored all pair observations by checking the accuracy of the coding and computation of reliability. Observations at level two continued until .80 was achieved. No pair of students made more than one extra observation to become reliable. This was also true for the Wagner and Anderson study for which students were provided similar training. Successful completion of tier-two made students eligible for tier-three observations.

Both level two and level three observations were scheduled for a graduate student (previously trained and reliable) to establish interobserver reliability with the undergraduate observer. The graduate "reliability" observer was randomly paired with a tier-three reliable student observer fully trained and already engaged in recording data. This interobserver inspection is necessary to maintain reliability on data that are gathered from diverse sources by independent observers. The interobserver reliability was computed in the same fashion as observer reliability; in order for the student's data to be included in this investigation, the reliability had to be .80 or better.

A total of 96 observers then completed two third-tier observations, independently, at their assigned elementary school. Each of the observations which was three hours long began either at the sound of the school's tardy bell, or exactly three hours before the end of the six-hour school day. Only the data collected at this level were used in this study. 


\section{Data Analysis}

Descriptive and inferential statistics including frequency distribution, $\underline{t}$ test for independent samples, analysis of variance, and multivariate analysis of variance were used in the analysis of the data collected for elementary music and classroom teachers. The Statistical Package for the Social Sciences (SPSS) was used in the analysis procedure.

Data for the first research question were reported as comparison of means. A factorial MANOVA (Multivariate Analysis of Variance) was used for the analysis of the second and third research questions, and also for the first subsidiary question. The intent was to examine the relationship of the independent variables (day of the week and time of day) to the dependent variable time-use in the teaching, monitoring, and non-curricular activities of two groups of teachers). According to Stevens (1998), a MANOVA, necessary to view the data from a multivariate perspective, also produces a parsimonious test of significance, which maintain the overall level of a Type I, error at .05 while maximizing the power of the test. Further, Green, Salkind, and Akey (2000) claim that a "one-way MANOVA evaluates a hypothesis that includes not only equality among groups on the dependent variables but also equality among groups on linear combination by these dependent variables" (p. 199).

The second subsidiary question required a comparison of the differences in timeuse between elementary music teachers and elementary classroom teachers regarding activities of teaching, monitoring, and non-curricular, based on demographic characteristics - ethnicity, level of training, and years of experience. Statistical analysis for this subsidiary question utilized two-way ANOVAs. 
CHAPTER IV

\section{RESULTS OF THE STUDY}

In general, the purpose of the study was to compare elementary music teachers and regular classroom teachers' time-use in classroom activities categorized as teaching, monitoring, and non-curricular. More specifically, this investigation sought to compare the time-use of teachers by grade level, time of day, and day of the week. Further, it sought to gain understanding of the extent to which certain demographic characteristics such as ethnicity, level of training, and years of experience determine the time-use of these two groups of teachers. Overall, this investigation was pursued in order to provide the basis on which to make decisions regarding time-use as it relates to opportunity for curriculum delivery.

This chapter presents quantitative analysis that includes both descriptive and inferential statistical procedures that address the three research questions and the subsidiary questions.

\section{Data Analysis for Participants}

The demographics of the teachers involved in the sample were analyzed and are presented before discussing the observational results of this study.

Data obtained for this study were gathered from elementary music and classroom school teachers in Miami-Dade County, Florida. The Miami-Dade County Public School System with a population of 350,000 students and 22,000 (secondary and elementary) teachers is divided into six regions based on geographical boundaries. The sample is representative of these regions. The target population of elementary teachers who teach in Miami-Dade County Public Schools included about 8,089 elementary teachers from 
1996 to 1998 . This number includes elementary classroom teachers, all specialist teachers of music, art physical education, ESOL, and others. Of the 8,089 elementary teacher population, 5,904 are classroom teachers who teach kindergarten through Grade 5, and 303 are music teachers. Both groups make up the target population of 6,207 elementary teachers (MDCPS, 1998, p. 144). A sample of 55 elementary music teachers and 69 elementary classroom teachers, or a total of 124 participants, was involved in this study.

The sample represents approximately $2 \%$ of the elementary teacher population. The pre-existing data of 197 observations collected during 1996 - 1997 school year (Wagner \& Anderson, 1999) were augmented with an additional 107 observations that were performed during the Fall Semester of 1997 - 1998 school year study. This additional data expanded the original data pool from 197 to 304 observations. The combined data set was used for the present study.

A summary by region of data pooled for all elementary teachers (elementary classroom and music teachers) in the sample is presented in Table 1. As shown in Table 1 , the frequency distribution of observations for the 124 elementary teachers (classroom and music) in the sample according to region indicates that Region $\mathrm{V}$ had the largest number of observations ( 83 or $27.3 \%$ ). The six regions are considered the general area of Miami-Dade County. They are based on geographical boundaries, each with a region superintendent and an administrative staff. In general, there are 302 Miami-Dade County Public Schools; 201 (67\%) elementary schools, 52 (18\%) middle schools, 31 (10\%) senior high schools, and $18(5 \%)$ alternative schools. Among the schools represented in Miami-Dade County, the elementary schools claim the highest percentage (67\%). Of the 
six regions represented in the County, Region $\mathrm{V}$ had the highest number of elementary schools (42), and Region II had the lowest number of elementary.

Table 1

Frequencies and Percentages of Observations for Music Teachers and Classroom

Teachers in the Sample per Region

\begin{tabular}{|c|c|c|c|c|}
\hline Region & $\begin{array}{l}\text { Schools } \\
\text { by Region }\end{array}$ & $\begin{array}{l}\text { Schools } \\
\text { in Sample }\end{array}$ & Freq. of Observations & Percent \\
\hline I & 34 & 11 & 55 & 18.1 \\
\hline II & 26 & 5 & 30 & 9.9 \\
\hline III & 34 & 6 & 46 & 15.1 \\
\hline IV & 35 & 7 & 46 & 15.1 \\
\hline V & 42 & 10 & 83 & 27.3 \\
\hline VI & 29 & 7 & 44 & 14.5 \\
\hline Total & 201 & 46 & 304 & 100.0 \\
\hline
\end{tabular}

Schools (26). The 46 elementary schools in the sample represent $23 \%$ of the total number of elementary schools.

The summaries of the frequency of observations within the sample are presented according to days of the week (Table 2) and time of day (Table 3). Table 2 presents an overview of the frequencies and percentages of observations performed for both groups of teachers (elementary music teachers and elementary classroom teachers) by day of the week.

The number of observations $(\mathrm{n}=157)$ for music teachers were nearly evenly distributed across the days of the week except for Monday, which shows 47 observations 
$(29 \%)$ performed on that day. The total number of observations performed for classroom teachers was 147 . There were fewer observations performed for classroom teachers on Mondays and Wednesdays.

Table 2

Frequencies and Percentages by Number of Observations Performed per Day of the $\underline{\text { Week }}$

\begin{tabular}{lcccc}
\hline & \multicolumn{2}{c}{ Observations of } & \multicolumn{2}{c}{ Observations of } \\
Day & $\begin{array}{c}\text { Elementary } \\
\mathrm{N}\end{array}$ & $\begin{array}{c}\text { Music } \\
\%\end{array}$ & $\mathrm{~N}$ & $\begin{array}{c}\text { Elemers } \\
\%\end{array}$ \\
\hline Monday & 47 & 29.3 & 19 & 12.9 \\
Tuesday & 27 & 17.2 & 30 & 20.4 \\
Wednesday & 27 & 17.2 & 22 & 15.0 \\
Thursday & 31 & 19.7 & 37 & 25.2 \\
Friday & 25 & 15.9 & 39 & 26.5 \\
Total & 157 & 100.0 & 147 & 100.0 \\
\hline
\end{tabular}

Table 3 indicates the frequencies and percentages of observations collected per morning and afternoon for elementary music teachers and elementary classroom teachers. Table 3 reveal that approximately 97 observations (56.7\%) for classroom teachers were collected during the mornings while 83 observations $(62.4 \%)$ were collected for classroom teachers during the afternoons. After the observational data were collected, further demographic data (gender, ethnicity, years of experience, and level of training) were obtained with permission from the Miami-Dade County Public School Personnel Office. 
Table 3

Frequencies and Percentages by Number of Observations Performed per Morning and Afternoon

\begin{tabular}{lccccc}
\hline & \multicolumn{2}{l}{ Observation of } & \multicolumn{2}{l}{ Observation of } \\
& \multicolumn{2}{c}{$\begin{array}{l}\text { Music Teacher } \\
\text { Time of Day }\end{array}$} & $\mathrm{N}$ & $\%$ & \multicolumn{2}{c}{ Classroom Teacher } & Total \\
\hline \multirow{2}{*}{ Morning } & 74 & $43.3 \%$ & $\mathrm{~N}$ & $\%$ & \\
Afternoon & 83 & $62.4 \%$ & 97 & $56.7 \%$ & 157 \\
Total & 157 & & 50 & $37.6 \%$ & 147 \\
& & & & & \\
\end{tabular}

The general population of 8,089 elementary teachers in the Miami-Dade Public Schools was comprised of 1,048 male teachers and 7,032 female teachers during 1997-1998. The ethnicity of the participants proved important to the study on the premise that the MiamiDade County Public School system is situated amidst a substantial concentration of ethnic groups. The enthic/racial composition of elementary teacher population for 1997-1998 was 2,752 white non-Hispanic, 2,363 black non-Hispanic, 2, 920 Hispanic, and 54 Asian/American Indian.

Five thousand two hundred and sixty eight (5268) elementary teachers of the general population of teachers have bachelors degrees and 3,029 have masters degrees. The range of the teaching experience of the general population of secondary and elementary teachers teachers is as follows: 7,052 have fewer than 1 year to 5 years 
experience; 2, 905 have 6 to 10 years experience; 1,418 have 11 to 15 years experience; and 5,524 have 16 or more years experience.

Table 4 summarizes the profile of the 55 elementary music teachers and 69 elementary classroom teachers. Gender is reported as a profile item but was not used in the analysis of demographic characteristics that affect teachers' time-use. Gender was not included because of the small representation of male elementary classroom teachers (7.2\%) of all elementary classroom teachers as compared to a larger representation of male elementary music teachers $(43.6 \%)$ of all elementary music teachers.

As shown in the Table 4, the two groups of teachers were generally equivalent in their demographic characteristics—gender, ethnic background, highest degree, and teaching experience. With reference to gender, $56 \%$ of the elementary music teachers were females as compared to the $92 \%$ of the elementary classroom teachers who were females. There was a higher proportion of elementary music male teachers $(43.6 \%)$ as compared with elementary classroom male teachers (7.2\%).

With regard to ethnic background, the white non-Hispanic comprised the greatest proportion of elementary music teachers (52\%). The Hispanic (37\%) and black nonHispanic (40\%) were the largest representation of within both groups of elementary teachers.

The highest proportion of teachers in both groups with only a bachelor's degree included $56 \%$ for elementary music teachers and $55 \%$ for elementary classroom teachers. About $37 \%$ of the elementary classroom teachers had sixteen years or more teaching experience; $29 \%$ of elementary music teachers had one to five years of teaching experience. 
Table 4

Profile of Research Participants ( $\mathrm{N}=124)$

Elementary Music Teachers $(\mathrm{N}=55)$ Elementary Classroom Teachers $(\mathrm{N}=69)$

Characteristic

$\mathrm{N} \quad \%$

$\mathrm{N}$

$\%$

Gender

$\begin{array}{lrrrr}\text { Female } & 31 & 56.4 & 64 & 92.8 \\ \text { Male } & 24 & 43.6 & 5 & 7.2\end{array}$

Ethnic Background

$\begin{array}{lrrrr}\text { Hispanic } & 19 & 34.6 & 27 & 37.3 \\ \text { White Non-Hispanic } & 29 & 52.7 & 15 & 22.4 \\ \text { Black Non-Hispanic } & 7 & 12.7 & 27 & 40.3\end{array}$

Highest Degree

Bachelor

$31 \quad 56.4$

38

55.6

Masters

$24 \quad 43.6$

31

44.4

Teaching Experience

$\begin{array}{lllll}1-5 \text { yrs } & 16 & 29.0 & 10 & 14.5 \\ 6-10 \text { yrs } & 10 & 18.2 & 19 & 27.5 \\ 11-15 \text { yrs } & 15 & 27.3 & 14 & 20.3 \\ 16 \text { or more } & 14 & 25.5 & 26 & 37.7\end{array}$

Data Analysis of the Research Questions

The results from the analysis of data collected to answer each of the three research questions are presented in this section. Because of the logic of the final analysis, the subsidiary questions will precede the research questions.

\section{Subsidiary Question One}

How does time-use for the activities subsumed under the teaching, monitoring and non-curricular categories compare for elementary music teachers and elementary classroom teachers? This question was addressed as follows. A MANOVA was 
performed to determine differences in the time-use between elementary music teachers and classroom teachers. Results from the analysis, Wilks' Lambda of .61, $\underline{F}(3,300)=$ $62.1, \mathrm{p}<.001$, indicated a significant difference between the group means (classroom versus music teachers) on a set of dependent variables - time-use in teaching, monitoring, and non-curricular categories. Significant group differences were determined by the Bonferroni Post Hoc test at a .05 level of significance. All three ANOVAs were significant at $\alpha=.05$. The results indicate that the univariate ANOVA for the teaching category time-use was significant, $(\underline{F}(1,302) 27.06, \underline{p}<.001)$. The univariate ANOVA for time in the monitoring category was also significant at, $(\underline{F}(1,302) 185.6, \underline{p}<.001)$, minutes spent in non-curricular time-use was significant at, $(\underline{\mathrm{F}}(1,302) 49.4, \underline{p}<.001)$. The group means and standard deviation for elementary music and classroom teachers' time-use in the three major categories (teaching, monitoring, and non-curricular) are reported in Table 5.

Table 5 indicates the result of an independent $t$ test to determine whether elementary music teachers allocate more time than do elementary classroom teachers to teaching, monitoring, and non-curricular activities. The test revealed a significant difference in the average time spent teaching, $\underline{\mathrm{t}}(302)=5.20, \mathrm{p}<.001$ : elementary music teachers $(\underline{\mathrm{M}}=68.01, \underline{\mathrm{SD}}=38.67)$ spent more time actively teaching than do elementary classroom teachers $(\underline{\mathrm{M}}=51.86, \underline{\mathrm{SD}}=26.57)$. Findings for the major category "Monitoring" showed a significant difference, $\underline{\mathrm{t}}(302)=-13.62, \mathrm{p}<.001$. Elementary classroom teachers $(\underline{\mathrm{M}}=81.42, \underline{\mathrm{SD}}=32.34)$ allocated more time to monitoring than do elementary music teachers $(M=37.96, \underline{S D}=22.39)$. Time spent on 
Table 5

Time-use by Group (Elementary Music and Classroom Teachers) Compared by Major Category of Activity

\begin{tabular}{|c|c|c|c|c|c|c|}
\hline \multirow[t]{2}{*}{$\begin{array}{l}\text { Major Category } \\
\text { of Activity }\end{array}$} & \multicolumn{2}{|c|}{$\begin{array}{l}\text { Elementary Music Teacher } \\
(\mathrm{n}=55)\end{array}$} & \multicolumn{4}{|c|}{$\begin{array}{l}\text { Elementary Classroom Teacher } \\
\qquad(\mathrm{n}=69)\end{array}$} \\
\hline & $\underline{M}$ & $\underline{\mathrm{SD}}$ & $\underline{M}$ & $\underline{\mathrm{SD}}$ & $\underline{t^{*}}$ & $\mathrm{p}$ \\
\hline Teaching & 68.01 & 28.67 & 51.86 & 26.57 & 5.20 & .001 \\
\hline Monitoring & 37.96 & 22.39 & 81.42 & 32.34 & -13.62 & .001 \\
\hline Non-Curricular & 73.28 & 36.15 & 47.04 & 29.47 & 7.03 & .001 \\
\hline
\end{tabular}

Note: ${ }^{*} \mathrm{df}=302$

"Non-curricular activities" also revealed a significant difference, $\underline{\mathrm{t}}(302)=7.03, \mathrm{p}<.001$.

Elementary music teachers $(\underline{\mathrm{M}}=73.28, \underline{\mathrm{SD}}=36.15)$ spent more time in non-curricular activities than do elementary classroom teachers $(\underline{\mathrm{M}}=47.04, \underline{\mathrm{SD}}=29.47)$.

An independent $t$ test was performed to further analyze the more detailed activity classification within each of the three categories. Table 6 presents the results. The intent of this analysis was to determine in greater detail what variances might be present in the different levels of activities within each major category and how they compared between the two groups of teachers.

Table 6 shows means standard deviation, $\underline{t}$ tests and $\underline{p}$ values of teacher time-use in the eighteen classroom activities in each of the major categories. Overall, the analysis revealed much more about time usage patterns between elementary music teachers and classroom teachers. In the teaching category, significant differences were found in the 
Table 6

Comparison of Elementary Classroom and Music Teachers by Detailed Activity

Classifications

\begin{tabular}{|c|c|c|c|c|c|c|}
\hline \multirow[t]{2}{*}{ Activity } & \multicolumn{2}{|c|}{ Music Teacher } & \multicolumn{3}{|c|}{ Classroom Teacher } & \multirow[b]{2}{*}{$\underline{\mathrm{p}}$} \\
\hline & $\mathrm{M}$ & $\mathrm{SD}$ & M & $\mathrm{SD}$ & $\underline{\mathrm{t}}$ & \\
\hline Teaching Time Total & \multicolumn{2}{|c|}{$(68.01)$} & \multicolumn{3}{|c|}{$(51.67)$} & \\
\hline Academic Instruction & 14.37 & 17.31 & 16.37 & 16.13 & 5.20 & .30 \\
\hline Social Instruction & 2.04 & 4.78 & 2.90 & 6.39 & -1.35 & .18 \\
\hline Subject Matter & 41.45 & 22.73 & 24.11 & 23.36 & 6.56 & .001 \\
\hline Discussion & 7.73 & 12.81 & 5.21 & 7.16 & 2.13 & .03 \\
\hline Reinforcement & 2.42 & 6.60 & 3.27 & 7.53 & -1.05 & .29 \\
\hline Monitoring Time Total & \multicolumn{2}{|c|}{$(37.96)$} & \multicolumn{3}{|c|}{$(81.42)$} & \\
\hline Schoolwide Activities & 3.34 & 8.23 & 9.15 & 13.66 & -4.52 & .001 \\
\hline Seatwork & 7.48 & 13.27 & 34.96 & 25.03 & -12.06 & .001 \\
\hline Preparation & 11.59 & 10.09 & 12.86 & 12.66 & -.97 & .34 \\
\hline Giving Directions & 5.62 & 7.50 & 9.76 & 10.90 & -3.87 & .001 \\
\hline Changing Activities & 8.13 & 8.25 & 12.08 & 10.59 & -3.64 & .001 \\
\hline Teacher Talk & 1.80 & 4.13 & 2.61 & 4.85 & -1.57 & .12 \\
\hline \multicolumn{3}{|l|}{ Non-Curricular Time Total } & \multicolumn{3}{|c|}{$(47.04)$} & \\
\hline Lunch & 16.04 & 19.64 & 11.48 & 14.26 & 2.30 & .02 \\
\hline Assemblies & 1.08 & 7.75 & .59 & 4.63 & .67 & .51 \\
\hline Planning & 44.47 & 33.19 & 21.80 & 24.94 & 6.69 & .001 \\
\hline Assigned Duties & 3.26 & 11.25 & 1.73 & 5.81 & 1.47 & .14 \\
\hline Interruption & 1.99 & 3.05 & 4.71 & 6.93 & -4.48 & .001 \\
\hline Travel & 3.04 & 5.96 & 4.34 & 7.72 & -1.65 & .10 \\
\hline Consultation & 3.40 & 8.63 & 2.39 & 8.64 & 1.01 & .31 \\
\hline
\end{tabular}

activities of subject matter $(\underline{\mathrm{t}}(302)=6.56, \underline{\mathrm{p}}<.001)$, and discussion $(\underline{\mathrm{t}}(302)=2.13, \underline{\mathrm{p}}<$ $.05)$. It appears that music teachers $(\underline{M}=41.45, \underline{S D}=22.73)$ spend more time teaching subject matter than do classroom teachers $(\underline{\mathrm{M}}=24.11, \underline{\mathrm{SD}}=23.36)$. Elementary music 
teachers $(\underline{M}=7.73, \underline{S D}=12.81)$ allocate more time to class discussion more than do classroom teachers $(\underline{M}=5.21, \underline{S D}=7.16)$.

Results for the monitoring category showed significant differences for schoolwide activities ( $\underline{\mathrm{t}}(302)=4.53, \mathrm{p}<.001)$, seatwork $(\underline{\mathrm{t}}(302)=-12.06, \underline{\mathrm{p}}<.001)$, giving directions ( $\mathrm{t}(302)=-3.87, \underline{\mathrm{p}}<.001)$, and changing activities $(\mathrm{t}(302)=3.64, \mathrm{p}<.001)$. The means and standard deviations for schoolwide activities $(\underline{M}=9.15, \underline{S D}=13.66)$, seatwork $(\underline{M}=34.96, \underline{\mathrm{SD}}=25.03)$, giving directions $(\underline{\mathrm{M}}=12.86, \underline{\mathrm{SD}}=12.66)$, changing activities $(\underline{\mathrm{M}}=9.76, \underline{\mathrm{SD}}=10.90)$ also indicate that classroom teachers devote more time to these activities than do elementary music teachers.

In the "Non-Curricular" category, significant differences were found for lunch (t $(302)=2.30, \underline{p}<.05)$, planning $(\underline{\mathrm{t}}(302)=6.69, \underline{\mathrm{p}}<.001)$, and interruption (t $(302)=$ -

$4.48, \underline{\mathrm{p}}<.001)$. The means for lunch $(\underline{\mathrm{M}}=16.04, \underline{\mathrm{SD}}=19.64)$ and planning $(\underline{M}=44.47, \underline{S D}=33.19)$ showed that music teachers allocate more time to planning and lunch than do classroom teachers. On the other hand, elementary classroom teachers $(\underline{\mathrm{M}}$ $=4.71, \mathrm{SD}=6.93)$ had more incidents of interruptions in their classrooms than did elementary music teachers.

\section{$\underline{\text { Subsidiary Question Two }}$}

Does time-use vary with demographic characteristics - ethnicity, highest level of training, and years of experience - for elementary music teachers and elementary classroom teachers? This question was addressed as follows. Mean scores were computed for ethnicity, level of training, and years of teaching experience to address the question of whether time-use varied for elementary music teachers and elementary classroom teachers on the basis of these demographic characteristics. A cross 
classification analysis was completed for each demographic characteristic-ethnicity, level of training, and years of experience-- to determine the number of participants and percentages that are contained within each of the cells of this descriptive study.

ANOVAs were then performed to determine whether significant differences exist for levels of each demographic characteristic (ethnicity, highest level of training and years of experience) on the dependent variable (time-use in all three categories of activityteaching, monitoring, and non-curricular). All tests were conducted at .05 level of significance.

Table 7 presents the cross classification analysis of the frequencies for participants (elementary music teachers and elementary classroom teachers) by ethnicity, highest degree, and years of experience. The analysis reveals that approximately $40 \%$ of the elementary classroom teachers were Hispanic compared with nearly $52 \%$ of the elementary music teachers who were white non-Hispanic and almost $12 \%$ who were black non-Hispanic. Teachers (elementary classroom and music) with only a Bachelor's degree comprised the highest percentage in both groups (56\% for music and $51 \%$ for classroom). Moreover, the results showed that elementary classroom teachers with sixteen or more years of experience represented the highest percentage (approximately $37 \%)$.

A two-way ANOVA was conducted to determine which demographic characteristic (ethnicity, level of training, or years of experience) had an effect on elementary teachers' time-use in teaching, monitoring and non-curricular activities. An ANOVA indicated no significant interaction between main effect (teacher type and 
Table 7

Frequencies for Participants by Ethnicity, Level of Training, and Years of Experience

\begin{tabular}{lllc}
\hline Ethnicity & Elementary Music Teacher & Elementary Classroom Teacher & Total \\
Frequency & 29 & & 25 \\
White - Non-Hispanic & $52.7 \%$ & $37.3 \%$ & 54 \\
Frequency & 7 & 15 & $44.3 \%$ \\
Black - Non-Hispanics & $12.7 \%$ & $22.4 \%$ & 22 \\
Frequency & 19 & 27 & $18.0 \%$ \\
Hispanics & $34.5 \%$ & $40.3 \%$ & 46 \\
Frequency & 55 & 67 & $37.7 \%$ \\
Total & $100 \%$ & $100 \%$ & 122 \\
\hline
\end{tabular}

Level of Training Elementary Music Teacher Elementary Classroom Teacher Total

\begin{tabular}{lccc} 
Frequency & 31 & 38 & 69 \\
Bachelors & $56.4 \%$ & $55.1 \%$ & $55.5 \%$ \\
& & & \\
Frequency & 24 & 31 & 55 \\
Masters & $43.6 \%$ & $44.9 \%$ & $44.4 \%$ \\
& & & \\
Frequency & 55 & 69 & 124 \\
Total & $100 \%$ & $100 \%$ & $100 \%$ \\
\hline
\end{tabular}

Experience Elementary Music Teacher Elementary Classroom Teacher Total

\begin{tabular}{lccc} 
Frequency & 16 & 10 & 26 \\
Less than $1-5$ yrs & $29.1 \%$ & $14.5 \%$ & $21.0 \%$ \\
Frequency & 10 & 19 & 29 \\
$6-10$ yrs & $18.2 \%$ & $27.5 \%$ & $23.4 \%$ \\
Frequency & 15 & 14 & 29 \\
$11-15$ yrs & $27.3 \%$ & $20.3 \%$ & $23.4 \%$ \\
Frequency & 14 & 26 & 40 \\
16 or more & $25.5 \%$ & $37.7 \%$ & $32.2 \%$ \\
Frequency & 55 & 69 & 124 \\
Total & $100 \%$ & $100 \%$ & $100 \%$ \\
\hline
\end{tabular}


ethnicity), teacher type and highest level of training, or teacher type and years of experience. Conversely, there was significance found for main effect, ethnicity, $\underline{F}$ (2, $116)=4.22, \mathrm{p}<.017$. Ethnicity had a greater effect on time-use in the teaching category than in the monitoring and non-curricular categories. Table 8 reports the result of the ANOVA for ethnicity.

Table 8

Analysis of Variance of Ethnicity (White Non-Hispanic, Black Non-Hispanic, and $\underline{\text { Hispanic) }}$

Source

Sums of Square

df

F $\quad$ Sig

Between Groups

63279.27

2

4.215

$.017 *$

Within Groups

870729.39

116

Total

934008.66

118

${ }^{*} \mathrm{p}<.05$

Follow-up analyses to the main effect for ethnicity were conducted. These tests consisted of all pairwise comparisons among the three types of ethnic groups (white nonHispanic, black non-Hispanic, and Hispanic). The Least Significant Difference (LSD) was used to control for Type I error across the pairwise comparisons with the three groups. This analysis revealed a mean difference of $\underline{\mathrm{M}}=-67.52, \underline{\mathrm{p}}<.005$. Black nonHispanic teachers allocated more time to teaching than did Hispanic teachers. There was no significant difference between white non-Hispanic and black non-Hispanic. 


\section{Research Question One}

What differences exist in elementary music teachers and elementary classroom teachers' time-use for teaching, monitoring and non-curricular activities across grade levels? This question was addressed as follows. Because elementary music teachers' time is scheduled so differently from that of elementary classroom teachers, a method of comparison was devised to compare possible grade level time-use differences in these two groups of teachers. It must be noted that for each three-hour observation, while elementary classroom teachers were responsible for only one grade level, elementary music teachers saw multiple grade levels in 30-minute and 45-minute time blocks-each, often at different grade levels. Elementary music teachers' time-use had to be converted, if comparisons were to be made. Therefore, for elementary music teachers' time, the following was followed.

- Minutes of accrued time-use were taken from all elementary music teachers' data spreadsheets and cast into the eighteen subsumed activities under the three main categories (Teaching, Monitoring, and Non-Curricular), summed by grade level.

- The sums of each of the eighteen activities were then divided by 180 (the total number of minutes in a single observation).

- These minute sums per eighteen activities could then be aggregated to get "minutes per category."

- Resultant values were the converted number of minutes per category, per grade level for the combined elementary music teacher population..

- These were then compared with the means per category for elementary classroom teachers. 
Because of the conversion of data, no statistical manipulation of means could be possible for the first research question. Table 9 reveals a comparison of the results in mean minutes across grade levels $(\mathrm{K}-5)$ for both elementary music teachers and elementary classroom teachers. Among the differences between the two groups of

Table 9

Distribution of Mean Minutes for Elementary Teachers' Time-Use in Major

Categories of Activities by Grade Level

\begin{tabular}{|c|c|c|c|c|}
\hline Categories & $\mathrm{K}$ & Grade I & Grade 2 & Grade 3 \\
\hline
\end{tabular}

Teaching

$\begin{array}{lllllll}\text { Music Teacher } & 73.96 & 72.64 & 76.01 & 65.28 & 70.71 & 63.35 \\ \text { Classroom Teacher } & 53.66 & 55.03 & 55.84 & 46.52 & 55.41 & 46.83\end{array}$

Monitoring

$\begin{array}{lllllll}\text { Music Teacher } & 39.97 & 31.36 & 39.09 & 33.17 & 47.09 & 36.35 \\ \text { Classroom Teacher } & 97.78 & 87.56 & 64.06 & 90.74 & 75.70 & 73.65\end{array}$

Non-Curricular

\begin{tabular}{crrrrrr} 
Music Teacher & 65.97 & 76.00 & 64.90 & 81.55 & 62.20 & 80.15 \\
Classroom Teacher & 28.56 & 37.41 & 60.10 & 42.81 & 48.94 & 59.65 \\
\hline
\end{tabular}

Note: Sums of mean minutes for each grade level equal 100\% (i.e. Music teacher 73.96 $+39.97+28.56=100 \%$ ), which is the sum total per teacher per category.

teachers, time spent teaching did not vary in a marked way. As was expected, mean minutes classroom teachers spent monitoring across grade levels was higher in the lower grades (Kindergarten, $\underline{M}=97.75$, Grade $1, \underline{M}=87.56$, and Grade $3, \underline{M}=90.74$ ) than they were in the higher grades. However, mean minutes spent monitoring activities across grade level by elementary music teachers did not increase. 


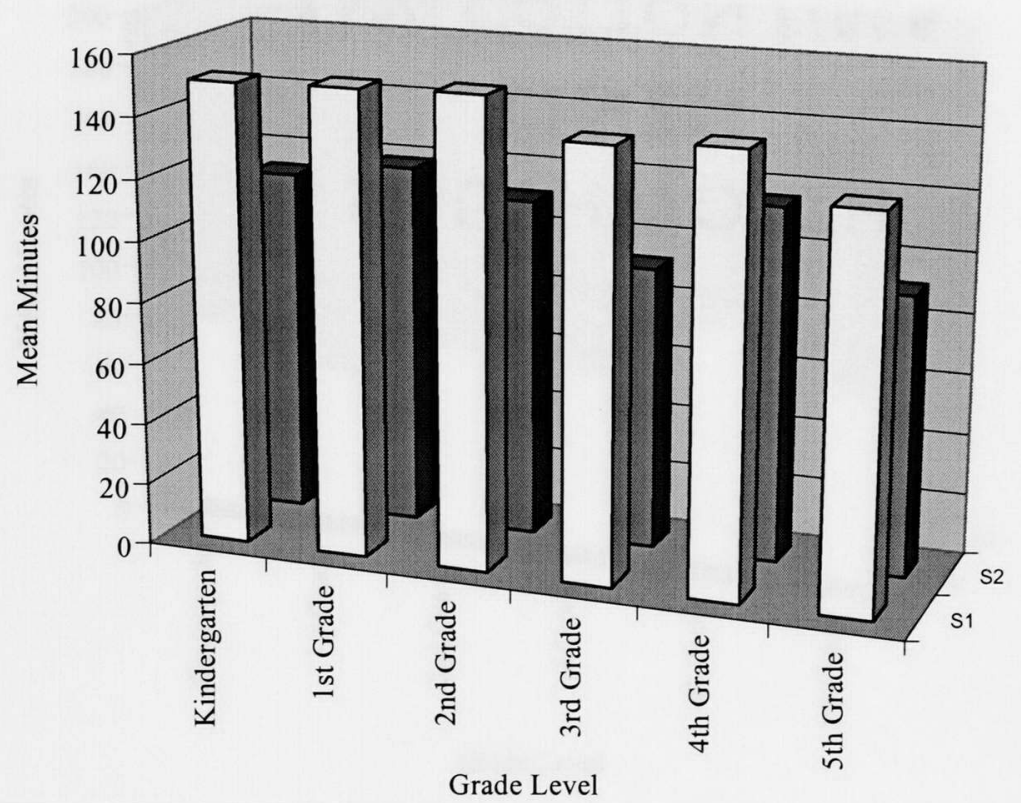

Figure 1.1. Mean Minutes Teaching 
Music Teachers

Classroom Teachers

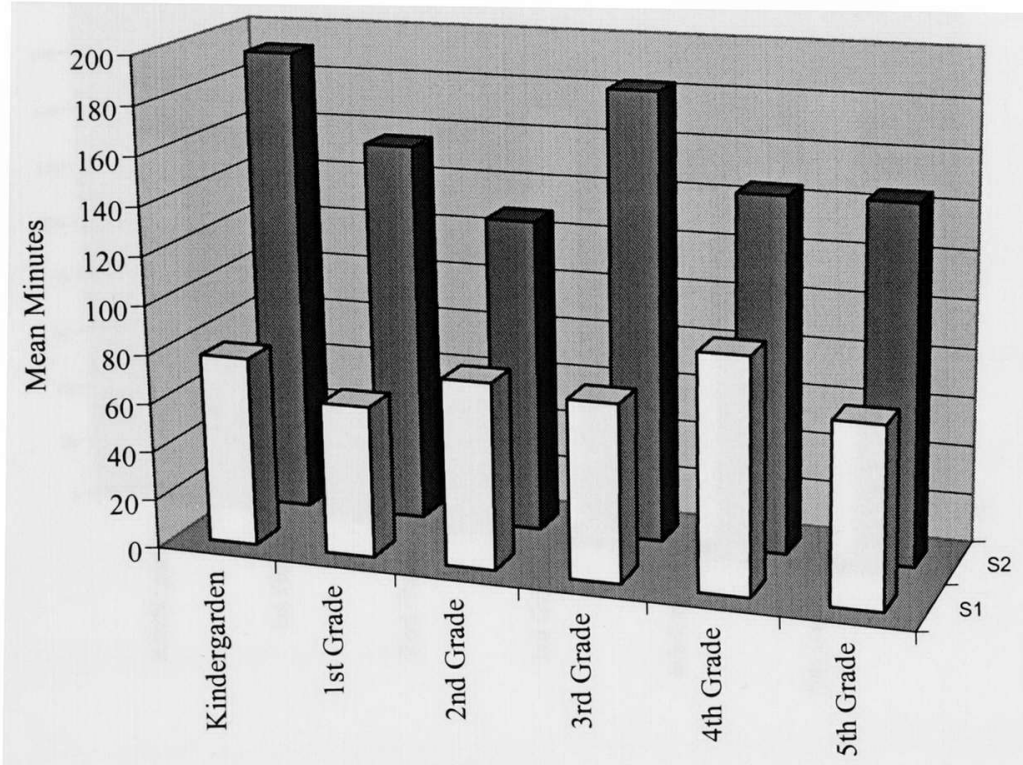

Grade Level

Figure 1.2. Mean Minutes Monitoring 


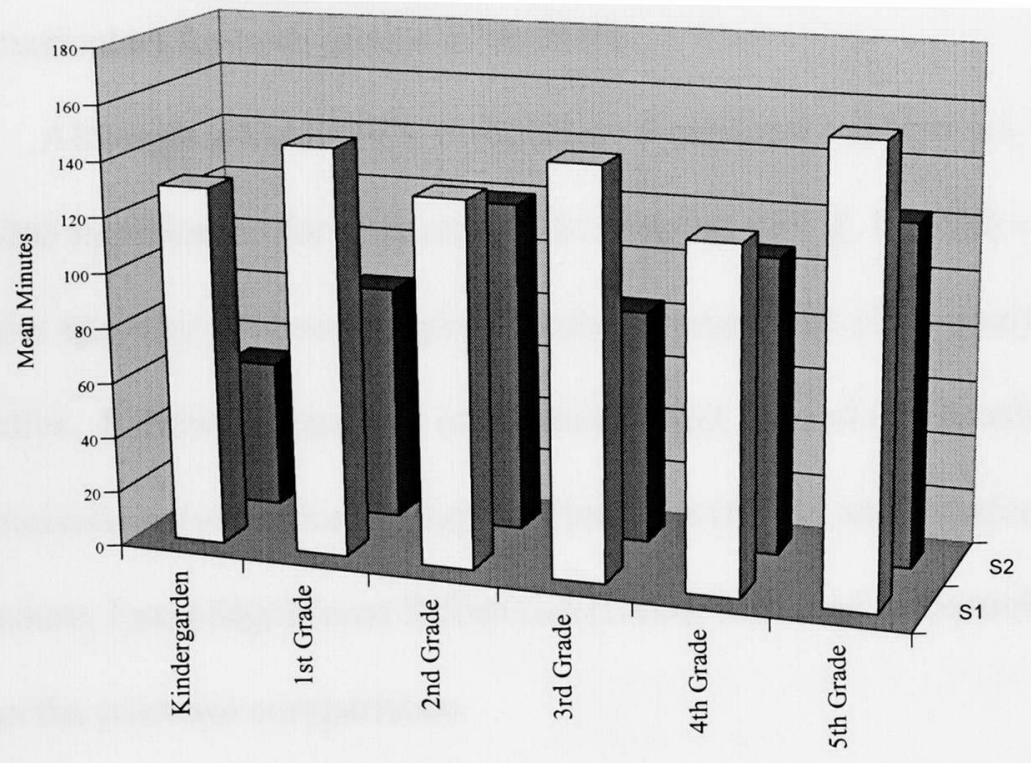

Grade Level

Figure 1.3. Mean Minutes Non-Curricular 
significance $(\underline{F}(1,294)=.982, p<.143)$ showed no difference for time of day and no significant interaction between type (music teacher and classroom teacher) or time of day (morning or afternoon). The result showed that time of day was not a significant factor in the teacher time-use in the three major categories of activities (teaching, monitoring and non-curricular) for both groups of teachers.

Although a MANOVA revealed no significance difference, a two-way ANOVA revealed significance for only main effect time of day, $\underline{F}(1,300)=414.35=<.031$ in minutes spent by the two groups of teachers (music and classroom) on non-curricular activities. Follow-up analyses of the main effect time of day consisted of pairwise comparisons between the two types of teachers (music and classroom). A Post Hoc procedure, Least Significant Difference (LSD), was used to control for Type I error across the pairwise comparisons.

The result of this analysis showed that the mean difference $(\underline{\mathrm{M}}=-25.94, \underline{p}<$ $.001)$ between time-use of the elementary music teacher and elementary classroom teachers on non-curricular activities was significant at the .05 level. These findings support the premise that elementary music teachers spent more time on non-curricular activities during the day did elementary classroom teachers. Because the analysis did not reveal which time of the school day (morning or afternoon) elementary music teachers allocate more time in non-curricular activities, a separate evaluation was carried out to ascertain this information. Table 10 presents the results of this analysis.

An explanation of the results in Table 10 is given in this paragraph. Separate independent samples $\underline{t}$ tests were performed for both elementary music teachers and 
Table 10

Analysis of Time-use Per Elementary Music Teachers and Elementary Classroom

Teachers in Major Categories by Time of Day

Elementary Music Teacher

Category

$\mathrm{N}$ (obs) $=145$

Mornings
$\underline{M} \quad \underline{\text { SD }}$

Afternoons

$\begin{array}{lllllll} & \underline{\mathrm{M}} & \underline{\mathrm{SD}} & \underline{\mathrm{M}} & \underline{\mathrm{SD}} & \underline{\mathrm{t}} & \underline{\mathrm{p}} \\ \text { Teaching } & 51.86 & 25.66 & 51.39 & 28.02 & 5.20 & .105 \\ \text { Monitoring } & 83.43 & 28.42 & 77.97 & 37.20 & .96 & .060 \\ \text { Non-Curricular } & 44.71 & 25.56 & 50.69 & 34.15 & -1.21 & .004^{*}\end{array}$

Category

Elementary Classroom Teacher

$\mathrm{N}(\mathrm{obs})=157$

\begin{tabular}{|c|c|c|}
\hline Mornings & Afternoons & \\
\hline$\underline{M} \quad \underline{S D}$ & $\underline{M} \quad \underline{\mathrm{SD}}$ & $\underline{t^{*}}$ \\
\hline
\end{tabular}

Teaching

$70.41 \quad 30.02$

$66.35 \quad 27.56$

$.882 \quad .745$

Monitoring

$38.63 \quad 21.99$

$37.33 \quad 22.83$

$.363 \quad .926$

Non-Curricular

$70.93 \quad 35.15$

$76.35 \quad 36.97$

$-.935 \quad .757$

Note: . Music $\mathrm{df}=145$ Classroom $\mathrm{df}=155^{*}$

elementary classroom teachers. The test showed a significant difference for elementary music teachers in time allocated to non-curricular activities during the day, $(\underline{t}(145)=8.64, \underline{p}<.004)$. Specifically, time spent on non-curricular activities in the afternoon $(\underline{\mathrm{M}}=50.69, \underline{\mathrm{SD}}=34.15)$ was greater than time spent in the morning 
$(\underline{M}=44.71, \underline{\mathrm{SD}}=25.56)$. Conversely, the test revealed, for elementary classroom teachers, no significant difference in time spent on non-curricular activities during the day, $(\underline{\mathrm{t}}(155)=.096, \underline{\mathrm{p}}<.757)$.

\section{$\underline{\text { Research Question Three }}$}

What differences exist in elementary music teachers and elementary classroom teachers' time-use for teaching, monitoring and non-curricular activities by day of the week? This question was addressed as follows. A general linear model (GLM) multivariate analysis of variance (MANOVA) was used to determine whether significant differences exist for the main effects day of the week (Monday through Friday) and type of teacher (music teacher and classroom teacher) and the interaction of day of the week and teaching category on the three dependent variables: teaching, monitoring, and noncurricular activities.

The GLM ANOVA produced a significant Wilks Lambda, $(\underline{F}(1,294)=.917 \mathrm{p}<$ $.013)$, for interaction by day of the week and teacher category on the dependent variables. The Bonferroni method determines that each ANOVA for teaching was non-significant for the teaching category $(\underline{F}(4,299)=.447, p=.775)$, while the ANOVA for monitoring was significant $(\underline{\mathrm{F}}(4,299)=4.65, \underline{\mathrm{p}}=.011)$. Post hoc analysis of the univariate ANOVA was performed, and each pairwise comparison was tested at the .05 level of significance. Three pairwise comparisons were significant. Findings revealed that elementary classroom teachers spent significantly more time monitoring throughout the week than did elementary music teachers.

Elementary classroom teachers allocated more time to monitoring on Thursdays and Fridays as compared to Mondays. For the non-curricular category, music teachers 
spent more time than did classroom teachers in non-curricular category on Fridays as compared to Mondays. Other than Monday, time spent on non-curricular activities on the other days (Tuesday, Wednesday and Thursday) was not significantly different.

\section{Summary}

In this chapter, the research data were analyzed and results have been presented in Table 1 through Table 10. Analysis of these data was used to compare the use of time by music and classroom teachers as determined by grade level, time of day and day of the week. The three broad categories of classroom activities were teaching, monitoring and non-curricular. The effects of the teacher demographic characteristics were explored. The MANOVA results for the first subsidiary question revealed a significant multivariate effect for teacher type. Follow-up univariate tests indicated that elementary classroom teachers spent significantly more time monitoring and less time teaching and engaged in noncurricular activities than elementary music teachers. An independent $t$ test showed that music teachers devoted more time to subject matter and classroom discussion. Of all the activities identified as monitoring activities, elementary classroom teachers spent more time in schoolwide activities, supervising seatwork, giving directions, and changing activities. Conversely, music teachers' time-use allocation was greater for non-curricular activities such as planning and lunch. However, interruptions occurred more frequently during times that elementary classroom teachers were teaching.

The analysis of the second subsidiary question indicated no significant differences in teachers' level of training or years of experience and teachers' use of time in the three categories of classroom activities. However, there was significant difference in teachers' ethnicity and the use of time. Of the three groups (white non-Hispanic, black non- 
Hispanic and Hispanic), black non-Hispanic teachers spend more time in teaching activities than did Hispanic teachers.

For the main research questions, the analysis indicated the following. Analysis for addressing the first research question revealed that elementary music teachers differed from classroom teachers in their use of time in monitoring and non-curricular activities across grade levels. A multivariate analysis of variance (MANOVA) was used to address the second research question to determine whether time of day had an effect on teachers' time-use in teaching, monitoring, and non-curricular activities. Results showed no significant differences in the interaction effect in allocation of time based on time of day. A consequent analysis (a two-way ANOVA) found significance differences for the main effect, time of day. Elementary music teachers and elementary classroom teachers differed in their use of time by day in non-curricular activities. Separate $\underline{t}$ tests were performed for elementary music teachers and elementary classroom teachers. Findings for elementary music teachers indicated that these teachers spent more time on noncurricular activities during the afternoons, while elementary classroom teachers did not differ in their time-use pattern for non-curricular activities for mornings and afternoons.

A MANOVA analysis for the third research question explored the effect of timeuse by day of the week and revealed significant differences for interaction of day of the week by teacher category on the dependent variables monitoring and non-curricular. Elementary classroom teachers monitored more on Thursdays and Fridays, while music teachers spent more time on non-curricular activities on Fridays. 


\section{CHAPTER V}

\section{SUMMARY, DISCUSSION AND CONCLUSIONS}

The successful delivery of the curriculum and its improvement depends to a certain extent, on how time is used in the classroom. Generally, how time is spent in the school involves the combined effort of the teacher, student, and school administrator. In the context of the classroom, teachers are central to managing classroom time because they are the ultimate decision-makers regarding its use.

Numerous studies on time-use and learning have been examined: (Borg, 1979; Brophy \& Good, 1986; Denham \& Liberman, 1980; Fisher, et al. 1980; Good \& Beckerman, 1978; Karweit \& Slavin, 1982; Rich \& McNelis, 1988; Rosenshine, 1980; Stigler \& Stevenson, 1991; Walberg, 1984 \& 1991). The results of these studies have led to attempts, by policymakers, to introduce time-use reform in American schools.

Advocating that time in schools be modified is predicated on the perception that time on task can be linked to student achievement. The longer students are engaged in academic work, the more likely they are to succeed. An important question raised by policymakers and educators is whether more time or less time facilitates more learning. Before such time-related decisions can be made, some researchers recommend that knowledge regarding how time is spent in the classroom should be ascertained. It is evident that students' time-use studies in the classroom have contributed significantly to time-use reforms in the schools. However, teachers are responsible for the transaction and management of classroom activities, therefore, it seems reasonable that their time-use pattern be studied. 
The purpose of this study was to determine the time-use pattern of elementary music teachers and elementary classroom teachers as influenced by grade level, time of day, and day of the week. The personal demographics of ethnicity, level of training, and years of experience were perceived as significant; it is important to determine whether specific characteristics affect teacher time-use. By examining these teachers time-use pattern, this study sought to understand the need for more precise data on teacher timeuse in the field of elementary education.

This chapter includes a summary of the study, an interpretation of the major findings in view of the parameters of the study and literature review, implications and conclusions, and, finally, recommendations for future research.

\section{Summary of the Study}

Data for this quantitative investigation were collected in the Miami-Dade County Public Schools by trained observers from an urban, public university in South Florida during the period 1996-1997 academic year and the 1998 Fall Semester. The research design employed observation as the mode of inquiry, and a convenience sampling method was utilized in the selection of participants for this study. A sample of 55 elementary music teachers and 69 elementary classroom teachers were involved in this investigation. The 124 teachers represent $2 \%$ of the target population of 8,089 elementary teachers in the six regions of the Miami-Dade County Public Schools.

The quantitative data used in this study were a combination of a pre-existing pool (197 observations) collected in 1996-1997 and additional data (107 observations) collected on music teachers during Fall 1998. The total number of observations was 304 
(157 observations for elementary music teachers and 147 observations for classroom teachers).

Analysis of demographic information revealed a noticeable disparity in female classroom teachers and male classroom teachers ( $92 \%$ vs. $7.2 \%)$. The percentage of male music teachers was higher than the percentage of male classroom teachers $(43.6 \%$ vs. $7.2 \%$ ). This finding substantiates the trend, in general education, that females make up the majority of elementary classroom teachers. Historically, male musicians have dominated the field of music. However, in music education, there exists a balance in the number of male and female music teachers at all levels (elementary, middle, and high school). The ethnic composition of the sample appears to be an analogous proportion of Hispanic, white non-Hispanic, and black non-Hispanic typical in most elementary schools in the Miami-Dade County Public Schools system. Most teachers in both groups have at least a Bachelors' degree; most of the elementary classroom teachers had at least 16 years of experience. Comparatively, most music teachers had 1-5 years of experience.

For the present study, systematic observation was used to investigate the time-use of two groups of teachers. The intent of this investigation was to find out whether teachers' time-use in the classroom activities was dependent on grade level, time of day, and/or the day of the week. It was assumed that if teachers were informed through empirical research regarding how time is used, they would be able to identify those factors that distinguish efficient and inefficient use of time in the classroom. This knowledge would provide the basis on which educators in general, could better modify time in the classroom with the purpose of increasing instructional time. Karweit (1988) 
stated that "time-use is important ... because it is an alterable feature of the school and is modified mainly by the personnel who are accountable for its use" (p. 32).

Descriptive analysis by means and graphs was used to answer the first research question. Other statistical procedures used to analyzed research questions two and three and the first subsidiary question included Analysis of Variance (ANOVA) and Multivariate Analysis of Variance (MANOVA). The second subsidiary question required cross classification, t-tests, and ANOVAs. Results were interpreted at the .05 level of significance.

The remainder of the chapter presents the major findings for each research question as well as relevant discussions, conclusions, and recommendations.

\section{Major Findings}

The intent of the first subsidiary question was to find out whether the time-use pattern of elementary classroom teachers differed from the time-use pattern of elementary music teachers in teaching, monitoring, and non-curricular categories of activities. Major findings are discussed in this section starting with the first subsidiary question. The first major finding revealed significant differences in the time-use of the two groups of teachers in all three categories of activities. Elementary music teachers allocated more time to teaching and to non-curricular activities than did elementary classroom teachers. One possible explanation for this finding could be that music teachers spend more time teaching as an artifact of the organization of the music classroom into short time blocks with classes changing every half hour or forty-five minutes. Students rotate and the resultant pressure is for the music teacher to deliver content in the specified time frame. Classroom teachers, on the other hand, spend considerably more time monitoring 
activities. Traditionally, classroom teachers have always been responsible for teaching all core subjects to a specific grade level for a greater portion of school day. Most often, students vary in abilities. Occasionally, there is need for the classroom teacher to have students engaged in seatwork individually or in small groups. The literature has established that specific subject matter and activity considerations are usually linked, and certain subjects such as reading and language arts require more monitoring activities during practice (Evertson et al., 2000).

Further analysis revealed that elementary music teachers spent more time in subject matter and non-curricular activities (e.g., planning and lunch). Classroom teachers, on the other hand, spent more time on seatwork, schoolwide activities, giving directions, and changing activities.

Findings concerning the other subsidiary question revealed the second major finding of this study. Of the three demographic characteristics (ethnicity, level of training, and years of experience), only ethnicity emerged as having significant influence on teachers' time-use. Findings indicate that black non-Hispanic teachers appeared to spend more time in classroom teaching activities than do white non-Hspanic and Hispanic teachers.

Analysis dealing with the first research question produced the third major finding. Grade level was not a significant factor in the teachers' use of class time in the teaching category. The findings showed significant differences in mean minutes allocated by the two groups of teachers, for the two other categories, monitoring and non-curricular. Elementary classroom teachers did more monitoring in Kindergarten through Grade 3, while time spent monitoring by elementary music teachers varied slightly. This finding 
suggests that elementary classroom teachers' perceptions of the cognitive, affective, and physical development of younger children could have influenced their time allocation patterns so that they spend more time on monitoring activities than on teaching activities. During their college training, most elementary teachers (classroom and music) are taught that younger children need lessons that include more activity because children at that stage are extremely active. It seems reasonable to assume that the teachers in this investigation might have been influenced by this perception. Differences in time-use in the non-curricular activities varied slightly and did not reflect great disparity in the two groups of teachers.

The second research question employed a MANOVA analysis. This analysis produced the fourth major finding: Elementary classroom teachers did not differ from elementary music teachers in the way they allocated their time to teaching and monitoring classroom activities across time of day (morning or afternoon).

Finally, a MANOVA analysis of the third research question revealed no significant interaction effect regarding how elementary classroom and music teachers compared in their use of time by day of the week. An ANOVA analysis revealed significance in time-use in monitoring and non-curricular activities on certain days of the week. This time allocation pattern showed that more monitoring activities than teaching activities occurred on Thursdays and Fridays. It could be assumed that students, on those days, nearing the end of the school week tend to be more "off-task". According to Rossmiller (1983) “students' off-task behavior is generally lower on Mondays and Fridays and before and after holidays" (p.48). Findings also indicate that more time was spent on non-curricular activities on Fridays as compared to Mondays. 


\section{Discussion Related to Research Questions}

The discussion relating to the research questions will focus first on the subsidiary questions followed by the research questions.

\section{Subsidiary Question One}

How does time-use for the activities subsumed under the teaching, monitoring, and non-curricular categories compare for elementary music teachers and elementary classroom teachers? A comparison of time-use for the two groups of elementary teachers revealed that elementary music teachers spent more time on teaching and non-curricular activities than on monitoring activities. In general, music education researchers (Allard, 1992; Forsythe, 1977; Hendel, 1995; Moore, 1976, 1981; Wagner \& Anderson, 1999; Wagner \& Strul, 1979; Wang \& Sogin, 1997) have reported that elementary music teachers spend the majority of class time on teaching activities. It is not surprising that the findings of the present study have revealed a similar time-use pattern for elementary music teachers.

On the other hand, findings concerning "monitoring" were significant at $\mathrm{p}<.001$, revealing that elementary classroom teachers had a higher mean for monitoring than did elementary music teachers. As suggested by Doyle (1986) and Prater (1992, monitoring is one of the key functions of the classroom teacher. Less monitoring occurs in the music classroom $(\underline{M}=37.96)$ as compared to the elementary classroom teachers $(\underline{M}=81.42)$. However, it appears that the subject matter that the classroom teachers teach requires more monitoring activities. The notion is that music teachers' subject matter differs from the subject matter of the elementary classroom teachers, and therefore, this difference gives rise to disparity in time spent on monitoring. The present study and the Wagner \& 
Anderson (1999) investigation represent the first attempts to compare time-use patterns of elementary music teachers and classroom teachers. These attempts account for most, if not all, of the activities present in, and common to, the classrooms of both the elementary music teacher and elementary classroom teacher. These activities were classified into three major categories-teaching, monitoring, and non-curricular. Hence, for the first time, classroom activities controlled by these two groups of teachers have been compared and documented. The fact that teachers vary in their time-use pattern has been established by this study and also by other time-use comparative studies (Allard, 1992; Bromme \& Pitman 1990; Horn \& Chalkind 1989; Moore, 1981; Sanford \& Evertson, 1983; Wagner \& Strul, 1979).

Further analysis of data on the specific activities provided more variations within the major categories. For example, for both groups of teachers, more time was allocated to the subject matter activity than to the other activities within the category of teaching (i.e., discussion, social instruction). Elementary music teachers devoted more time $(\underline{M}=41.45)$ to actual teaching than did classroom teachers $(\underline{M}=24.11)$. Elementary music teachers also allocated more time to class discussion $(\underline{\mathrm{M}}=7.73)$. The literature suggests that subject area, teacher differences, and the organization of music teachers in meeting their classes are likely to contribute to variances in the teacher time-use patterns. The instructional pattern used by a number of elementary music teachers probably has some influence on their time use. Hendel (1995) observed that some elementary music teachers spend more time giving academic information within the limited 25-minute class time, while others make a brief presentation focused on academic information, followed by student's music performance. Moreover, music teachers' instructional approach tends 
to be simple, succinct, successive, and complete. As observed by some music educators, elementary music teachers seem to allocate more time to teaching activities for the following reasons. Elementary music teachers have been reported to have the ability to pace and distribute their instructional time efficiently with about $44 \%$ of the class time spent on presenting and reinforcing academic content at a rapid pace (Hendel, 1995)hence their ability to establish reasonable time limits for each musical task.

Some music educators (Forsythe, 1977; Harrison 1983; Nolin, 1981) also believe that the nature of the subject matter (music) influences students' attending behavior, interest, and involvement in the activity that is pursued. If students remain focused and are interested in an activity, the teacher will be able to spend more time teaching instead of dealing with off-task behavior that interferes with students' learning time.

Additionally, elementary music teachers in this study seem to have used time as an effective yardstick in managing classroom activities during the class period and during the school day. Consequently, the music teachers have been able to devote more time to teaching.

"Seatwork" is the other monitoring activity on which the elementary classroom teachers spent a significant amount of time $(\underline{M}=34.96)$. Elementary classroom teachers also spent more time than did elementary music teachers in monitoring activities such as schoolwide activities ( $\underline{M}=9.15)$, preparation $(\underline{M}=12.86)$, giving directions $(\underline{M}=9.76)$, and changing activities $(\underline{M}=12.08)$. The greatest disparity in time-use for both groups of teachers was in seatwork. The mean for music teachers was $\underline{M}=7.48$ and the "seatwork" mean for elementary classroom teachers was $\underline{\mathrm{M}}=34.96$. For elementary classroom teachers, the findings for seatwork were consistent with other research results on the 
time-use in seatwork activity. Rosenshine (1980) reported that seatwork activity occupied 66 percent of class time, Walberg (1991) reported 47 percent, and Colbert reported $35 \%$. However, the curriculum in most general music classrooms does not involve much seatwork activity. Music classroom activities generally engage the teacher in teaching more than in monitoring. To make this claim, seatwork for the music teacher should be equated with seatwork for the classroom teacher. In the present study, it was determined before observing both teacher groups, that the seatwork activity would required independent work, testing, cooperative learning activities, writing and doing work sheets under the supervision of the teacher (See Appendix B).

According to Nye and Nye (1977), the general music classroom can be structured to meet certain curricular designs and needs. For example, the teacher in the traditional classroom would provide musical experiences that are performance centered for whole class instruction. On the other hand, the teacher in a non-traditional classroom would provide musical experiences that require students to work individually as well as in small groups. The non-traditional setting usually requires more monitoring by the music teacher. However, some music teachers have preferred to select aspects of both approaches and adapt to suit their own music classrooms. In view of the findings that time spent on seatwork for elementary music teachers was minimal, it can be assumed that these teachers used the traditional approach to providing musical experiences for the students. Therefore, it can be surmised that there was more whole class instruction and fewer incidences of writing, and testing, or small group activity.

It also seems logical that pursuits such as schoolwide activities, giving directions, and changing activities are events that consume elementary classroom teachers' class 
time. These procedural activities cannot be avoided in the elementary classroom; however, consideration must be given to the amount of time devoted to these activities. Rossmiller (1983) states that "the skill of the teacher in managing transitions between activities is an important factor in time utilization" (p.46). A noteworthy result of the present study is elementary music teachers' ability to manage monitoring activities. These findings are congruous with previous findings. Wagner and Strul (1979) found that experienced teachers were more efficient in "giving directions" than were inexperienced teachers. Moore (1981) also found that elementary music teachers in America devoted less time to "getting ready" than did British teachers.

It is standard practice for elementary music teachers to spend more time in the planning activity and lunch than in other non-curricular activities such as assemblies, travel, and administratively assigned duties. Music teachers' higher proportion of time for planning is usually designated and scheduled by the school administrator as part of the specialist teachers' contracted time within the school day. During that scheduled time, the specialist teacher is expected to do lesson planning and other school related activities, unlike the classroom teacher who engages in these activities when their students are with the specialist teacher. The present study found that elementary classroom teachers had more interruptions occurring in their classrooms than did music teachers. This is not unusual because a variety of interruptions are typical in this classroom setting. In general, non-curricular activities seem to consume much of the teacher's time. Prater (1992) and Rossmiller (1983) reported that up to 50 percent of the school day is devoted to non-curricular activities. 
Does time-use vary with demographic characteristics- - ethnicity, level of training, and years of experience-for elementary music teachers and elementary classroom teachers? The second subsidiary question focused on the effect of specific personal characteristics such as ethnicity, level of training, and years of experience on elementary teachers' time-use in the classroom. The results indicate that there were no statistically significant differences between level of training or years of experience and elementary teachers' use of time. The results of the ANOVA revealed that black non-Hispanic elementary teachers differed from Hispanic teachers in their time-use.

Of the limited number of studies on ethnicity as an influence on teachers' timeuse, only one known study (Horn \& Chalkind, 1988) correlates teachers' time-use with ethnicity. The study found no significant differences in the time-use of non-Hispanic and Hispanic private and public school teachers (secondary and elementary). The teachers in the present study were from Hispanic, white non-Hispanic and black non-Hispanic backgrounds, and taught in a culturally diverse region. The findings revealed that ethnicity, to some degree, does influence the way elementary classroom and music teachers use their time.

Further research is needed in order to explore what environmental elements and/or factors could be present in the classrooms of teachers who are black non-Hispanic and Hispanic. Alternatively, including other ethnic groups or backgrounds in the study would help to uncover factors that impede or enhance teachers' time allocation to teaching activities. 


\section{Research Question One}

What differences exist in elementary music teachers and elementary classroom teachers' time-use for teaching, monitoring and non-curricular activities across grade levels? This question was designed to determine whether grade level had any impact on the time-use of the elementary music teachers and elementary classroom teachers in the three major categories of activities: teaching, monitoring, and non-curricular. Differences were found in time allocation in the monitoring and non-curricular categories. Time allocation in the teaching category differed slightly. For music teachers there was a slight variation in time allocated to teaching across grade level. When compared with classroom teachers there is also a similar time-use pattern across grade levels. However, the findings in the Wagner et al., (1985) study differed. The findings in that study revealed that as grade level increased, time allocated to teaching activities increased for classroom teachers.

The finding in the present study also differs from what was found in Amen's (1982) investigation. She reported that in lower grades (K-3), music teachers time allocation decreased as grade level increased. There was a similar pattern for the upper grades (4-6). Findings of the two studies (Amen, 1982; Wagner et al., 1985) are inconsitent with the findings in the present study. Perhaps the difference in time allocation patterns across grade levels for both classroom and music can be ascribed to teacher awareness. Brophy and Good (2000) suggest that teachers who are unaware of the impact of certain behaviors continue to engage in them. Similarly, "teachers are most likely to change when provided with information that shows a discrepancy between what they want to do and what they are doing” (Brophy \& Good, 2000, p. 33). Teachers are 
more involved in teacher education programs that focus on helping them develop the capacity for self-awareness. If participants in the present study were engaged in such programs, they would be more aware of certain teacher behaviors, including time-use.

The findings for the monitoring activities indicate that time-use allocation patterns vary slightly across grade levels for music teachers. However, there was a difference across grade levels for elementary classroom teachers. Although not a gradual increase or decrease, there was more monitoring done at the kindergarten level and at the Grade 3 level. Classroom teachers of Grades 1 and 2 showed a slight decrease in monitoring activity. These findings were inconsistent with those of other studies. Borg (1980), Rosenshine (1980) and Sanford and Evertson (1983) found that seatwork, a monitoring activity, claimed as much as $65 \%$ of class time, suggesting that this monitoring activity takes precedence over other activities. There was no indication in these studies that the time allocation of this magnitude occurs across grade level. A study that investigated teacher time-use across grade levels reported that seatwork and monitoring activity decreased as grade level increased (Wagner et al., 1985). Again, this change in teacher time-use pattern could be attributed to teachers' self-awareness.

Even though music teachers allocated more time to non-curricular activities than did elementary classroom teachers, for each group of teachers time allocation across grade level showed slight variation. Classroom teachers showed less time allocated to non-curricular activities in Kindergarten, Grade 1, and Grade 3. The literature indicated that non-curricular activities do claim a significant portion of class time and seem to erode academic learning time (Prater, 1992; Rossmiller, 1983). It appears that in the present study, time allocated to non-curricular activities is more congruent to time 
allocation in another study, which found that teachers in the elementary classroom teachers allocated only 15 percent of the time to those activities (Walberg, 1991).

\section{Research Question Two}

What differences exist in elementary music teachers and elementary classroom teachers' time-use for teaching, monitoring, and non-curricular categories by the time of day? The second research question explored the relationship of teacher time-use to time of day. The purpose of this question was to ascertain whether mornings or afternoons might influence how teachers allocated their time to the major activities of the school day. There were no significance differences in the way teachers spent their time teaching and monitoring during mornings or afternoons. The findings in this study seem to conflict with the general "grass roots" notion that more teaching and learning take place in the mornings than in the afternoons, because there are fewer interruptions, and students are more focused and ready to learn. Apparently, teachers in the present study did not experience these kinds of interruptions, and, therefore were able to direct teaching in the afternoons as well. However, there was significant difference in the time allocation for non-curricular activities for these two groups of teachers. For music teachers, more time was spent in non-curricular activities in the afternoons. This time allocation pattern for the non-curricular category suggest that even though there might have been some degree of interruption during the afternoons this music teachers were not prevented from allocating time to teaching.

\section{Research Question Three}

What differences exist in elementary music teachers and elementary classroom teachers' time-use for the teaching, monitoring and non-curricular categories by day of 
the week? The third research question was designed to ascertain how elementary music teachers and classroom teachers spent their time in the three major categories of activities by day of the week. An interaction effect between teacher type and day was not found; however, an ANOVA revealed differences between monitoring and non-curricular activities and day of the week. As the week progressed from Monday to Friday teacher time-use decreased for teaching activities and increased for monitoring activities and non-curricular activities.

Colbert (1979), in a study dealing with classroom teacher behavior and instructional organizational patterns, used time as one of the context variables. The findings of the present study are similar to Colbert's whose investigation of fourth grade teachers indicated that Monday was the day teachers organized students into instructional groups, assigned tasks, and taught. Conversely, Friday was the day to allocate time mainly to testing, monitoring, seatwork, and organizing work areas. The Cornbelth and Korth (1980) study examined the influence of day of week on student's time-use. A rhythm in student's time-use pattern showed an increase in time-use from Monday to Friday for science and social studies, whereas language arts and math had down-time (fewer academic activities) on Thursday and Friday, respectively. These researchers assumed that knowledge regarding students' time-use patterns would help teachers better plan activities and structure their time more efficiently. Since the participants in the present study are limited to elementary schools and elementary music and classroom teachers in Miami-Dade County, no claim can be made that they are representative of all teachers. However, it can be postulated that in last twenty years, elementary music 
teachers and elementary classroom teachers have not changed the ways they allocate their time by day of the week.

Conclusions and Implications for Curriculum and Instruction According to Ben-Peretz and Bromme (1990) curriculum and instruction planning means organizing time. The knowledge of time-use in the classroom seems to encourage teachers to be more structured and organized. The knowledge regarding time allocation in the elementary classrooms might enable elementary teachers to decide, on the basis of empirical research, what activities to include or eliminate. Elementary teachers might also become more sensitive about the individual as well as the group needs of their students.

Currently, teachers are required to contribute to, and participate in, the planning of the curriculum. Such curriculum planning requires a timeline for delivery, and the teachers will be responsible for implementing the curriculum. Therefore, what they do, in terms of knowing how to manipulate time in relation to the delivery of the curriculum might well determine the students' success. The implication of the "day of the week" findings for curriculum is that this knowledge can help teachers become aware of what aspects of the curriculum they can and should deliver on certain days of the week. Connelly and Clandinin (1990) noted that the "Short units of instruction often begin on Monday and on Friday; for instance, in elementary schools, the introduction of new spelling words on Monday, word activities through the week, and testing on Friday" (p. $52)$.

Findings for teacher time allocation and curriculum instruction imply that elementary teachers should be aware of the precise measurement and allocation of time 
that they currently use in the classrooms. Decisions can then be made regarding the individual needs of student and what subject areas need to be allocated more time so that content can be organized and delivered more efficiently.

This investigation confirms that elementary music teachers do allocate more time than do elementary classroom teachers in the teaching and non-curricular categories of activities, while elementary classroom teachers allocate more time to monitoring than do music teachers. The results have also brought into focus the influence of day of the week on elementary teachers' time-use than time of day. The findings on grade level confirm the pattern of time allocation by elementary classroom teachers. Colbert (1979) and Cornbelth and Korth (1980) reported that teachers tend to engage in teaching activities during the first three days of the week and that more down-time is experienced on Thursdays and Fridays. Clandinin and Connelly (1990) also provided confirmation: elementary classroom teachers engage students in fewer academic activities on Thursday and Friday giving the impression that these are the lighter days of the school week. The trend continues in today's elementary classrooms.

\section{Recommendations for Future Research}

The meaning and knowledge of time will continue to have its impact and take on new significance for schools in this $21^{\text {st }}$ Century. Therefore, much value lies in future research that will provide a solid foundation upon which teachers and administrators can make prudent decisions about the allocation of time in the elementary classroom. The findings in this study could give insight for further research in the following areas. 
1. A study should be pursued with regard to the instructional methods used by elementary classroom teachers and elementary music teachers to see whether instructional methods might have an impact on teacher time-use.

2. A study should be designed to compare music teachers and other subject area teachers in middle school or high school. Therefore a replication of this study at those levels might give further insight into time-use patterns and behaviors in those classrooms.

3. This study should be replicated using both a qualitative approach and quantitative approach to see what further insights would be gained when these two methodologies are combined.

4. Further exploration is necessary to discover what elements and/or factors in the classrooms of teachers of diverse ethnicities (white non-Hispanic, black non-Hispanic, and Hispanic) impede or enhance alloting more time to teaching activities. 


\section{REFERENCES}

Abeles, H. F., Hoffer, C. F., \& Klotman, R. H. (1994). Foundations of music education. $\left(2^{\text {nd }}\right.$ ed.). New York: Schirmer Books.

Allard, M. A. (1992). A comparison of specialists and non-specialists teaching elementary beginning string music: Time use, student attentiveness, and performance quality. Unpublished doctoral dissertation, University of Texas, Austin.

Anderson, L. W., \& Walberg, H. J. (1993). Timepiece: Extending and enhancing learning time. Reston, Virginia: NASSP.

Amen, B. (1982). The effect of selected factors on the time spent teaching music by elementary classroom teachers. Unpublished doctoral dissertation, Indiana University, Bloomington, IN.

American heritage dictionary ( $2^{\text {nd }}$ ed.). (1976). Boston: Houghton-Mifflin.

Arlin, M. (1979). Teacher transitions and disrupt time flow in the classroom. American Educational Research Journal, 16, 42-56.

Baldridge, W. R. (1984). A systematic investigation of listening activities in the elementary general music classroom. Journal of Research in Music Education. 32(1), 7093.

Bennett de Marrais, K., \& Le Compte, M. (1995). The way school works: A sociological analysis of education. New York: Longman.

Ben-Pertz, M., \& Bromme, R. C. (1990). The nature of time in schools: Theoretical concepts, practitioner perceptions. New York: Teachers College.

Berliner, D. C. (1979). Tempus educare. In P. Peterson and H. Walberg (Eds.), Research on teaching, (pp. 120-135). Berkeley: McCutchan.

Berliner, D. C. (1983). Developing conceptions of classroom environments: Some light on the T in classroom studies at ATI. Educational Psychologist, 18, 1-13.

Berliner, D. C. (1990). What's all the fuss about instructional time? In M. BenPertz \& R. Bromme (Eds.), The nature of time in schools: Theoretical concepts, practitioner perceptions, (pp. 3-35). New York: Teachers College.

Berliner, D. C., \& Biddle, B. J. (1995). The manufactured crisis: Myths, fraud and the attack on America's public schools. Massachusetts: Addison-Wesley. 
Bloom, B. S. (1968). Learning for mastery. Evaluation comment, 1(2), University of California at Los Angeles, Center for the Study of Evaluation. Reprinted in C. W. Fisher \& D. C. Berliner (Eds.), (1985). Perspective in instructional time (pp. 7393). New York: Longman.

Bloom, B. S. (1974). Time and learning. American Psychologist, 29, 682-88.

Brendell, J. K. (1996). Time use, rehearsal activity, and student off-task behavior during the initial minutes of high school choral rehearsals. Journal of Research in Music Education, 44 (1), 6-14.

Borg, W. R. (1980). Time and school learning. In C. Denham \& A. Lieberman (Eds.), Time To Learn (pp. 33-68). Washington, DC: National Institute of Education.

Bromme, R., \& Homberg, E. (1990). Mathematics teachers' perception of time in class. In M. Ben-Pertz \& R. Bromme (Eds), The nature of time in schools: Theoretical concepts, practitioner perceptions, (pp. 161-181). New York: Teachers College.

Brophy, J., \& Good, T. (1986). Teacher behavior and student achievement. In Merlin C. Witrock, (Ed.). Handbook of research on teaching: A project of the American Educational Research Association ( $3^{\text {rd }}$ ed. ; pp. 361-363). New York: Macmillian.

Brophy, J., \& Good, T. (2000). Looking in classrooms $\left(5^{\text {th }}\right.$ ed.). New York: Addison Wesley Longman.

Bruno, J. E. (1997). It's about time: Leading school reform in an era of time scarcity. Thousand Oaks, CA: Corwin Press.

Callahan, R. (1962). Education and the cult of efficiency. London: University of Chicago.

Cawelti, G., \& Adkisson, J. (1985, April). ASCD study reveals elementary school time allocations for subject areas; other trends noted. ASCD Curriculum Update, pp. 1-10.

Carroll, J. B. (1963). A model of school Learning. Teachers College Record, 64 (8), 723-33.

Carroll, J. B. (1985). The model of school learning: Progress of ideas. In C. W. Fisher \& D. C. Berliner (Eds.). Perspectives on Instructional Time (pp. 29-58). New York: Longmans.

Colbert, C. D. (1979, April). Classroom teacher behavior and instructional organization patterns. Paper presented at the annual meeting of the American Educational Research Association, San Francisco, CA. 
Colwell, R. (Ed.). (1992). Handbook of research on music teaching and learning: A project of the Music Educators National Conference. New York: Schirmer Books.

Connelly, F. M., \& Clandinin, D. J.(1990). The cyclic temporal structure of schooling. In M. Ben-Pertz \& R.Bromme (Eds.), The nature of time in schools: Theoretical concepts, practitioner perceptions, (pp. 3-35). New York: Teachers College.

Connelly, F. M., \& Clandinin, D. J. (1993). Cycles, rhythms and the meaning of school time. In L. W. Anderson \& H. J. Walberg (Eds.). Timepiece: Extending and enhancing learning time (pp. 9 - 14). Reston, VA: NASSP.

Cornbleth C., \& Korth, W. (1980). Context factors and individual differences in pupil involvement in learning activity. Journal of Educational Research, 7, 477-492. 286-298.

Cunningham, P. M., (1991). Making seatwork work. Reading Horizons, 31 (4),

Denham, C., \& Liberman, A. (1980). Time to learn. Washington, DC: National Institute of Education.

Doyle, W. (1986). Classroom organization and management. In M. C. Wittrock (Ed.). Handbook of research on teaching: A project of the American Educational Research Association. ( $3^{\text {rd }}$ ed.; pp. 392-433). New York: Macmillian.

Evertson, C. M., Emmer, E. T., \& Worsham, M. E. (2000). Classroom management for elementary teachers. Boston: Allyn and Bacon.

Evertson, C. M. \& Green, J. L. (1986). Observation as inquiry and method. In M. C. Wittrock, (Ed.). Handbook of research on teaching: A project of the American Educational Research Association. ( $3^{\text {rd }}$ ed.; pp. 162-162). New York: Macmilllian.

Evertson, C. M., \& Harris, A.H. (1992). What we know about managing classrooms. Educational Research. 49(7), 74-78.

Feiman-Nemser, S. \& Floden, R. E. (1986). The cultures of teaching. In M. C. Wittrock, (Ed.). Handbook of research on teaching: A project of the American Educational Research Association. ( $3^{\text {rd }}$ ed.; pp. 392-431). New York: Macmilllian.

Fisher, C. W., Berliner, D. C., Filby, N. N., Marliave, R. S., Cohen, L. S., \& Dishaw, M. M. (1980). Teaching behavior academic learning time and student achievement: An overview. In C. Denham \& A. Lieberman (Eds.). Time to learn. (pp. 2-32). Washington, DC: National Institute of Education. 
Fitzgerald J., Wright, E. N., Eason, G., \& Shapson, S. (1978, March). The effects of subject of instruction on the behaviors of teachers and pupils. A paper prepared for the annual meeting of the American Educational Research Association, Toronto.

Flanders, N. (1970). Analyzing teacher behavior. New York: Addison Wesley.

Forsythe, J. L. (1977). Elementary student attending behavior as a function of classroom activities. Journal of Research in Music Education, 25, 228-239.

Forsythe, J. L., \& Kelby, M. M. (1989). Effects of visual-spatial added cues on fourth-graders'melodic discrimination. Journal of Research in Music Education, 37(4), 272-277.

Fredrick, C. W. \& Walberg, H. J. (1980). Learning as a function of time. Journal of Educational Research. 73, 183-194.

Funkhouser, J. E., Humphery, D. C., Panton, K. L. M., \& Rosenthal, E. D. (1995). A research review: The educational uses of time. U. S. Department of Education, Office of Educational Research and Improvements. 4. Washington, DC: Policy Studies Associates.

Gall, M. D., Borg, W. R., \& Gall, J. P. (1996). Educational research: An introduction. $\left(6^{\text {th }}\right.$ ed.). New York: Longman.

Galton, M. (1988). Structured observation techniques. In J.P. Reeves, (Ed.). Educational research, methodology, and measurement: An international handbook $\left(3^{\text {rd }}\right.$ ed.), ( pp. 469-474). Oxford: Pergamon.

Garretson, R. L. (1976). Music in childhood education. Englewood Cliffs, NJ: Prentice-Hall.

Gay, L. R. (1996). Educational research: Competences for analysis and application. Ohio: Prentice-Hall.

Gelberg, D. (1997). The Business of reforming American schools. Albany, NY: State University of New York.

Good, T. L., \& Beckerman, T. M. (1978). Time and task: A naturalistic study in sixth grade classrooms. The Elementary School Journal, 78, 193-201.

Goolsby, T. W. (1996). Time use in instrumental rehearsals a comparison of experienced, novice, and student teachers. Journal of Research in Music Education, 44 (3), 286-303. 
Goolsby, T. W. (1999). A Comparison of expert and novice music teachers' preparing identical band compositions: An operational replication. Journal of Research in Music Education. 47 (2), 174-187.

Green, S. B., Salkind, N. J. \& Akey, T. M. (2000). Using SPSS for windows: Analyzing and understanding data. $\left(2^{\text {nd }}\right.$ ed.) Upper Saddle River, NJ: Prentice Hall.

Gump, P. V. (1967). The classroom behavior setting: Its nature and relation to student behavior. Washington, DC: U.S. Office of Education, Bureau of Research. (ERIC Document Reproduction Service No. ED 015515).

Harnishchfeger, A., \& Wiley, D. E. (1985). Origins of active learning time. In C. W. Fisher \& D. C. Berliner (Eds.). Perspectives on instructional time. (pp. 133-56). New York: Longmans.

Harrison, L. N. (1983). Getting started in elementary music education. Englewood Cliffs, NJ: Prentice-Hall.

Hendel, C. (1995). Behavioral characteristics and instructional patterns of selected music teacher. Journal of Research in Music Education, 43, 182-203.

Horn, R. \& Chalkind, S. (1989). The allocation patterns of teachers in public and private schools: 1984-86. (NCES Report No. CS 89-104). Washington, DC: U.S. Department of Education. Winston.

Jackson, P. W. (1968). Life in the classroom. NewYork: Holt, Rinehart and

Jaques, E. (1982). The form of time. New York: Crane Russak.

Judd, C. H. (1918). Introduction to the scientific study of education. Boston: Ginn.

Karweit, N. L. (1988, February). Time-on-task: The second time around. NASSP Bulletin, pp. 31-37.

Karweit, N. L., \& Slavin, R. E. (1982) Time-on-task: Issues of timing, sampling, and definition. Journal of Educational Psychology, 74, 844-51.

Kliebard, H. M. (1995). The struggle for the American curriculum $\left(2^{\text {nd }}\right.$ ed.). New York: Routledge.

Kostka, M. J. (1984). An investigation of reinforcements, time use, and student attentiveness in piano lesson. Journal of Research in Music Education. 32 (2), 113-122. 
Kuhn, T. L. (1974). The effect of teacher approval and disapproval on attentiveness, musical achievement and attitude of fifth grade students. In C. K. Madsen, R. D. Greer \& C. H. Madsen, Jr. (Eds.), Research in music behavior (pp. 40-48), New York: Teachers College.

Leach, D. J., \& Tunnecliffe, M. R. (1984). The relative influence of time variables on primary mathematics achievement. Austrialian Journal of Education, 28, $126-131$.

Lehman, P. R. (1987). Music in today's school: Rationale and commentary. Reston,VA: MENC

Leonhard, B., \& House, D. (1972). Historical foundations of music education. Chicago, IL: University of Chicago.

Lewin, J., \& Nolan, J. F. (2000). Principles of classroom management: A professional decision-making model. Boston: Allyn and Bacon.

Madsen, C. K., \& Geringer, J. M. (1983). Attending behavior as a function of inclass activity in university music classes. Journal of Music Therapy, 20(1), 30-38.

Madsen, C. H., \& Madsen, C. K. (1983). Teaching discipline: A positive approach for educational development, ( $3^{\text {rd }} \mathrm{Ed}$.). Raleigh, NC: Contemporary.

Mark, M. L. (1986). Contemporary music education. New York: Schirmer Books.

Medley, D. M., Mitzel, H. E. (1963). Measuring classroom behavior by systematic observation. In N. L . Gage (Ed.), Handbook of research on research on teaching: A project of the American Research Association. Chicago: Rand McNally.

Miami Dade County Public Schools (MDCPS). (1997). District and school profiles: 1996-1997. Miami, FL.

Miami Dade County Public Schools (MDCPS). (1998). District and school profiles: 1997-1998. Miami, FL.

Miller, L. (1980). BTES: Implications for Staff Development . In C. Denham \& A. Lieberman (Eds.), Time To Learn. (pp. 179-170) Washington DC: National Institute of Education.

Montgomery, A. (1985). The effect of selected factors on the use of instructional time by elementary music specialist in Atlantic Canada. Unpublished doctoral dissertation. University of Prince Edward Island, Prince Edward Island. 
Moore, R. S. (1976, October). Videotaped comparisons of beginning versus experienced elementary music specialists in the use of teaching time, and developing and piloting the "music teaching interactions form". Paper presented at the Second National Symposium on Research in Music Behavior. Milwaukee, WI.

Moore, R. (1981). Comparative use of teaching time by American and British elementary music specialists. Bulletin of the Council for Research in Music Education, 66, 62-68.

Moore, R. S., \& Bonney, J. T. (1987). Comparative analysis of teaching time between student teachers and experienced teachers in general music. Contributions to Music Education, 14, 52-58.

Morrison, H. C. (1926). The practice of teaching in the secondary school. Chicago: University of Chicago.

Murray, K. (1974). The effect of teacher approval/disapproval on musical performance, attentiveness, and attitude of high school choruses. In C. K. Madsen, R. D. Greer, \& C. H. Madsen, Jr. (Eds.), Research in music behavior: Modifying music behavior in the classroom (pp. 165-180). New York: Teachers College.

Music Educators National Conference (MENC). (1986). The school music program: Discription and standards. ( $\left.2^{\text {nd }} e d.\right)$. Reston, VA: MENC.

National Commission on Excellence in Education. (NCEE). (1983). A nation at risk: The imperative for educational reform. Washington, DC: U. S. Government Printing Office.

National Commission on Instruction. (NCI). (1972). The music specialist in the elementary school. Music Educators Journal, 59(3) 60-63.

National Education Association (NEA) (1987). Extending the school the school day/year: Proposals and results. Washington, DC: National Education Association.

National Education Commission on Time and Learning (NECTL) (1994). Prisoners of time. Washington DC: US Government Printing Office.

Nazareno, A., \& Bousquet, S. (1999, June 25). County has disproportionate rate of bad scores. The Miami Herald. P. 1.

Nolin, W. (1991). Patterns of attitudinal development in general music classes. Update: Applications of research in music education, 5, 33-36.

Nye, R. E., \& Nye, V. T. (1977). Music in the elementary school. $\left(4^{\text {th }}\right.$ ed). Englewood Cliffs, N J: Prentice-Hall. 
Olson, J. (1990). The influence of time on the Science Curriculum. In Miriam Ben-Pertz \& Rainer Bromme (Eds.), The nature of time in schools: theoretical concepts, practitioner perceptions, (pp 227-239). New York: Teachers College.

Petzold. R. (1978). Role of specialist teachers and classroom teachers in art, music, and physical education programs in selected IGE schools: Survey of existing practices. Madison, WI: Wisconsin Research and Development Center for Individualized Schooling.

Prater, M. A. (1992). Increasing time-on-task in the classroom. Intervention in school and clinic. 28(1) 22-27.

Price. H. E., \& Hardin, L. E. (1988). Elementary school music teachers' comparative use of classroom time: Teachers who are and are not Orff-Schulwerk certified. Missouri Journal of Research in Music Education, 27, 30-49.

Rich, H. L., \& McNelis, M. J. (1988). A study of academic time on task in the elementary school. Educational Research Quarterly, 12(1) 37-46.

Romberg, T. A., \& Pitman, A. J. (1990). Curricular materials and pedagogical reform: Teachers use of time in teaching mathematics. In M. Ben-Pertz \& R. Bromme (Eds.), The nature of time in schools: Theoretical concepts, practitioner perceptions, (pp. 189-226). New York: Teachers College.

Rosenshine B., \& Frust N. (1973). The use of direct observation to study teaching. In Travers R M W (Ed.). Second handbook of research on teaching: A project of the American Educational Research Association. (pp. 122-83). Chicago: Rand McNally.

Rosenshine, B. V. (1979). Content, time and direct instruction. In P. L. Peterson \& J. Walberg (Eds.). Research on teaching: Concepts findings and Implications, (pp. 28-56). Berkley, CA.

Rosenshine, B. V. (1980). How time is spent in the elementary classroom. In C. Denham \& A. Lieberman (Eds.), Time to learn. (pp. 107-123) Washington, DC: National Institute of Education.

Rossmiller, R. A. (1983). Time-on-Task: A look at what erodes time for instruction. NASSP Bulletin, 67 (465), 45-49.

Sanford, J. P., \& Evertson, C. M. (1983). Time use and activities in junior high classes. Journal of Educational Research, 76 (3) 140-143.

Shehan, P. K. (1987). Effects of rote versus note presentations on rhythm learning and retention. Journal of Research in Music Education, 35(2), 117-162. 
Slattery, P. (1995). A postmodern vision of time and learning: A response to the National Education Commission Report of Time. Harvard Educational Review, 65(4). Winter.

Smith, G. A. (1992). Education and the environment: Learning to live with limits. New York: State University of New York.

Snapp, D. (1967). A study of the accumulative musical and verbal behavior of teachers and students in fifth grade. Unpublished master's thesis. Ohio State University, Columbus.

Sogin, D. W., \& Vallentine, J. F. (1992). Use of instructional time and repertoire diversity in university applied music lessons. The Quarterly, 3 (4), 32-76.

Stallings, J. A., \& Mohlman, G. G. (1988). Classroom observation techniques. In J. P. Reeves, (Ed.). Educational research, methodology, and measurement: An international handbook ( $3^{\text {rd }}$ ed.), ( pp. 469-474). Oxford: Pergamon.

Stevens, J. (1998). Applied multivariate statistics for the social sciences. $\left(3^{\text {rd }}\right.$ ed.). Mahwah, NJ: Lawrence Ehrlbaum Associates.

Stigler, J. W., \& Stevenson, H. W. (1991). How Asian teachers polish each lesson to perfection. American Education, 15(1), 12 - 20, 43-47.

Stodolsky, S. S., Ferguson, T. L., \& Wimpelberg, K. (1981). The recitation persists, but what does it look like? Journal of Curriculum Studies, 13, (121-130).

Tabel, D. K. (1992). The evaluation of music teachers and teaching. In Richard Colwell (Ed.). Handbook of Research on Music Teaching and Learning: A project of the Music Educators national Conference, (pp. 320 -329). New York: Schirmer Books.

Thompson, K. P. (1984). Music is growing up. In M. E. Ramsey (Ed.). It's music! (pp. 21-30). Wheaton, MA: Association for Chilhood Education International. Strategy.

U. S. Department of Education. (USDE). (1991) America 2000: An education

U. S. Department of Education. (USDE). (1994). Breaking the tyranny of time (Teacher Forum) Washington, D.C.

U. S. Department of Education. (USDE). (1996). Goals 2000: Increasing student achievement through state \& local initiatives. 
U.S. Department of Education, National Center for Education Statistics (USDE/NCES) (1994). How much time do public and private school teachers spend in their work?

Wagner, M. J., Allen L. C., \& Shoemaker, S.S. (1985). An investigation of the use of elementary school teachers' classroom time. The Florida Journal of Teacher Education, 17-29.

Wagner, M. J., \& Anderson, M. J. (1999, July). A comparison of time use in elementary school: Music teachers vs. classroom teachers. In N. Jeanneret and K. Marsh (Eds.). Australian Society for Music Education XII National Conference (pp. 204 - 212). Austrailia: University of Sydney.

Wagner, M. J., \& Strul, E. P. (1979). Comparisons of beginning vs experienced elementary music educators in the use of teaching time. Journal of Research in Music Education. 27, 113-125.

Walberg, H. J. (1984). Improving the productivity of America's schools. Educational Leadership, 41(8), 19-27.

Walberg, H. J. (1988). Synthesis of research on time and learning. Educational Leadership, 45(6), 76-85.

Walberg, H. J. (1991). Extended learning time. Washington DC: U. S. Department of Education.

Walberg, H. J. \& Frederick, W. C. (1991). Extending and intensifying learning time. U.S. Department of Education, Office of Educational Research and Improvements.

Wang, C. C. (1984). Effects of some aspects of rhythm on tempo perception. Journal of Research in Music Education, 32(3), 169-176.

Wang, C. C., \& Sogin, D. W. (1997). Self-reported versus observed classroom activities in elementary general music. Journal of Research in Music Education, 45 (3), 444-456.

Watkins, R. C. (1993). Nonperformance time use in high school choral rehearsals Update: Applications of Research in Music Education, 3, 1-14.

Watkins, R. C. (1996). Nonperformance time use in high school choral rehearsals: A follow-up study. Update: Applications of Research in Music Education, 2. 4-8. 
Wig, J. A., Jr., \& Boyle, J. D. (1982). The effect of keyboard learning experiences on middle school general music students'music achievement and attitudes. Journal of Research in Music Education, 30(3), 163-172.

Witt, C. A. (1986). Use of class time and student attentiveness in secondary instrumental music rehearsals. Journal of Research in Music Education, 34 (1), 34-42.

Wyne, M. D. \& Stuck, G. B. (1982). Time and learning: Implications for the classroom teacher. The Elementary School Journal, 83(1) 67-75.

Yarbrough, C. (1975). Effect of magnitude of conductor behavior on musical performance, attentiveness, and attitude of students in selected mixed chorus. Journal of Research in Music Education, 23, 134-146.

Yarbrough, C. (1988). Content and pacing in music teaching. In P. J. Flowers (Ed.), Current Issues in Music Education: Vol 13. Student and teacher competencies: Interacting for success (pp. 9-28). Columbus, OH: Division of Music Education, School of Music, Ohio State University.

Yinger, L. (1977). A study of teacher planning: Description and theory development using ethnographic and information processing methods. Unpublished doctoral disertation. East Lansing, MI: Michigan State University.

Zabel, R. H., Peterson, R. L., \& Smith, C. R. (1988). Use of time by teachers of behaviorally disordered students: A replication. Behavioral Disorders 13 (2), 89-97. 
APPENDICES 
Appendix A - Teacher Time-Use Categories 
Teaching (T) (teacher with students)

$\begin{array}{ll}\text { Students remain passive (teacher lecturing) } & \\ \text { Academic Instruction } & (\mathrm{AI}) \\ \text { Social Instruction } & (\mathrm{SI}) \\ \text { Students are actively engaged } & (\mathrm{D}) \\ \text { Discussion } & \text { (RA) } \\ \text { Reinforcement Activity } & \\ \text { MUSIC SUBJECT MATTER } & (\mathrm{S}) \\ \text { Singing } & (\mathrm{PI}) \\ \text { Playing Instruments } & (\mathrm{R}) \\ \text { Rhythm } & (\mathrm{MO}) \\ \text { Movement Activities } & (\mathrm{L}) \\ \text { Listening } & (\mathrm{i} . \mathrm{e} . \mathrm{L} / 23+\mathrm{R} / 5) \\ \text { Combinations of Activities } & \\ & \\ \text { CLASSROOM SUBJECT MATTER } & (\mathrm{Re}) \\ \text { Reading } & (\mathrm{La}) \\ \text { Language Arts } & (\mathrm{Ma}) \\ \text { Mathematics } & (\mathrm{Ss}) \\ \text { Social Studies } & (\mathrm{Sc}) \\ \text { Science } & (\mathrm{i} . \mathrm{e} . \mathrm{L} / 23+\mathrm{Re} / 5) \\ \text { Combinations of Activities } & \end{array}$

Monitoring (M) (teacher with students)

Schoolwide Activity

Seatwork

Preparation

(P)

Directions

Changing Activity

Teacher Talk

Non-Curricular Activities (NC) (teacher not with students)

Lunch

Assemblies

Planning

(PL)

Administratively assigned duties

(AD)

(hall, bus, café, etc.)

Interruptions

Teacher travel time

Consultations

(C)

(w/volunteers, parents, colleagues) 
Appendix B - Definitions for Each Category Used to Code Teacher Time-Use 


\section{DEFINITIONS FOR EACH CATEGORY \\ USED TO CODE \\ TEACHER TIME-USE}

\section{Teaching (T) (teacher with students)}

\section{Students are passive (teacher lecturing)}

AI Academic Instruction: Teacher engaged in explaining and teaching of subject matter, which include lecturing, questioning and discussion SI Social Instruction: Teacher engaged in instruction of information unrelated to subject matter such as classroom rules, school routines and social values.

(Students are actively engaged)

D Discussion: Verbal interaction between student and teacher directly related to subject matter in focus.

RA Reinforcement Activity: Any teacher directed activity used for positive or negative reinforcement. Positive reinforcement includes, recess, tokens, free time, etc. Negative Reinforcement includes writing repetitious sentences, heads on desk, and other disciplinary actions.

\section{MUSIC SUBJECT MATTER}

S Singing: Teacher engaged in activities that involve the performance of vocal music by the student.

PI Playing Instruments: Teacher engaged in the directing of performance of instrumental activities by the student. This includes rhythm and melody instruments. 
$\mathbf{R} \quad$ Rhythm: Teacher engaged in directing rhythm activities using percussion instruments and body rhythm (e.g. hand clapping, tapping, finger snapping, etc.).

Mo Movement Activities: Teacher engaged in directing students performing movement activities in which they use their bodies to express a variety of musical concepts.

L Listening: Teacher engaged in listening activities involves students attending to music that is being played (directed listening experiences). (i.e. $\mathrm{La} / 23 \& \mathrm{Re} / 5$ ) Combinations of Activities: When the teacher is engaging some students in one activity and others in another, use both codes, and record number of students in each.

\section{CLASSROOM SUBJECT MATTER}

Re Reading: Teacher engaged in directing reading activities that involves the student reading aloud while the rest of the class attentively follows in their text.

La Language Arts: Teacher engaged in activities that involve the performance of playlets, readings, and the presentation of poetry by the students.

Ma Mathematics: Teacher engaged in directing activities that involve students and/or demonstration of mathematical problems or question and answer session related to solving mathematical problems.

SS Social Studies: Teacher engaged in directing social studies activities involving students learning about the cultures of various 
countries and also participating in activities in which they experience facets of the culture under investigation.

Sc Science: The teacher engaged in directing the participation of students in science activities that involve reading and experiments.

i.e. La/23 \& Re/5 Combinations of Activities: When the teacher is engaging some students in one activity and others in another, use both codes, and record number of students in each.

\section{Monitoring (M) teacher with students}

SA Schoolwide Activity: This activity includes supervising announcements, lunch count, fire drills, dismissal, counseling sessions, and money collecting.

Sw Seatwork: This activity requires independent work, testing, cooperative learning activities, writing, and doing work sheets during class period supervised by the teacher.

P Preparation: Teacher supervising students engaged in time required to prepare for change such as lining up, travel time, drinking water, stretching, eating snacks, or leaving class to go to the restroom.

DI Directions: Teacher giving instructions and/or explaining how assignments are to be accomplished, or the movement from place to place.

CA Changing Activity: The teacher-directed activity where the teacher engages in getting ready for the next activity that includes setting-up equipment or arranging students, passing out materials and/or focusing students' attention on the next activity. 
TT Teacher Talk: Irrelevant teacher directed conversation that is not related to the Subject matter.

\section{Non-Curricular Activities (NC) no students involved}

Lu Lunch: Teacher's "midday" break

A Assemblies: An externally scheduled activity that involves supervision of participation by students.

PL Planning: The teacher is engaged in planning and preparation for academic instruction.

AD Administratively Assigned Duties: The teacher performing specific duties assigned by the school administration e.g., hall, bus, or cafeteria supervision.

I Interruptions: This includes unscheduled interruptions from outside such as other teachers or students entering the class, intercom announcements, and extraneous noise.

TR Teacher's travel Time: Teacher engaged in movement from one location to the next within the school.

C Consultation: Teacher engaged in consultation with volunteers, parents, or colleagues regarding students' welfare. 
Appendix C - Instructions for Observers 


\section{INSTRUCTIONS FOR OBSERVERS}

\section{(A protocol)}

This semester, we want you to do your observations and forms in the elementary music classroom (or elementary classroom).

\section{Introduction to Observation}

I. We're beginning to look at the way teachers use their time during the school day. Today I'll give you a package of materials regarding that. But before I give you the packet of materials, I want you to know that we've broken the use of teachers' time into three broad categories. We call those "teaching," "Monitoring," and Non-curricular" activities.

II. Can you tell me some teacher activities under the teaching heading?" (list those while brainstorming. Do the same for each category.)

III. Do we have all the things that teachers do in their day? Here's our list, with each of those categories broken into what we think teachers do. See if these categories make sense to you (Pass out packets of observation materials)

IV. Look at our categories, and see if they fit your conception of a teacher's job (Discuss)

\section{Teacher Time-use Form}

I At any change of teacher activity, on the form, you are to briefly describe what the new activity is, and then code it according to the three broad categories described here on the board. Insert the exact time that the new activity started, because at the very end, we're going to ask you to determine how much time was spent in each activity, to the nearest minute.

II. Let's talk about what happens if the teacher has students doing more than one activity at a time. Look at Combinations of Activities on your Category sheet. (Explain briefly)

III. As each activity progresses, you will have time to sub-categorize the activity as well. Use the codes that are on the Teacher Time-Use Categories form.

IV. Are there any questions? (Answer questions). (Tell them to figure the minutes for each category-and indicate that you will not tolerate math errors here....after all, the form is no good if you can't condense what you've seen) 


\section{Directions}

I. Your assignment for this class will be to complete two three-hour observations. These can be done from the time the tardy bell rings at the opening of school, until three hours have lapse; or beginning before the ringing of the school's dismissal bell. We are looking at three-hour blocks of time only. (answer questions - and there will be many)

II. Before you take your final data however, there are some things you will need to do: First, you must practice using the form on your own for a least two hours. We suggest two one-hour sessions at first. Then you must practice with a partner twice, each for one hour. If you cannot find a partner at your school, you are to find one here in this class and get your data here, on my time-use in this class.

III. You will do two independent observations - with a partner. These MUST match, in the same time frame, 8 out of 10 entries, both for time and for category and sub-category. Less than $80 \%$ agreement will require further partner reliability training.

IV. The observations that you do in the field must be accurate. So training becomes very important to us. We will be coming out to your school to do our own reliability checks. It's a three part training process: 1) Train for two hours on your own. 2) Train with a partner and become reliable with each other. 3) Do two accurate three-hour observations in your field school... on your own...but only after you have achieved reliability.

\section{Why are we doing this?}

When the real data are in, we will look at how time is actually used in the elementary music classrooms. We'll pool our real data from this and other classes, and then we can begin to decide if, as teachers, we want to spend our time in these pursuits. We can begin to make educated decisions in this area. Don't forget, we're having you do this to make you the best classroom teacher you can be. 
Appendix D - Teacher Time-Use Log 


\section{Teacher Time-Use Log}

School

Teacher's Name

Grade Level

(if Applicable)

Observer's Name
Date

Morning/Afternoon (Circle One)

Music/Regular Class (Circle One)

Class

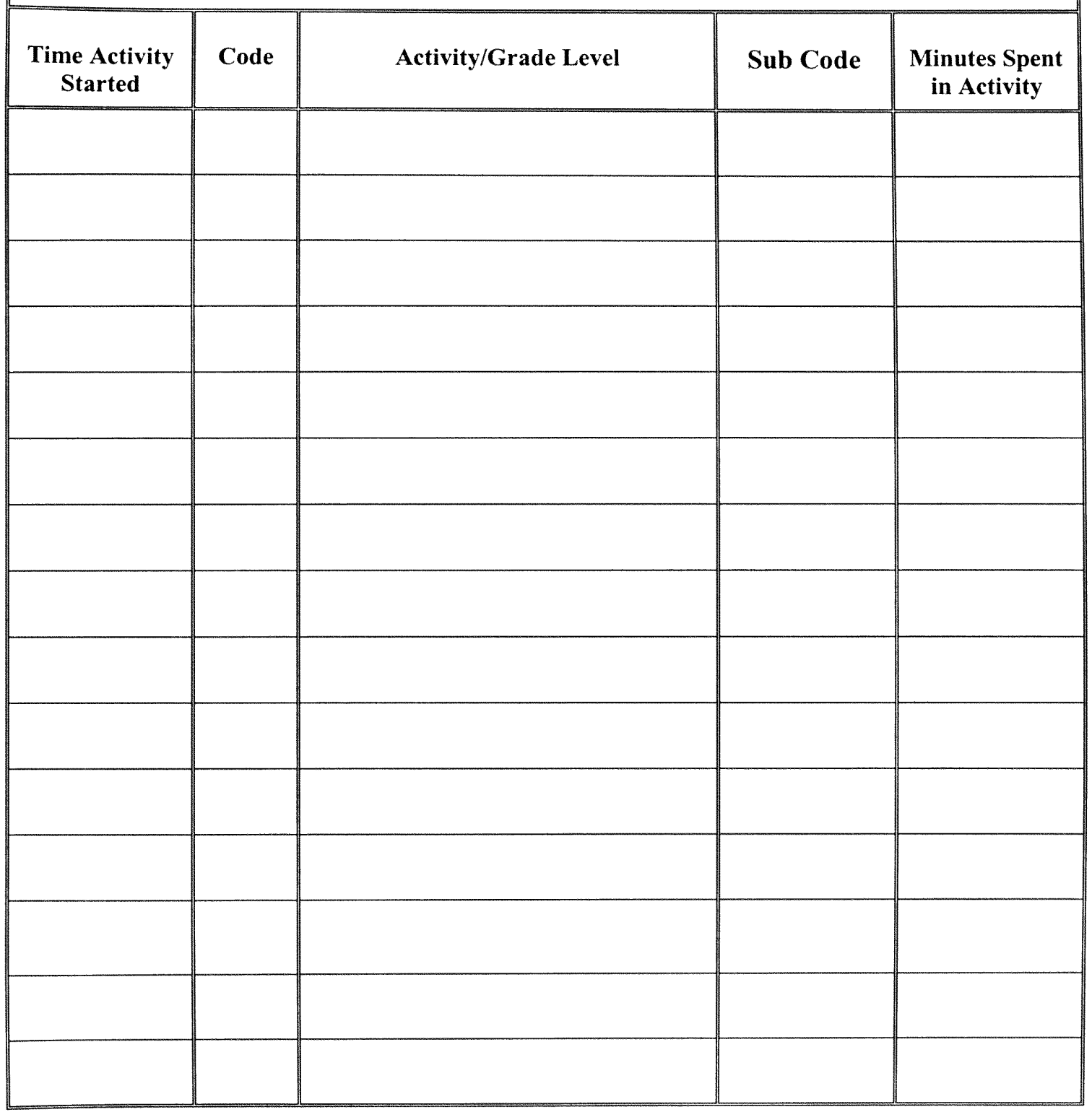


July 26,1945

1964

1968

1972

1973

1974

1977

1977-1982

1982-1986

1987-1995
Born, Jamaica, West Indies

AA., Secretarial Science

West Indies College

Jamaica West Indies

LRSM., Music Education

West Indies College

Jamaica, West Indies

BA., Business Administration

Eastern Michigan University

Ypsilanti, Michigan

BA., Music Education

Eastern Michigan University

Ypsilanti, Michigan

BA., Music Education

Eastern Michigan University

Ypsilanti, Michigan

MA., Music Education

Eastern Michigan University

Ypsilanti, Michigan

Music Teacher $(\mathrm{K}-12)$

Detroit Schools

Detroit, Michigan

Lecturer, Music Education

Northern Caribbean University

(Formerly West Indies College)

Jamaica, West Indies

Department Chairperson, Music Education

Northern Caribbean University

(Formerly West Indies College)

Jamaica, West Indies 


\section{PUBLICATIONS}

Wagner, M. J. and Anderson, M. J. (1999). A comparison of time-use in elementary school: Music teachers vs classroom teachers. In N. Jeanneret and K. Marsh (Eds.). Australian Society for Music Education XII National Conference, (pp. 204 - 212). Austrailia: University of Sydney. 